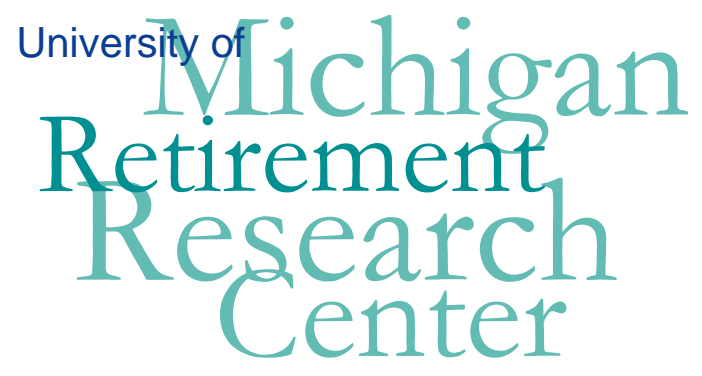

Working Paper WP 2005-101

\title{
Enhancing the Quality of Data on Income and Wealth
}

Honggao Cao and Daniel H. Hill, F. Thomas Juster, \& Michael Perry

\begin{tabular}{|c|c|}
\hline $\mathrm{M}$ & $\mathrm{R}$ \\
\hline $\mathrm{R}$ & $\mathrm{C}$ \\
\hline
\end{tabular}$\quad$ Project \#: UM04-10 


\title{
"Enhancing the Quality of Data on Income and Wealth"
}

\author{
Honggao Cao \\ University of Michigan \\ Daniel H. Hill \\ University of Michigan \\ F. Thomas Juster \\ University of Michigan \\ Michael Perry \\ University of Michigan
}

June 2005

\author{
Michigan Retirement Research Center \\ University of Michigan \\ P.O. Box 1248 \\ Ann Arbor, MI 48104
}

\section{Acknowledgements}

This work was supported by a grant from the Social Security Administration through the Michigan Retirement Research Center (Grant \# 10-P-98362-5). The findings and conclusions expressed are solely those of the author and do not represent the views of the Social Security Administration, any agency of the Federal government, or the Michigan Retirement Research Center.

\section{Regents of the University of Michigan}

David A. Brandon, Ann Arbor; Laurence B. Deitch, Bingham Farms; Olivia P. Maynard, Goodrich; Rebecca McGowan, Ann Arbor; Andrea Fischer Newman, Ann Arbor; Andrew C. Richner, Grosse Pointe Park; S. Martin Taylor, Gross Pointe Farms; Katherine E. White, Ann Arbor; Mary Sue Coleman, ex officio 


\title{
Enhancing the Quality of Data on Income and Wealth
}

\author{
Honggao Cao, Daniel Hill, F. Thomas Juster, and Michael Perry
}

\begin{abstract}
Over the last decade or so, a substantial effort has gone into the design of a series of methodological investigations aimed at enhancing the quality of survey data on income and wealth. These investigations have largely been conducted at the Survey Research Center at the University of Michigan, and have mainly involved two longitudinal surveys: the Health and Retirement Study (HRS), with a first wave beginning in 1992 and continued thereafter every other year through 2004; and the Assets and Health Dynamics Among the Oldest Old (AHEAD) Study, begun in 1993 and continued in 1995 and 1998, then in every other year through 2004. This provides and overview of the main studies and summarizes what has been learned about correcting longitudinal inconsistencies that arise.
\end{abstract}

\section{Keywords:}

Item nonresponse, respondent behavior model, don’t know, refusal, asset survey, HRS 


\section{Introduction}

Over the last decade or so, a substantial effort has gone into the design of a series of methodological investigations aimed at enhancing the quality of survey data on income and wealth. These investigations have largely been conducted at the Survey Research Center at the University of Michigan, and have mainly involved two longitudinal surveys: the Health and Retirement Study (HRS), with a first wave beginning in 1992 and continued thereafter every other year through 2004; and the Assets and Health Dynamics Among the Oldest Old (AHEAD) Study, begun in 1993 and continued in 1995 and 1998, then in every other year through 2004. The HRS and AHEAD studies were merged in 1998.

At least 5 identifiable studies have been conducted on the quality of the asset and income data in the HRS and AHEAD datasets. In this paper, we give overviews of three issues that are examined in depth in the attached appendices, A, B, and C. A fourth issue is analyzed in depth following these overviews. And a fifth issue is noted, discussed briefly in the overview part of the paper, and examined in more detail in appendix D. These issues are:

- the use of unfolding brackets to convert “don’t know” or “refuse” responses to amount questions into a set of categorical responses containing lower and upper bounds;

- the use of improved estimates of rate of return to capital to convert underestimates of capital income to estimates that, while they contain the usual measurement error, no longer contain substantial biases;

- an attempt to improve the match between the periodicity of income receipt as measured by the survey question and by the actual event; 
- the correction of substantial underestimates of assets in experimental measurements in the AHEAD 1993 survey. The experiments turned out to involve confused wording in the financial asset section of the questionnaire as well as problems in other design features. These issues were first noted in Rohwedder, et al. (2004). We also use these revised asset measurements to correct estimates of capital income as implemented in HRS in Juster, Lupton, and Cao (2002) (Appendix B).

- the correction of underestimates of second-home wealth in AHEAD 1995 and HRS 1996 that resulted from a straight-forward skip-sequence error.

\section{Unfolding Brackets: Overview of Appendix A}

Data quality is an issue of longstanding concern among researchers interested in wealth accumulation (Curtin, Juster, and Morgan 1988; Ferber 1959; Lansing, Ginsberg, and Braaten 1961). Recently, available wealth data have proliferated, as many surveys have incorporated wealth modules into studies whose major objectives were quite different than the measurement of wealth or savings. In this paper we argue that some relatively simple survey extensions may significantly improve the quality of household economic data. The survey extensions are "follow-up brackets" - bracket categories offered to respondents who initially refused or were unable to provide an exact value for their assets or income. Brackets represent partial responses to asset questions and can significantly reduce uncertainty about the actual value.

Applied in this form to wealth modules, these extensions originated in the Panel Study of Income Dynamics (PSID) and were used extensively in the recently fielded Health and Retirement Survey (HRS) and the Asset and Health Dynamics Among the Oldest Old Survey (AHEAD). 
Their value is clearest in surveys with relatively short wealth modules. Although application of this methodology to surveys mainly concerned with wealth risks alienating respondents with an excessive number of follow-up questions, wealth surveys with extensive modules might also be able to use brackets successfully by tailoring brackets to specific assets or using them judiciously. Use of follow-up brackets appears to provide a partial remedy to deal with nonignorable non-response bias, a critical problem with economic survey data. Our estimates indicate that wealth imputations based on this methodology are typically higher by a factor of two compared to conventional "hot-deck" imputations made without these brackets. In the two surveys that we examine, the failure to use brackets understated population estimates of nonhousing wealth by $19 \%$ among those in their 50 s and by $9 \%$ among those over 70 . The effect of this methodology on behavioral models has yet to be assessed.

\section{Background}

Assets are notoriously poorly reported on surveys. Non-response is pervasive, and other evidence (Curtin et al. 1989) suggested that the values may also be reported with errors. Although many prominent surveys have included wealth modules, their quality has been viewed with skepticism, due partly to large numbers of missing values. Three types of cognitive problems may help explain why missing-data rates are so high for many forms of household wealth. First, the respondent may simply not know the answer to the question, particularly if the answer requires adding several different accounts or placing a value on hard-to-measure assets like a business. Second, the respondent may have a rough idea of the amount but assumes that the interviewer wants a very precise figure. Third, the respondent may refuse to disclose the value of assets, because he or she regards it as too personal or intrusive. 
These considerations may help explain why some wealth components are subject to higher missing-data rates than others. For example, many individuals are quite inactive investors. They may have a much better idea of the amount in their checking account than in their common stock holdings. These households buy stock infrequently, do not check the price with any regularity, and have only a very general notion of their value. In contrast, households with checking accounts get a monthly statement from banks, which is often used to monitor expenditures. Housing equity offers another interesting contrast. Respondents are more willing to respond to questions about the market value of their homes, possibly because they may feel that anyone, including the interviewer, is able to make a pretty good guess about how much their quite-visible home is worth.

Survey designers have tried various ways to mitigate the missing data problem in financial variables. One strategy, discussed in the early methodological literature (Ferber 1959; Juster, 19XX), was to encourage respondents to reduce missing data by providing exact data from financial records. But records were often inaccessible and almost always incomplete, so additional information was always necessary. Another technique, used extensively in early waves of the Surveys of Consumer Finances (SCF), gives respondents a range card with letters corresponding to quantitative intervals (e.g., an amount between $\$ 5,000$ and $\$ 7,499$ would be represented by the letter E).

These various methods of mitigating missing-data problems all have pluses and minuses. First, any method of following up "don't know" or "refuse" responses is time-consuming and runs some risk of annoying or badgering the respondent. Second, follow-ups that take the form of range cards can be used effectively only in personal interview surveys. Third, unfolding bracket 
questions provide a uniform stimulus and are generally easy to answer, but are necessarily limited to placing values into relatively few categories. Finally, failure to probe for exact answers may result in some loss of exact answer data.

The HRS and AHEAD methodology involved two main features. First, unfolding brackets (is the amount more than x?) placed the respondent's asset into one of a set of categories; second, interviewers were told not to extensively probe "don't know" or "refuse" responses, but rather to proceed to the first question in the unfolding bracket sequence. The design philosophy was that dropping the usual practice of probing for exact answers would shorten the survey and minimize chances of annoying respondents. The loss of data quality resulting from losing some exact answers (either by not probing or by learning to provide ranges rather than exact amounts) would hopefully be smaller than the gain resulting from converting completely missing data to categorical data. In HRS wave 1, the strategy used in the 1984 and 1989 PSID wealth module was adopted, where unfolding brackets were used for financial assets and debts, but range cards were used for housing assets and were also a possibility (on a voluntary basis) in the financial asset module. In later waves where telephones were the primary medium (AHEAD 1 and 2, HRS 2 and 3), range cards were not used, and all assets used unfolding brackets.

\section{Missing Values and Data Quality}

This section documents the ability of follow-up brackets to limit the effects of initial nonresponse. Table 1 in Appendix A lists the prevalence of item non-response in the HRS and AHEAD asset modules; exact data non-response is shown in column 3 of this table. Housing yields the lowest non-response rates, with less than 5\% of HRS respondents not providing an exact home value and almost twice as many having trouble with the mortgage. Missing values 
are considerably larger among the financial and tangible asset categories, often on the order of 30\% or more. For example, 1 in 3 HRS business or common stock owners had initial nonresponses on the value of their businesses or stocks. In most cases, a larger fraction of AHEAD households than HRS households did not give an exact value to their assets. Among asset owners, 32\% of AHEAD (28\% of HRS) households did not report the exact amount in their checking and savings accounts. In general, item non-response ran about 4-8 percentage points larger in AHEAD than in HRS. Because most AHEAD respondents are at least 70 years old and many are in their 80s, reasonable caution in the face of a stranger, minor forgetfulness, or other mild cognitive problems may account for AHEAD's somewhat higher item non-response rates. Severe cognitive problems were more likely to result in the use of a proxy respondent.

Non-response to asset questions is commonplace in all household surveys with wealth modules, and these problems are not unique to HRS and AHEAD. For example, 38\% of the owners of common stock did not provide an exact value to the amount question in the 1986 SIPP; the comparable figure for the 1983 SCF was $25 \%$. Roughly one-third of respondents in both of these surveys did not respond with an exact amount about the value of their businesses.

This picture of large amounts of missing data changes dramatically if the categorical data obtained from unfolding brackets are considered. The value of brackets depends first on whether they induce sufficient numbers of respondents to provide range responses. Some believe that non-respondents to asset questions are hard-nut cases, reluctant for privacy reasons to reveal their asset values. In this common view of non-response as dogmatic refusal, the cost of countering the initial non-response with more probing is thought to be high and the yield in new information low. But our experience in HRS and AHEAD suggests that convincing non- 
respondents to provide bracketed responses is often easy. To illustrate, Table 1 of Appendix A separates missing-data responses on HRS and AHEAD into three subcategories: categorical data obtained from a range card, unfolding brackets, and the residual - cases where the respondent refused to provide any information. The proportion of all missing data converted to range card or unfolding bracket responses is shown in the last column.

Although we cannot know what information might have been obtained by direct probing, both surveys showed a substantial reduction in the amount of completely missing information with the unfolding technique. For example, the range categories converted a 33\% item non-response for stocks in HRS to only 9\% of cases for which we have no information on value. In many financial asset categories, brackets reduced HRS item non-response (defined as no information) by $75 \%$. Because we have only a partial response to a question and not an exact value, this reduction in item non-response is not the same as eliminating item non-response entirely for these cases. But although knowing that a value lies within some prespecified range does not equal knowing an exact value, it is extremely valuable for imputation.

Table ! of Appendix A shows that brackets were even more successful in decreasing item nonresponse in AHEAD. For example, brackets converted a 45\% full-item non-response in stock value to only $8 \%$ of cases with no information on value. On average, brackets reduced nonresponse for asset items by more than $80 \%$, a conversion rate that exceeds even HRS. In general, full item non-response (no information on value) in both surveys ends up in the single digits after the brackets are offered.

While providing some information about the distribution of asset values, a legitimate concern is whether unfolding brackets reduce the probability of reporting exact data. Unfolding brackets 
might encourage respondents to avoid the difficult cognitive task of counting up asset values in favor of the simpler one of providing "yes" or "no" answers to various threshold amounts. Although plausible, our evidence from these surveys actually goes in the opposite direction. We examined respondents who used unfolding brackets in the early parts of the survey to see whether they were also more likely to use brackets in answering questions in the later part of the survey. In fact, just the reverse is true - for all assets, respondents who use brackets early tended to provide exact responses later. Our speculation is that respondents may learn from the bracket questions that a rough approximation to asset value is of sufficient accuracy and use that insight to provide exact answer data (often in round numbers) later in the survey.

The HRS and AHEAD survey design also sheds some light on the motivation for non-response. In the initial question sequence, respondents who did not give an asset value were separated into two categories: those who refused to respond [refusals (REF)], and those who said that they did not know [don't knows (DK)]. This is an important distinction, not only for the eventual success rate in converting completely missing data into bracket responses, but also in estimating the distribution of the unknown-asset values. Although some respondents are reluctant to reveal the value of their assets, others may simply be unsure of precise values, an uncertainty that translates into non-response. It turns out that most of these unsure respondents can be persuaded to place their asset values within range limits, information that turns out to be very valuable indeed.

Table 2 of Appendix A provides some insight into this issue by listing the distribution of HRS cases originally recorded as "DK" or "REF" on asset questions. Respondents who went completely through the bracket sequence are labeled complete bracket. Those who went partly through the bracket sequence, but refused at some later point, are called partial bracket. Finally, 
those who refused to respond to any of the bracket questions are labeled DK or REF. Data are shown separately for those who originally responded DK and for those who originally responded REF.

The data show a substantial difference in willingness to provide bracket responses between original DK and REF responses. Almost 90\% of initial DK responses provided either complete or partial bracket data; the great majority - typically $80 \%$ or more - gave complete bracket information. In contrast, more than half of those initially responding REF on a specific item typically refused to provide any additional information about that asset; only about $40 \%$ on average provided complete bracket information. Perhaps some respondents who are unsure of precise values may initially be polite refusals; these respondents are willing to provide some information about asset values with the follow-up brackets. This marked contrast in the behavior of DK and REF responses suggests that the two need to be handled separately when imputations are being done.

\section{Imputation of Missing Values: Methods}

Follow-up bracket questions persuaded many initial non-respondents to provide ranges for their asset values. Without brackets, imputation would treat these converts as if they had the same assets as exact-answer respondents with similar personal attributes. It turns out that for both HRS and AHEAD, exact-answer cases are heavily weighted toward the lower end of the asset value distribution, whereas REF and DK cases are weighted more toward the upper end. As one example, just 8\% of HRS households giving exact answers had business equity in excess of $\$ 500,000$, compared to 19 (22) \% of those who gave initial don't know (refusal) responses, but who answered the bracket question sequence. In general, based on respondents who eventually 
used the brackets, REF cases are weighted more toward the upper end of the amount distribution than DK cases.

\section{- $\quad$ Bracket Respondents}

One way to establish the information value of brackets is to estimate missing values as though the bracketed data were not available. Accordingly, we imputed values under two assumptions for respondents who placed their assets within brackets. The first (brackets used) recognizes that the correct value must lie within self-reported limits and that only respondents with assets within those limits should serve as potential donors. The second (brackets ignored) uses the conventional procedure - all exact-answer respondents serve as potential donors. In both cases the full list of personal attributes described earlier is used in the imputation algorithm. Table 3 of Appendix A shows means and medians (averaged over 25 iterations) for each nonhousing asset. The row labeled "average value" contains the weighted average of individual asset values where the weights are the fraction holding each asset among all bracketed assets.

The quantitative differences produced by these two imputation methods are substantial, especially for HRS households. For example, we estimate a mean HRS business asset of $\$ 348,600$ when brackets are used, with a standard deviation of that mean across the 25 iterations of $\$ 21,546$. This estimate is well in excess of the mean business asset of $\$ 165,986$ when bracket information is ignored. In virtually every case, the differences in means in Table 3 of Appendix A are well in excess of the standard errors of these estimates. Mean HRS nonhousing imputations are $67 \%$ higher when brackets are used than when brackets are ignored. The difference from using brackets appears somewhat greater for tangible than for financial assets;

our estimate of mean business equity among HRS (AHEAD) respondents is more than \$182,000 
$(\$ 120,000)$ greater when the brackets are used in imputation. Although not trivial, the bias is considerably smaller in AHEAD; our estimated average asset value using brackets was 29\% higher than when they were ignored. Because these discrepancies are as great with medians, the higher mean values are not simply the consequence of a few very high values.

There are many plausible reasons for this difference between the two surveys. Most important, given the age difference between the samples, is that there are fewer AHEAD respondents with extremely high asset values. Second, relative to their total portfolio, AHEAD respondents have fewer assets in categories, such as business equity, where the bias is particularly large. Finally, HRS respondents use both unfolding brackets and range cards, whereas only unfolding brackets were used in AHEAD. The difference between using and ignoring brackets was larger with range cards. For example, average nonhousing asset values were about 50\% higher for those who used unfolding brackets than for exact data responses, compared to about $100 \%$ higher for respondents who answered using range cards. The reason may be that range cards contain many more categories than unfolding brackets do, especially at very high asset values. Thus it is possible that the unfolding bracket categories may still understate respondents' asset values.

\section{- Final Non-response Imputations}

More accurate estimates of missing data for respondents who gave bracketed responses are only part of the gain from the use of brackets. The indirect benefit is that bracketed respondents provide a more relevant donor pool for final non-response cases. Table 7 of Appendix A lists imputed mean values for all "final non-response cases" using two alternative donor pools. The

first, more conventional pool consists of respondents who provided exact answers to asset questions. This pool corresponds to that used by many survey organizations when they conduct 
their imputations. In contrast, the second pool uses as donors only respondents who gave bracketed responses. We believe that the latter is more representative of the final non-response cases, because they share an initial reluctance to answer asset questions. If anything, the pool of bracketed respondents will still understate asset values of the final non-responses, who are even more reluctant than bracket respondents to reveal their assets.

Table 7 of Appendix A demonstrates how critical the correct donor pool may be. The value of the average HRS (AHEAD) nonhousing asset is approximately 63 (42) \% larger using bracketed responses than exact answer responses as donors. Once again, the largest understatements occur in both surveys in the tangible asset categories (business, farms and other real estate). For example, business equity in HRS is higher by roughly $\$ 130,000$ if we use the donor pool of unfolding bracket responses instead of the conventional donor pool of exact answer responses.

\section{$\underline{\text { Report on Some Extensions and Conclusions }}$}

Although unfolding brackets can improve the quality of financial data, research on their optimal design and implementation is just at the beginning stages. These issues are complex and in need of additional research; their potential importance is briefly sketched here.

Even if the best set of bracket thresholds are chosen, the issue of whether there exists an anchoring effect associated with the choice of an initial threshold in the sequence remains. Anchoring occurs when the content of the question itself conveys information about what the probable "correct" answer is. For example, if respondents are asked about the size of their checking accounts, responses may be influenced by whether the first question is at the $\$ 100$ level, the $\$ 1,000$, or the $\$ 10,000$ level, even if the final set of bracket categories are the same. Because respondents may assume that question designers know more than they do, the entry 
point may tell respondents something about what the "correct" answer is. A sequence that starts with $\$ 100$ will convey the impression that small numbers are more likely to be correct than large numbers, whereas a sequence starting with $\$ 10,000$ may give the opposite impression.

To address this question, a group of respondents in the second wave of AHEAD were asked to place their savings account values into bracket thresholds. While the final set of thresholds were the same, the initial threshold value varied randomly across respondents. The cumulative distribution of savings account values varied systematically with alternative initial entry points. For example, the cumulative fraction of cases less than $\$ 10,000$ was $49 \%$ when the initial entry point was $\$ 1,000$ compared to $37 \%$ when it was $\$ 20,000$. Anchoring effects produced less bias in mean values when the initial entry point was in the middle rather than at either end of the distribution. Because most HRS and AHEAD bracket sequences start toward the middle of the distribution, the bias in mean values in these surveys may be moderate.

The HRS and AHEAD unfolding bracket questions all had a common format where the initial bracket question is phrased: "Is it more than $\mathrm{x}$ ?" But there are alternative ways to phrase the question, with some obvious possibilities being: "Is it x or more?"; or "is it more than x, less than $\mathrm{x}$, or about equal to $\mathrm{x}$ ?" The distinction in these three questions is whether or not the rounded number specified by $\mathrm{x}$ is associated with a "yes" or a "no" response (if the question is "more than $\mathrm{x}$," then the rounded number calls for a "no" response), and whether the respondent can indicate that their asset holdings are just about the same amount as the rounded number. Based on analyses of some experimental data from HRS and AHEAD, there is little difference in the "x or more" and "more than $\mathrm{x}$ " versions, but the balanced question (is it more than $\mathrm{x}$, less than $\mathrm{x}$, or 
about equal to $\mathrm{x}$ ) provides a somewhat different distribution of responses, with about 5-10\% of respondents reporting that "about equal to $\mathrm{x}$ " is the correct answer.

\section{Conclusions}

This paper has investigated some survey techniques used in the HRS and AHEAD surveys. These techniques - follow-up bracket responses - reduce the implications of initial non-response to wealth questions and narrow uncertainty about precise asset values. Because initial levels of item non-response in HRS and AHEAD are similar to those obtained in other household surveys, follow-up brackets may also lower the pervasiveness of complete item non-response in other surveys.

The potential value to other household surveys of follow-up brackets goes beyond simply reducing non-response. Our evidence suggests that missing wealth data involves nonignorable response bias, and that follow-up brackets provide a partial remedy to this problem. For example, our estimates imply that household surveys may distort the age-wealth profile by understating wealth in the preretirement years relative to the postretirement years by $10 \%$. Even if there were no effect on nonignorability, range brackets undoubtedly produce efficiency gains as the size of the imputation error is reduced. One must be careful in extrapolating our results to other household surveys that differ in many ways besides the use of brackets. But we think that our results are strong enough to recommend that multipurpose surveys with relatively short wealth modules try follow-up brackets to mitigate a serious problem of nonignorable non-response. In fact, based largely on the HRS and AHEAD experience, the new 1996 National Longitudinal Survey of Youth has already incorporated an extensive use of brackets in its wealth module. 


\section{Underestimates of Income From Assets-Part I: Overview of Appendix B}

The last decade has seen substantial progress in improving the quality of micro-data on both income and wealth. Some of these developments are documented in recent papers by Juster and Smith (1997), Juster, Lupton, Smith and Stafford (2004), and Hurd, Juster and Smith (2003). These papers explore a number of quality enhancements: the use of unfolding brackets for income or wealth components that convert “don't know” or "refusal” responses into quantitative imputations that contain measurement error but little or no bias; the use of improved estimates of changes over time in wealth and active saving to generate measures of capital gains or losses; the use of a merged questionnaire sequence that integrates survey questions about asset holdings and income flows from these assets to reduce the bias in estimates of income from capital; and finally, matching of the periodicity specified in income questions to the actual periodicity of income receipts as a way to enhance the quality of reports for certain income categories.

These enhancements of survey data on income and wealth, while substantially improving the quality of the cross section data, do not come without a cost. A major problem associated with any change made to the methodology used in a panel survey is that they tend to produce time series inconsistencies. By definition, quality improvements reduce the bias and/or measurement error of the cross section point estimate but, by doing so, introduce a bias in the estimate of change over time.

One way to avoid producing such a time series inconsistency is to freeze the survey technology, thus eliminating any quality enhancement. As a long run strategy, this is clearly a bad idea - robust empirical findings cannot be obtained from poor data. A preferred alternative would be to develop methods of recovering time series consistency in the face of data enhancements. In this section of the paper, we explore methods of recovering time series 
consistency in the measurement of income from capital in the Health and Retirement Survey (HRS).

Respondents in both Waves 1 (1992) and 2 (1994) of the HRS were asked to report all sources of income in a stand-alone series of questions. The conventional view is that these questions should be reported together since they all have the characteristic of being resource flows. In a separate set of questions, the value of household assets and liabilities were obtained. Again, the idea was that these are all stock values and thus should be grouped together. However, while this classification of flows and stocks into separate groups is useful from the perspective of the researcher, it may not be the optimum question structure from the viewpoint of the survey respondent. Given that the source of asset income is the asset itself, it makes sense to integrate stocks and flows in a way that allows the survey respondent to consider these dollar amounts at the same time. This innovation was implemented in the HRS beginning in Wave 3 (1996) and continues to be the methodology used in all following waves including Wave 4 (1998), Wave 5 (2000) and Wave 6 (2202). Hurd, Juster and Smith (2001) examine the effect of this data collection enhancement and find that the income from capital almost doubles between Waves 2 and 3, suggesting the reduction of a serious bias resulting from the stock/flow separation of asset amounts and income. And as noted in that paper, other surveys, such as the Current Population Survey, also suggest a serious underestimate of income from assets using the conventional survey design that has income from assets reported in one module and the assets reported in a separate module.

Although clearly indicating a substantial improvement in the measurement of asset income, the mean doubling between Waves 2 and 3 of the HRS is problematic for researchers wishing to utilize the panel aspect of the survey. The results of any time series study of HRS 
asset income will be dominated by this technology change in data collection. To correct the problem we propose a strategy that utilizes the distribution of the rates of return to assets obtained in the unbiased data. Random imputation of asset income rates of return in Waves 1 and 2, using Wave 3 as the donor distribution, are used with the asset values of Waves 1 and 2 to generate an estimate of asset income.

Two crucial assumptions are required if this strategy is to be successful. First, it is assumed that although there is a time series inconsistency in the estimate of asset income, the estimates of asset values are not contaminated by this bias. We provide evidence that the measurement of asset values is indeed consistent over time and that the major source of bias in the rate of return to assets stems from the measurement of asset income. Second, the donor distribution must be an adequate representation of the true distribution in the time period where the imputations are being made. To determine how robust our strategy is to this assumption, we provide imputed estimates based on donor distributions coming from HRS Waves 3, 4 and 5. The stability of the imputed estimates across donor distributions is noteworthy.

In the next section, we examine the HRS data on household financial wealth and income flowing from that wealth. We discuss the possibility of various sources of measurement error in the time series across Waves 1 through 5 and provide the mean rate of return to financial assets in these years. We outline three imputation procedures and discuss their relative advantages and disadvantages. These procedures are applied to the HRS asset income data and the results are reported in Section 4. The robustness of each procedure is examined as are the various imputation strategies. Concluding remarks are provided in Section 5.

\section{Survey Structure Induced Bias in the HRS Financial Asset Income}

Financial wealth in the HRS is defined as the sum of four components: checking, saving 
and money market accounts; CD’s, savings bonds and Treasury bills; publicly traded corporate equities and equity mutual funds; and corporate bonds. Each of these potentially yields some amount of asset income. Data from the 1992 and 1994 Waves are based on the conventional survey format while the 1996, 1998 and 2000 Waves are based on the revised format that integrates questions about asset holdings with questions about income from assets. In the conventional format, respondents are asked whether they own any of the four financial assets, or have any investment in real estate or any business or farm equity, and how much they own if the y report owning any. In a later section of the questionnaire, respondents are asked about income from a variety of sources (wages or salary, workers compensation, veterans' benefits, business income, rent, Social Security, pensions, interest or dividends, etc.). In the revised question sequence, households are asked whether they have each of the four financial asset components noted above. If the respondent claims to own a particular asset, they are asked about its value and, if greater than zero, whether they received any dividend or interest income from that asset. If they claim to have received asset income, they are asked how much and how often. Similar question sequences are asked for each of the four types of financial assets.

Gross differences in the reporting of income from assets across the five waves are enormous. These are shown in Table 1 of Appendix B. In 1992 and 1994, using conventional methodology, only about a third of the sample reported income from financial assets while almost two-thirds reported zero income from assets. These proportions were approximately reversed in 1996, 1998 and 2000 using experimental methodology, with almost two-thirds reporting income from assets and a bit more than one-third reporting zero income from assets. Interestingly enough, the proportion of the sample reporting ownership of financial assets is essentially the same on all five waves: the fraction owning financial assets is a bit over $80 \%$ in 
1992, and goes up slightly in each later year as one would expect during a vigorous economic expansion.

Another way to look at the linkage between assets and income from assets is to examine the proportion of the sample reporting zero income from assets within different asset percentiles across survey years. This is provided in Table 2 of Appendix B. In the lowest asset category (zero to the $25^{\text {th }}$ percentile), the proportion of the sample reporting zero income from assets is over 90\% in all five survey years, although it is a bit higher in 1992 and 1994 than in 1996, 1998, or 2000. The differences by year become substantial when we look at higher asset percentiles. For example, in the $90^{\text {th }}$ percentile and above, the 1992 and 1994 proportions of households reporting zero income from assets are, respectively, 22\% and 36\%, extraordinarily high numbers for households in the upper $10 \%$ of the financial asset distribution. Integrating the survey questions on asset income into the asset and liabilities module reduces the proportion of households reporting zero income from assets to about 3\% in that percentile group. Substantial differences in the fraction of households reporting zero income from assets also show up in the $25^{\text {th }}-50^{\text {th }}$ percentile, in the $50^{\text {th }}-75^{\text {th }}$ percentile, and in the $75^{\text {th }}$ through the $90^{\text {th }}$ percentile. In the $25^{\text {th }}-50^{\text {th }}$ percentile, the fraction of households reporting zero income from assets goes from about $80 \%$ using the conventional survey format to between 40 and 50\% using the revised format The fraction reporting zero goes from over $50 \%$ in the conventional mode to about $12 \%$ in the revised mode in the $50^{\text {th }}-75^{\text {th }}$ percentile, while going from about a third in 1992 and 1994 to around 5\% in 1996, 1998 and 2000 in the $75^{\text {th }}-90^{\text {th }}$ percentile.

Tables 3a, 3b and 3c of Appendix B contain a more detailed picture of the change in income from financial assets and in asset holdings over the five survey years and over the percentile distribution of financial asset holdings. The pattern of the data in these tables is very 
consistent. In Table 3a, which has mean income from financial asset holdings by percentiles of financial asset holdings, the full sample means in 1992 and 1994 are roughly 50\% of the means in 1996, 1998 or 2000. This across year mean difference stems largely from differences among households whose financial asset holdings are in the $75^{\text {th }}$ percentile or higher. For example, in the $90^{\text {th }}-100^{\text {th }}$ percentile, mean asset income is about $\$ 8,000$ in 1992 and 1994 , but about $\$ 18,000, \$ 22,000$ and $\$ 23,000$ in 1996, 1998 and 2000, respectively - roughly a three-fold increase. In contrast, in the $50^{\text {th }}-75^{\text {th }}$ percentile, the 1996,1998 and 2000 data look to be about the same size as the 1992 data, all of which are higher than the 1994 mean.

Table $3 \mathrm{~b}$ contains mean financial asset holdings across asset holding percentile groups. No pattern difference is evident between the 1992-1994 data and the 1996-1998-2000 data. By year, the mean grows substantially, as one would expect during a period of economic prosperity with substantial capital gains. In the $50^{\text {th }}-74^{\text {th }}$ percentile, the mean grows from roughly $\$ 15,000$ to slightly over $\$ 22,500$ - a $50 \%$ increase over the eight-year period. In the $90^{\text {th }}+$ percentile group, the mean grows from around $\$ 300,000$ in 1992 to about $\$ 650,000$ in 2000 - roughly a two-fold increase. Thus the pattern that one would expect in the absence of any survey innovation is exactly what one finds in Table 3b. Mean financial asset holdings grows steadily and substantially over the 1992 to 2000 period with no indication that the growth rate is affected by the transition from conventional survey methods to the revised method. Generally speaking, the growth rates over the entire period tend to average about $9 \%$ per year with growth being larger in the higher percentiles than in the lower ones.

The effect of the revised survey format conditioned on asset holdings is presented in Table 3c which provides the mean of the average rate of return to financial assets, defined as the ratio of financial asset income to financial assets. Note that this is a mean of individual rates 
rather then the ratio of the means from Tables 3a and 3b. The mean average rate of return over all households increases by roughly 50\% from the conventional format to the revised format. This pattern can be seen across the asset groups as well. For households with financial assets above the $90^{\text {th }}$ percentiles, the mean of the average rate of return jumps from $3.3 \%$ and $2.4 \%$ in 1992 and 1994, respectively, to 4.6\% in 1996 after which it stays relatively constant.

The data displayed in Tables 1, 2 and 3 of Appendix B make it clear that time-series analysis of the effect of income change on various types of behavior would be greatly aided if the income component that reflected the return on financial assets could be adjusted to ensure consistency. The problem is that all datasets using the conventional HRS survey design (asking about a long set of income components, including dividends and interest income) will seriously underestimate income flows from financial assets and hence overstate the change across the conventional and revised survey years.

There are at least two potentially important ways in which biased measurement error is introduced into reported financial income from 1992 and 1994 - error in reporting having any asset income, and error in reporting the value of asset income conditional on having any at all. As indicated in Table 2 of Appendix B, a striking features of the quality enhancement in measuring income from capital is that the merged question sequence converts the proportion of respondents who report zero asset income from $71 \%$ in Wave 2 to $38 \%$ in Wave 3. Even more striking is that the merged module converts the proportion of households with financial assets above the $90^{\text {th }}$ percentile who reported zero interest or dividend income from $36 \%$ in Wave 2 to $2.3 \%$ in Wave 3 . Thus, one possibility could be that the bias in reported financial income is generated solely by households who actually have but report no asset income. This would imply no bias among households who reported asset income and thus require the imputation of only 
those households who report owning assets but no asset income. If we limit comparisons to households reporting some asset income in each year we might find the same degree of time series consistency that we find in the level of asset holdings from Table 3b. If that were true, we could focus on devices for imputing values to households that reported owning financial assets with no asset income in Waves 1 and 2 based on relationships observed in wave 3.

To examine this hypothesis, Table 4 of Appendix B reproduces Table 3c for households who report positive income from financial assets. Among all households, the mean average rate of return for 1992 and 1994 seems much more in line with those from the later waves. However, this masks some remaining time series inconsistencies across the financial asset distribution. The average rate of return for households with financial assets above the $90^{\text {th }}$ percentile, households with by far the most asset income on average (Table 3a), remains roughly 40\% lower in 1992 and 1994 than in 1996, 1998 or 2000. Thus, while the elimination of households who report no asset income alleviates some of the time series inconsistency, it fails to do so for the most relevant households, i.e. households with significant asset income. This is strong evidence against the hypothesis that the only survey induced bias is among households reporting no asset income. The existence of survey structure induced bias appears to be present both in households reporting positive asset income as well as in those reporting zero asset income.

\section{Imputation Strategy}

The average rates of return reported in Table 3c of Appendix B are not only evidence of the measurement error in asset income from Waves 1 and 2 of the HRS, but also suggest a possible solution to correcting the problem. As noted above, there is a high degree of consistency in financial wealth across all waves in the HRS. The time series consistency is a product of the fact that the survey instrument did not change over the years. Furthermore, the use of a follow-up 
sequence of unfolding bracket questions for respondents reporting 'don't know' or 'refuse' in the collection of asset and liability data, combined with random imputation within brackets, greatly minimizes any bias in the measurement of financial wealth. The result is that, while the time series consistency of financial asset income is clearly suspect, the reliability of measured financial wealth is strong. ${ }^{1}$ It is thus possible to use the rates of return computed for the 1996 data to assign a rate of return to households in 1992 and 1994. These rates of return can then be combined with the financial wealth data for those households to impute an unbiased measure of financial asset income.

\section{Imputation Results}

The imputation procedures used in this paper rely heavily on the distribution of the rate of return in 1996. The central assumption is that the rate of return distributions for Wave 1 and 2 of the HRS are biased downward while the Wave 3 distribution, although not free of measurement error, has no such bias. The rate of return distribution for Waves 1, 2 and 3 are provided in Table 5a, 5b and 5c of Appendix B, respectively. These rates are computed only for households who have financial assets. However, it is important to note that there are many households who report a zero interest on dividend income, and thus have a zero rate of return.

The survey induced bias is clear by comparing the Wave 3 distribution with that of Wave1 and 2. The median rate of return for all households in 1996 is $2.4 \%$. This value is zero for households in 1992 and 1994. Moving up the rate of return distribution, the bias remains. The average rate of return in 1996 is $5.7 \%$ at the $75^{\text {th }}$ percentile while only being $3.3 \%$ and $1.5 \%$ in

\footnotetext{
${ }^{1}$ Note that unfolding brackets were implemented in the collection of asset income in all waves except Wave 1 . This makes the reliability of asset income in Wave 1 even more suspect.
} 
1992 and 1994, respectively. Not surprisingly, average rates at a given percentile are smaller for lower values of financial assets. This is largely a result of the fact that the number of households with zero asset income increases. Households with small amounts of financial assets are more likely to have a portfolio that yields little to no asset income. For households in the lowest asset group, the median rate of return is zero in all years of the survey. Nevertheless, the pattern of the

bias is consistent. The median rate of return for households with financial assets in the 50 to

$75^{\text {th }}$ percentile is 3.1\% in 1996. In 1992 and 1994, this value remains at zero.

\section{Conclusion}

In this paper we note the substantial effects of asking survey respondents about asset income in a merged asset/income module in which the income question sequences directly followed after the asset sequences rather than being asked in a separate income module. The inability of many surveys to ascertain accurate asset income data is certainly a product of this phenomenon. We go on to note that the improvements made by correcting this survey flaw do not come without a cost. This cost is a substantial seam problem between the years in which the survey technology is improved. In an attempt to improve cross-year consistency in the financial asset income series of the Health and Retirement Survey, we propose a number of imputation strategies that take advantage of the fact that cross-year consistency is maintained in the levels of financial assets.

Using various schemes to impute an average rate of return to households in 1992 and 1994, we are able to establish a time series of financial asset income with similar consistency to that of financial wealth. The strategy that yields the best results is one which combines a household's own portfolio allocation information from later waves of the data with random imputation of rates of return within various financial asset groups where the donor distributions 
come from the 1996 survey year. These results are notably robust to replacing the 1996 donor distribution with that of either the 1998 or 2000 survey years. A version of this imputation procedure that also accounts for gross outliers in the average rate of return yields a time series of financial asset income that is consistent with macroeconomic trends.

Future work will include correcting the income from privately owned business or farms, and real estate. Income from these two assets shares the same time series inconsistency as the financial asset income examined in this paper since it was also asked in a separate model from the value of the assets. The bias in business, farm and real estate asset returns is more difficult to correct since the rates of return are far more idiosyncratic than they are for financial wealth. Nonetheless, once these issues are adequately resolved, a superior measure of total household income will be made available.

\section{Underestimates of Income from Assets-Part II: Overview of Appendix C}

\section{$\underline{\text { Introduction }}$}

There has been concern about the reliability of survey estimates of income and wealth ever since such measures began to be collected systematically in the 1940s and 1950s (Sudman and Bradburn (1974); Radner (1982)). Obtaining accurate and unbiased household wealth measures has been problematic due to the reluctance of the extremely wealthy to participate in social science surveys at all, and the widespread prevalence of item non-response to wealth questions in particular. Ironically, using new survey innovations, there has been considerably greater progress in mitigating problems for wealth measurement than for income. For example, given the extreme skew in wealth distributions, the bias resulting from the substantially higher non-response rates among very wealthy households has been dealt with in the various Surveys of 
Consumer Finances conducted since 1983 by the use of special sampling frames (such as tax files) that over-sample the super-wealthy. Similarly, the growing use of unfolding bracket techniques to handle missing data problems have resulted in reduced measurement error and lower bias due to non-ignorable item non-response to wealth questions (Juster and Smith (1997)). To date, no parallel progress has been documented for income measurement.

In this paper, we attempt to remedy this situation by evaluating two survey innovations aimed at improving income measurement. These innovations are (1) integrating the question sequences for income and wealth which may elicit more accurate estimates of income from capital than has been true in the past, and (2) changes in the periodicity over which income flows are measured, which may provide a closer match between what the survey respondent knows best and the periodicity contained in survey measurement. These innovations have been introduced into both the Health and Retirement Study (HRS) and the study of Asset and Health Dynamics Among the Oldest Old (AHEAD). Based on the results reported in this paper, the potential return in quality of income measurement from these innovations is substantial.

\section{Data Sources and Bias in Income Reporting}

Questions about income rank among the most difficult to answer in household surveys (Sudman and Bradburn (1974); Coder and Scoon-Rogers (1995)). Besides any reluctance respondents may have in revealing information they consider private and sensitive, significant cognitive issues exist that may make it difficult for respondents to accurately report their incomes. Especially when asked about the incomes of other family members, their knowledge about the actual income amounts may be quite limited. Some incomes are received on an irregular basis so that accuracy of reports may depend on how soon after the last receipt the survey questions are asked. Similarly, the dollar amounts involved may be variable from period 
to period, or taxes and other expenses may or may not be deducted. Finally, respondents may be asked to report their incomes over a time span that is different than how their incomes are received or remembered. These factors may result both in a significant bias (typically underreporting) or in mis-reporting or random measurement error.

Table 1 of Appendix C gives some indication about the extent of income under-reporting by comparing Current Population Survey (CPS) estimates of various types of income relative to external benchmark estimates according to CPS validation studies. Across all income sources, CPS income reports are 89 percent of the benchmark indicating an 11 percent under-report on average. However, there exists considerable variation around that average. There is little bias in CPS wage and salary incomes which are 98 percent of the benchmark. Social Security Income contains more bias (95 percent of the benchmark), but appears to be less understated than the other major source of retirement income, private pensions. But private pensions may be a case where the benchmark is too high since it includes lump sum withdrawals and rollovers to other accounts such as IRAs and Keoghs. Excluding such lump sum payments places the CPS pension income at about 84 percent of the benchmark (Woods (1996); Schieber (1995)). By far, the most severe under-reporting occurs in interest and dividends, where CPS reports are about half the external benchmarks. Even when these income sources are reported without bias, there remains the problem of substantial measurement error in reports of amounts (Ferber (1966), Moore, Stinson, and Welniak (1997)).

Our research will rely on data from three well known surveysCthe Health and Retirement Survey (HRS), the Asset and Health Dynamics of the Oldest Old (AHEAD), and the Current Population Surveys (CPS).

HRS and AHEAD are both longitudinal surveys with data collected every other year. Both surveys obtained extensive information about the economic situation of the households, 
including a complete accounting of assets stock and income flows. In addition to housing equity (with separate detail for the first and second home), assets were separated into the following categories in HRS and AHEAD: other real estate; vehicles; business equity; IRAs or Keoghs; stocks or mutual funds; checking, savings, or money market accounts; CD's, government savings bonds, or treasury bills; other bonds; trusts and estates; other assets; and other debt. Similarly, separate questions were asked in both surveys about a long list of income sources for both the respondent and spouse: wages and salaries, self-employment income, tips and bonuses, unemployment compensation, workers= compensation, Social Security income, supplemental security income, private pension income, welfare, disability income, veterans benefit or military pension. In addition, questions were asked at the household level about rental income, income from business, interest and dividends, annuities, and food stamps.

There are two specific enhancements implemented in HRS and AHEAD aimed at improving the quality of income measurement, the integration of income from asset questions with questions about the assets from which such income is derived, and the use of periodicity questions that for certain income sources more closely reflect the frequency with which such income is received. We discuss these enhancements in detail below. HRS and AHEAD income and asset modules are given to the knowledgeable financial respondent, the eligible respondent most knowledgeable about the household's financial situation. Especially in AHEAD, proxy respondents are occasionally used if the financial respondent is not physically able to respond or suffers from severe cognitive problems. Because the integration of asset and income questions took place between the second and third waves of HRS and the first and second waves of AHEAD, across-wave comparisons of reports of income from capital provide a convenient way 
of evaluating the impact of this integration. Since AHEAD did not vary the periodicity of income reporting, on that issue we turn to another survey for comparison.

The Current Population Surveys (CPS) are the most widely used source to monitor labor force and income changes by year in the United States, and thus represent a useful standard of comparison to HRS and AHEAD. CPS conducts interviews each month with the number of households interviewed varying from 47,000 to 57,000 households during the 1990s (Current Population Reports). CPS households are interviewed for four successive months, are not interviewed for the next eight months, and then are interviewed once again for four successive months. Annual incomes from many sources are obtained during the March interview. Consequently, although CPS is normally not thought of as a panel, approximately half the respondents are interviewed across two adjacent March interviews.

Since no questions are asked about the value of household assets, the CPS cannot be used to evaluate the merit of integrating asset and income questions. However, CPS does ask questions about a long list of income sources using varying reporting periodicities. CPS income sources include wages and salaries, self-employment income, tips and bonuses, unemployment compensation, workers’ compensation, Social Security income, supplemental security income, private pension income, welfare, veterans benefit or military pension. In addition, questions were asked at the household level about rental income, income from business, interest and dividends, annuities, and food stamps. CPS questionnaires are typically answered by one household member who may or may not be the most knowledgeable about its financial affairs.

\section{The Measurement of Income from Assets}

Table 1 of Appendix C indicated that the most serious under-reporting of income takes place in measures of income from capital. The cleanest case is interest and dividend income, 
since the underlying sources of the income flows, holdings of common stock, bonds, CDs, checking and savings accounts, money market funds, etc. are more likely to be reliably reported by the household than the income generated from these assets. But a comparison of the fraction of households who report holding an asset and the fraction who report receiving any interest or dividend income from that asset strongly suggests that survey estimates of income from assets are badly underestimated. In the typical survey, the fraction of households reporting interest or dividend income is much smaller than the percentage reporting ownership of assets that might yield an interest or dividend income flow. To illustrate, 75 percent of HRS wave 2 households report holding some financial assets, but less than 30 percent report having any interest or dividend income.

In light of this gross inconsistency in income and asset reports, in the third wave of HRS and the second wave of AHEAD we revised the way income questions were asked. Essentially, we created a merged asset and income module in which questions about particular types of assets were followed immediately by questions about income from that asset. The key to this entire sequence is the way in which income-yielding assets are handled. The question sequence we developed asked first about ownership of the asset; for those households reporting ownership we then asked about the value of the assets; we next asked whether any income was received from the asset and, if so, about the periodicity and whether or not about the same amount was received every period. For households reporting ownership, value, some income, and a monthly periodicity, with about the same amount received every month, the idea was to calculate last year's income from the periodic amount and the periodicity. For households reporting that the amount received every period wasn't always the same, we branched to a question about the amount of income received from the asset in the prior calendar year. This question sequence was 
used for the four types of financial assets included on HRS and AHEAD (checking, savings, and money market accounts; CDs, savings bonds and Treasury Bills; stocks; and bonds), as well as for real estate investment equity and business and farm equity.

Comparisons of results from this new way of asking about income from assets (used in HRS 3 and AHEAD 2) with estimates of income from assets produced by the conventional survey methodology (as reflected by HRS 2 and AHEAD 1) show dramatic differences in income amounts reported. Table 2 of Appendix C highlights the impact by listing mean income and the value of asset holdings by source in HRS 2 and 3 and AHEAD 1 and 2. The effects of the integration are quite dramatic. Between HRS 2 and HRS 3, income from these financial assets, real estate investments, and business and farm equity combined increased from $\$ 5,669$ a year to $\$ 9,266$ a year. Some of this increase in income may be due to the growing asset values common to the 1990s, but this can explain only a small part of the increase. While the value of assets goes up by about 14 percent between HRS 2 and 3, income from assets increased by 63 percent. While the integration of asset and income questions affected all income sources, the impact was largest in income amounts from the four financial assets (a greater than two-fold increase), and smallest in income from business and farm (a 32 percent increase). Following the integration of the asset and income questions, capital income increases of an even larger magnitude (over \$8 thousand compared to about \$3.5 thousand) appear between AHEAD 1 and 2.

The failure to report interest or dividend income using the conventional survey format, while in an absolute sense related to the size of asset holdings, appears to apply throughout the full range of asset holdings. Table 3 of Appendix C provides the relevant data for HRS 2 and 3, dividing the sample into asset categories ranging from none to more than a quarter of a million, and then sub-dividing income into categories starting with none and going up to $\$ 25,000$ or 
more. Examine first the relationship between asset holdings and income flows for the sum of the four financial assets contained in the surveys. Ninety percent plus of households in HRS 2 who report a small amount of financial assets (\$1-\$2499) also report zero interest or dividend income. In contrast, 63 percent of HRS 3 households in the same asset group report zero interest or dividend income.

But the most dramatic results occurs among those with a great deal of these assets. For example, 31 percent of HRS 2 households who had more than $\$ 250,000$ of financial assets still reported that they received no income at all from these assets. That result is not plausible and indicates that without tying the income questions to the presence and amount of the asset there is a substantial understatement of the prevalence and level of income from assets. The integration of the asset and income question resulted in a substantial decrease in the inconsistency between asset and income reports. In HRS 3 among those with more than \$250,000 in these financial assets, only 3 percent did not report any income from this source.

It is not surprising if people with a few dollars of interest or dividend income report that they had zero interest and dividend income. It is quite surprising that many people with more than a quarter of a million dollars of financial asset holdings report zero interest or dividend income when the question is asked in the conventional format relative to what they report when the question is asked in the merged format. We believe that the better quality income reports are obtained with the merged format because a respondent has just been asked to think about the existence and size of asset holdings. This merged format makes it difficult to report zero income having just reported substantial asset holdings. Whatever the explanation, the merged income/asset format produces a dramatic improvement in the reporting of income flows from assets. 
There are also some income distribution consequences to the enhanced reporting of income from capital. This income tends to be held by wealthier households so that underreporting of income may simultaneously understate the extent of income inequality in the population. This issue is examined in Table 4 of Appendix $C$ which stratifies households into quintiles by the amount of their total household income in HRS1, and within each quintile, lists the amount of total capital income reported in HRS 2 and HRS3. While HRS 3 numbers indicate that much more capital income is reported in the aggregate, the increased reporting of income from capital had very little impact on those households in the bottom fifth of the income distribution whose income declined relative to incomes in all other quintiles. In contrast, those households in the top quintile registered an increase in capital income of over $\$ 7000$ between HRS2 and HRS3. In general, the size of the increase in capital income between waves 2 and 3 grew across income quintiles. This pattern implies that the absolute income gap of the well-to-do relative to the poor is understated by conventional survey methods of obtaining household income.

\section{The Effect of Income Periodicity}

The second survey innovation we evaluate concerns the time span or periodicity over which income is reported. For simplicity, many surveys have respondents report all income sources in the same periodicity even though periodicity and regularity of payments may vary a great deal by source. Yet, especially for income sources which are not variable, respondents may know and answer best if the question refers to the time interval at which they normally and most recently receive that income. (Tourangeau, Rips, and Rasinki (2000)). When respondents are requested to report in a periodicity different than that of usual receipt, we may be asking them to perform quickly some difficult cognitive and computation tasks. The value of a specific periodicity may 
be highest for income flows that tend to continue indefinitely, to change slowly (perhaps due a COLA adjustment), and to arrive with uniform periodicity (typically a month).

Given these specifications, the most likely income flows to gain from alternative periodicities may be income sources generally received by older and retired households. The most common source in this category is Social Security benefits, which are received monthly, are adjusted annually for Cost of Living changes, do not have taxes withheld, and involve withholding only to the extent that respondents select Medicare Part B as an option (more than 90 percent do). In this case, asking the amount of last month’s Social Security check may produce better estimates of Social Security income than asking, as is the usual case, for Social Security benefits paid during the most recent calendar year. Thus, it seems better to estimate Social Security benefits by asking about last month’s Social Security check, multiplying it by twelve for respondents who began to receive Social Security payments prior to the beginning of the most recent calendar year (and multiplying it by the appropriate number of months for households who began to receive payments sometime during the prior calendar year).

Since at least for sub-populations of recipients the truth is known, Social Security may also represent the ideal income source to gauge respondents' ability to report their income accurately. By age 70 when there are no earnings tests or Social Security disability income, Social Security income is fixed legislatively by a formula that depends on the history of past earnings and on family composition. If there are no changes in family composition due to divorce, separation, or death, Social Security income is only revised across calendar years by a universal Cost of Living Adjustment (COLA) first given in the January check each year. To eliminate such demographic reasons for changes in Social Security income, we restricted our AHEAD sample to households where both respondents were at least 70 years old in the first 
wave and where no marital status changes or deaths occurred between the first and second wave. We also required both respondents to have received some Social Security income in each wave so that there is no ambiguity that we are dealing with program beneficiaries. Finally, cases were deleted when Social Security income was imputed in either wave of the panel.

Given these sample restrictions, Social Security income in our remaining sample should only change due to a COLA. To compare reports of Social Security income across successive waves, we adjusted the wave one report by any COLA that would have taken place given the month and year of interviews. Between waves, most (86.5 percent) AHEAD respondents had two COLA adjustments, but 8.4 percent had only one while 5.1 percent had three. If all respondent reports were completely accurate, these adjusted wave one and actual wave two reports of Social Security income would be identical. Differences between them therefore reflect reporting error.

The first column in Table 5 of Appendix C displays percentile distributions of arithmetic differences in wave one Social Security income (adjusted for subsequent COLA's) and wave two Social Security income. While respondents report monthly incomes, for comparison with other surveys, we list differences on an annual basis for the year 1995. The specific year chosen does not affect the results. The median difference in Social Security income is small the COLA adjusted wave 1 report is $\$ 57$ higher per year than the wave 2 report of Social Security income. Half of respondents give reports that are no more than $\$ 200$ apart, 80 percent give reports within roughly $\$ 800$ of each other, and 90 percent lie no more than $\$ 1,500$ (or 23 percent) apart. Reporting errors appear to be symmetric so that each wave is equally likely to be higher than the other.

Are these AHEAD income reporting errors large or small? The answer depends on the context in which the data are used. For cross-sectional analyses since mean Social Security 
incomes were about $\$ 9600$ in 1995, Table 5 indicates that AHEAD reporting errors are nine percent or more for one in five respondents. But for analysis relying on the panel nature of the data (within person changes in Social Security income, the problem is far more serious. To illustrate, all within person variation in Social Security income in our sample in Table 5 represents measurement error by construction.

Another way to answer this question is to compare AHEAD income reports to those obtained from other prominent surveys that rely on different methodologies to obtain data on income. The Current Population Surveys (CPS) provide such a comparison. During the 1990s, CPS made several revisions in the way it asks income questions, including Social Security income. Before 1994, CPS respondents were asked to report Social Security income for the last calendar year. Starting in 1994, respondents first selected the periodicity (monthly, quarterly, or annual) in which they wanted to report and then gave a dollar amount for this periodicity. There is a clear preference for a monthly interval for Social Security income. For example, in 1996, 77 percent of CPS respondents selected monthly as the easiest way of reporting Social Security income while 23 percent selected yearly. No matter which periodicity was chosen, the income still referred to the last calendar year. For example, if the respondent chose monthly, they were asked to give their monthly income during an average month last year. CPS staff would then convert all incomes to an annual basis which is the way income is available on public use tapes. We matched respondents across two successive March panels for 1992 and 1993 (when CPS asked for annual Social Security income) and 1996 and 1997 when the new CPS reporting system had been in place for a while. Individuals were matched based on their sex, race, age, education, and line number. Matches had to be exact on sex, race, and line number and no more than two years apart in age and at most one year of schooling apart. We then imposed the same 
sample deletions used in the AHEAD sample. That is, we retained only cases in which each respondent (and spouse) were at least 70 years old in the first March survey, no deaths or marital changes occurred between March interviews, Social Security incomes were not imputed in either interview, and there was a positive report of Social Security income in both March interviews.

The second and third columns in Table 5 list percentile differences in Social Security income from the second March CPS interview minus the COLA adjusted Social Security income from the previous March CPS. Once again, the median difference was small, less than 50 dollars a year. However, differences in CPS reports of Social Security income are considerably larger than those in AHEAD. For example, the $90^{\text {th }}$ and $10^{\text {th }}$ percentiles in the CPS were about plus and minus $\$ 1,900$ compared to approximately $\$ 800$ in AHEAD. Alternatively, roughly one fifth of CPS respondents had measurement errors in their Social Security incomes of 20 percent or more. In general, reporting errors appear to be about twice as large in CPS as in AHEAD. Moreover, the size of these CPS reporting errors seem to be about the same when the new reporting methodology of March of 1996 and 1997 is used as when the old CPS annual income methodology was used in March of 1992 and 1993. Apparently, these revised CPS methods did not lead to any overall improvement in the quality of income reports for Social Security income.

Why then are the quality of AHEAD reports on Social Security income apparently superior to those obtained in CPS? Several factors could produce these differences. In particular, CPS does not necessarily interview the most knowledgeable financial respondent, a problem that may be compounded by interviewing someone else other than the older person or his/her spouse. However, when we restricted our analysis to single person households (where there were no options about whom to interview), we found that reporting errors were still about twice as large in CPS as in AHEAD. A more likely explanation is that CPS respondents do not report in the 
form in which they received their most recent check, monthly check which excludes the deduction of the Medicare Part B premium.

To see this, the penultimate column in Table 5 lists differences in CPS Social Security income among those reporting in a monthly interval in both 1996 and 1997. CPS errors in Social Security incomes are much smaller when consistent monthly units reporting is employed. In fact, more than 60 percent of the difference between CPS and AHEAD reporting errors is explained by the use of a monthly interval. The final column in Table 5 indicates some additional quality improvement is obtained by limiting CPS respondents to those reporting in a monthly interval and after Medicare premium deductions in both 1996 and 1997. Much of the remaining difference with AHEAD is likely a consequence of the fact that, even using monthly intervals, CPS is asking respondents to perform the more difficult computational task of calculating what they received in an average month last year while AHEAD is simply asking them to remember the last check. Requiring those respondents who said they found it easier to report in an yearly interval to report monthly instead is likely to result in improved reports as the preference for yearly reporting has little conviction behind it. Even among respondents who reported in a yearly interval in 1996, two-thirds of them reported in a monthly interval one year later. ${ }^{\mathrm{i}}$

\section{$\underline{\text { Conclusion }}$}

Although under-reporting of income is often thought to be a problem for those at the bottom of the economic strata, the results presented in this paper indicate that at least for some sources of income it is more of a problem for those at the top of the heap. These income sources include income from financial assets, rental income from property, and income from business or farms. These income sources are understated by a factor of two in conventional household surveys. Fortunately, this appears to be a problem with a solution at hand-integration of asset 
and income modules in surveys. Such an integration was introduced into the third wave of the Health and Retirement Survey and the second wave of AHEAD. The net result was an almost doubling of these income components as well as a much more consistent reporting by households of their income and their assets. Can the benefits of this innovation carry over to other surveys? The merged income/asset module will work best for surveys like PSID, NLS and SIPP which are designed to collect information about asset holdings and about income flows and which have about the same number of asset categories as HRS. But the merged module may work less well in studies like the SCF, which has very detailed asset holdings (roughly 100 categories in all) so that a merger of the income and asset modules may be impractical.

The interesting case involves surveys like CPS that do not currently obtain data on asset holdings in part because data on assets are thought to be sensitive (thereby encouraging refusals) and also to take too much survey time to administer. To deal with these concerns, an interesting possibility is to experiment randomly with modified versions of the merged income/asset module design that may be less sensitive and less time consuming than the full HRS treatment. One idea would be to ask about the presence or absence of asset holdings, but not about amounts. If assets were present, one would next ask whether there is any income associated with those assets and the periodicity and amount of income flows. Asking simply about the presence of assets is unlikely to be as sensitive or time consuming, but may produce some of the data quality benefits of associating income flows with assets. Another possibility is to ask about asset values but only within very broad intervals. Such knowledge may be sufficient to remind respondents of the likely income amounts they receive from these assets. Similarly, asking respondents to answer using a time interval consistent with how income is received significantly improves the quality of reports about income. This is certainly the case with Social Security, where the same amount is 
received many times in a regular periodicity. The same rationale may hold for many major sources of income. Pension payments are much like Social Security payments, except that some fraction of pension payments will involve tax withholding, and many pensions are not adjusted for Cost of Living changes. But question sequences that ask about tax withholding and about Cost of Living changes should handle this problem quite well. A similar situation is likely to be the case for Veterans' Benefit payments which have the same features as Social Security or Pension payments once they start, they continue until the death of the recipient, and may continue beyond that depending on demographic circumstances.

\section{Underestimation of Assets in AHEAD 1993}

In the design of the income and asset sections of the AHEAD 1993 survey, a number of experiments were tried both in terms of question sequences and question wording. Not all of the enhancements worked, and many had clearly negative consequences. For example, AHEAD 1993 asked about income before asking about assets which appears to have resulted in a substantial understatement of the level of financial assets. The apparent reason is the inclusion of the introductory phrase, “Aside from anything that you have already told me about, do you (or your h/w/p) have any holdings of common stock, money market funds, CDs, corporate bonds...” Many respondents apparently took the phrase “Aside from anything you have already told me about” as not referring solely to questions about assets, where the phrase is highly important and needs to be used to avoid duplication, but to apply to the questions in the previous section that asked about income from financial assets. Thus a substantial number of people reported income from financial assets and then said that "aside from...” they did not own any such asset. The result is a severe underestimate of the 1993 levels of financial asset holdings (see Rohwedder, 
Haider and Hurd 2004). It appears that the underestimation is of the order of $\$ 40,000$ per household, or roughly $30 \%$ of total financial asset holdings—-this underestimate affects all four financial asset categories queried.

In addition, there is a moderate underestimate of asset holdings in the form of IRA and Keogh accounts in the AHEAD 1993 survey, probably due in large part to the fact that many more detailed questions were asked about IRAs and Keoghs in subsequent waves, but only a single question was asked in 1993. As a result, reports of holdings of IRAs and Keoghs tend to be on the low side in the 1993 AHEAD survey.

Finally, the value of owned businesses or farms appears severely underestimated in 1993. This is probably due in part to the omission of "farm" assets as opposed to the standard wording, which specifies "business or farm” assets. However, this is unlikely to be the only explanation. The underestimate appears severe compared to asset holdings in other waves, and it seems likely that many respondents who owned farms would have reported their farm as a business asset.

One of the consequences associated with ownership underreporting in individual asset components is a clear time-series inconsistency in total assets, which is illustrated in Figure 1 below and documented in more detail in Table 1. 


\section{Figure 1. Mean Values of the Total Non-Housing Assets in AHEAD}

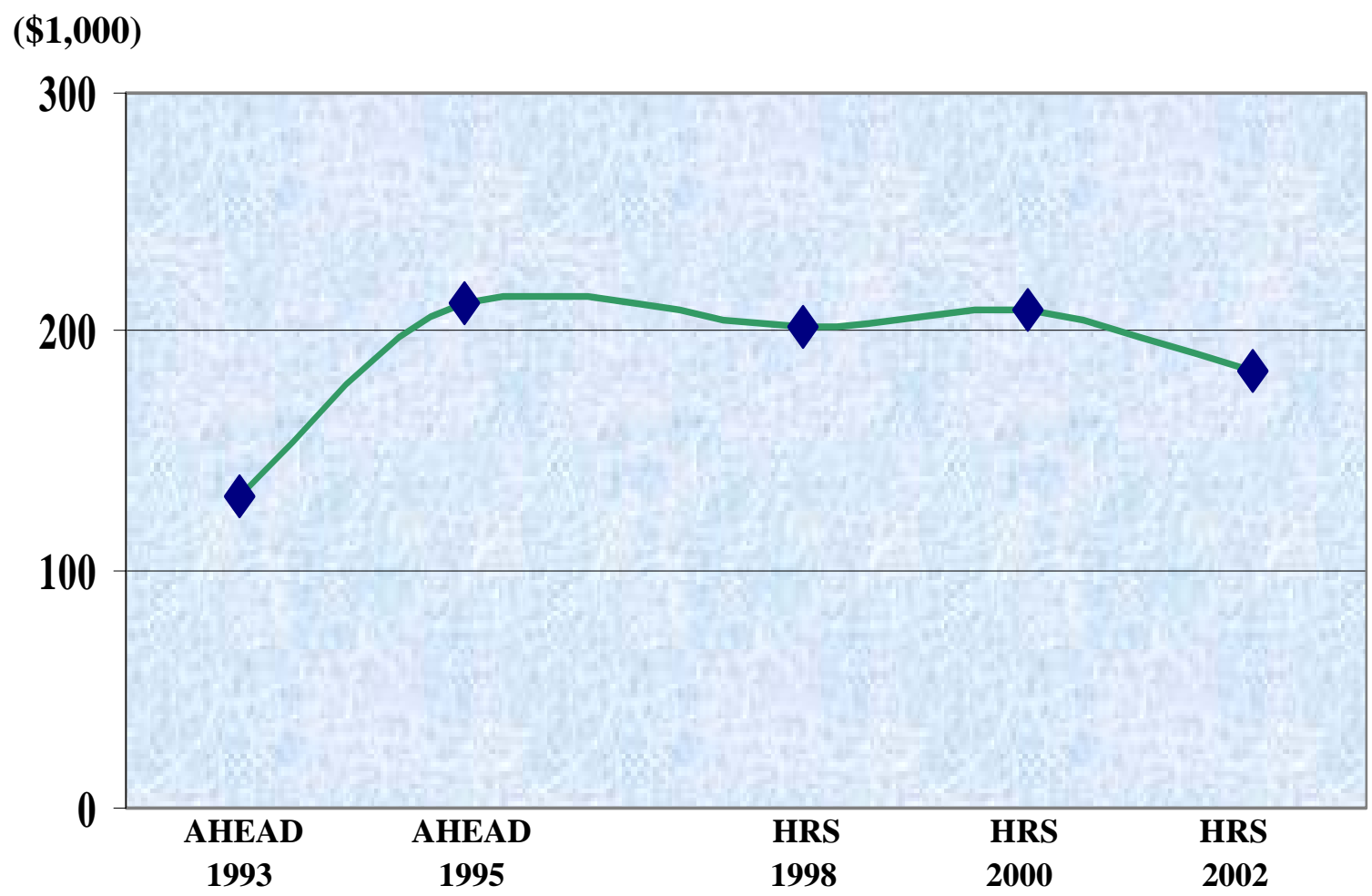

Weighted Results, in the 2002 dollars

There are a number of ways in which asset underreporting can be corrected. One procedure is to use the cross-wave relationship found in asset ownership among AHEAD data waves to identify a sample of underreporting households in AHEAD 1993, and then use imputations to improve the quality of the asset data for those households. Preliminary results show that this correction produces ownership patterns in AHEAD 1993 that are more consistent with those in other AHEAD waves, and the estimated mean value of the total non-housing assets increases by about $\$ 25,000$.

In the other sections of the paper, we first describe the survey design problems in AHEAD 1993 that we speculate to be the primary cause of the problems with the asset data. We then describe our asset correction procedure, which is based on differences in the cross-wave 
relationship of asset ownership found in AHEAD data waves. This section concludes with a comparison of the AHEAD 1993 asset data before and after corrections, as well as the use of this corrected asset data to impute financial asset income in AHEAD 1993 using the procedure applied to HRS 1992 and 1994 in Appendix B.

\section{$\underline{\text { Survey Design Problems in AHEAD } 1993}$}

The strategy used for collecting asset data in AHEAD 1993 differed from that used in any other AHEAD wave in two respects. First, unlike as in AHEAD 1995, 1998 and 2000 where questions regarding an asset and the income from the asset were closely aligned in an integrated questionnaire module, asset information was collected separately from income information in AHEAD 1993. ${ }^{2}$

Second, when asset questions were asked in AHEAD 1993, the wording and sequencing of some questions was problematic. Combined with the fact that the asset section followed, rather than preceded, the income section, this sequence appears to have misled a significant number of households who owned financial assets to report not owning any such assets. To see how this might have occurred, consider the following asset ownership question for stocks and mutual funds:

"(Aside from anything you have already told me about,) Do you [or your (husband/Wife/partner)] have any shares of stock in publicly held corporations, or mutual funds?"

While the wording beginning with "Do you" was exactly the same as in later waves, the phrase at the beginning of the question "Aside from anything you have already told me about" was not. This could have encouraged many respondents who owned stocks or mutual funds to give a negative response to this question, because some information about stock or mutual funds had

\footnotetext{
${ }^{2}$ This problem also exists in HRS 1992 and 1994.
} 
already been covered in the income section, when respondents were asked whether they were receiving regular income from various sources including IRA distribution, stocks, bonds, savings accounts, CDs, and rental properties. In other words, a respondent who owned stock or mutual funds might think that he/she no longer needed to report the asset because he/she had already talked about it in the income section.

Two other survey design problems also lead to downward-biased asset measurements in the AHEAD 1993 survey. First, AHEAD 1993 contains only one question about IRA value, while in other waves, the sequence begins by asking how many IRAs the respondent and spouse has and then asks about the three largest. Second, in AHEAD 1993, the question about businesses/farms owned by respondents omits the word "farm," hence missing some respondents who would have otherwise reported a value because they owned a farm.

The impact of these problems on the quality of the asset data may be seen in Table 1, where the percentages of asset-owning households and the mean values of the individual asset components are compared across waves. The most conspicuous differences between the AHEAD

\section{Table 1. AHEAD Asset Ownerships and Mean Values Across Waves}




\begin{tabular}{|c|c|c|c|c|c|}
\hline Asset Type & $\begin{array}{l}\text { AHEAD } \\
1993\end{array}$ & $\begin{array}{l}\text { AHEAD } \\
1995\end{array}$ & $\begin{array}{l}\text { HRS } \\
1998\end{array}$ & $\begin{array}{l}\text { HRS } \\
2000\end{array}$ & $\begin{array}{l}\text { HRS } \\
2002\end{array}$ \\
\hline Real Estate & $\begin{array}{l}\% 18 \\
\$ 25,254\end{array}$ & $\begin{array}{l}\% 15 \\
\$ 29,185\end{array}$ & $\begin{array}{l}\% 12 \\
\$ 29,804\end{array}$ & $\begin{array}{l}\% 13 \\
\$ 31,225\end{array}$ & $\begin{array}{l}\% 11 \\
\$ 24,497\end{array}$ \\
\hline Business/Farm & $\begin{array}{l}\% 4 \\
\$ 8,769\end{array}$ & $\begin{array}{l}\% 7 \\
\$ 17,883\end{array}$ & $\begin{array}{l}\% 6 \\
\$ 17,638\end{array}$ & $\begin{array}{l}\% 6 \\
\$ 18,687\end{array}$ & $\begin{array}{l}\% 6 \\
\$ 18,821\end{array}$ \\
\hline IRA & $\begin{array}{l}\% 17 \\
\$ 10,582\end{array}$ & $\begin{array}{l}\% 20 \\
\$ 15,091\end{array}$ & $\begin{array}{l}\% 20 \\
\$ 16,405\end{array}$ & $\begin{array}{l}\% 22 \\
\$ 16,875\end{array}$ & $\begin{array}{l}\% 22 \\
\$ 15,349\end{array}$ \\
\hline $\begin{array}{l}\text { Stock/Mutual } \\
\text { Fund }\end{array}$ & $\begin{array}{l}\% 20 \\
\$ 30,154\end{array}$ & $\begin{array}{l}\% 30 \\
\$ 74,014\end{array}$ & $\begin{array}{l}\% 31 \\
\$ 68,171\end{array}$ & $\begin{array}{l}\% 33 \\
\$ 73,109\end{array}$ & $\begin{array}{l}\% 31 \\
\$ 56,084\end{array}$ \\
\hline Bond & $\begin{array}{l}\% 6 \\
\$ 6,403\end{array}$ & $\begin{array}{l}\% 9 \\
\$ 13,057\end{array}$ & $\begin{array}{l}\% 8 \\
\$ 10,384\end{array}$ & $\begin{array}{l}\% 9 \\
\$ 8,264\end{array}$ & $\begin{array}{l}\% 9 \\
\$ 11,626\end{array}$ \\
\hline $\begin{array}{l}\text { Checking/Savings } \\
\text { Account }\end{array}$ & $\begin{array}{l}\% 77 \\
\$ 22,953\end{array}$ & $\begin{array}{l}\% 84 \\
\$ 28,632\end{array}$ & $\begin{array}{l}\% 84 \\
\$ 24,132\end{array}$ & $\begin{array}{l}\% 83 \\
\$ 23,661\end{array}$ & $\begin{array}{l}\% 87 \\
\$ 26,368\end{array}$ \\
\hline CD & $\begin{array}{l}\% 22 \\
\$ 11,376\end{array}$ & $\begin{array}{l}\% 32 \\
\$ 21,385\end{array}$ & $\begin{array}{l}\% 32 \\
\$ 21,741\end{array}$ & $\begin{array}{l}\% 34 \\
\$ 23,101\end{array}$ & $\begin{array}{l}\% 32 \\
\$ 20,254\end{array}$ \\
\hline Vehicle & $\begin{array}{l}\% 72 \\
\$ 8,837\end{array}$ & $\begin{array}{l}\% 69 \\
\$ 8,013\end{array}$ & $\begin{array}{l}\% 68 \\
\$ 7,563\end{array}$ & $\begin{array}{l}\% 69 \\
\$ 7,223\end{array}$ & $\begin{array}{l}\% 68 \\
\$ 6,961\end{array}$ \\
\hline Other Assets & $\begin{array}{l}\% 10 \\
\$ 3,425\end{array}$ & $\begin{array}{l}\% 9 \\
\$ 5,090\end{array}$ & $\begin{array}{l}\% 10 \\
\$ 7,270\end{array}$ & $\begin{array}{l}\% 10 \\
\$ 6,440\end{array}$ & $\begin{array}{l}\% 10 \\
\$ 4,374\end{array}$ \\
\hline Debt & $\begin{array}{l}\% 14 \\
\$ 1,152\end{array}$ & $\begin{array}{l}\% 13 \\
\$ 815\end{array}$ & $\begin{array}{l}\% 12 \\
\$ 611\end{array}$ & $\begin{array}{l}\% 11 \\
\$ 689\end{array}$ & $\begin{array}{l}\% 10 \\
\$ 1,029\end{array}$ \\
\hline $\begin{array}{l}\text { Total Non- } \\
\text { Housing Assets }\end{array}$ & $\begin{array}{l}\% 91 \\
\$ 127,501\end{array}$ & $\begin{array}{l}\% 92 \\
\$ 211,534\end{array}$ & $\begin{array}{l}\% 92 \\
\$ 202,495\end{array}$ & $\begin{array}{l}\% 93 \\
\$ 208,894\end{array}$ & $\begin{array}{l}\% 93 \\
\$ 183,126\end{array}$ \\
\hline Net Worth & $\begin{array}{l}\% 94 \\
\$ 219,860\end{array}$ & $\begin{array}{l}\% 96 \\
\$ 311,135\end{array}$ & $\begin{array}{l}\% 96 \\
\$ 302,215\end{array}$ & $\begin{array}{l}\% 97 \\
\$ 312,375\end{array}$ & $\begin{array}{l}\% 96 \\
\$ 292,640\end{array}$ \\
\hline
\end{tabular}

Note: Weighted results in 2002 dollars. The first row represents percentage of asset-owning households, the second row the mean value of the asset. "Total Non-Housing Assets" is equal to the sum of the first nine asset components minus "Debt". "Net Worth" is equal to "Total NonHousing Assets" + "Housing Equity”.

1993 asset data and the data in any other wave were significant ownership underreporting in businesses/ farms, IRAs, stocks and mutual funds, bonds, checking/savings, money market accounts, and CDs, T-bills, and government bonds. The financial assets, in particular, were strongly downward biased, with the mean value of financial assets biased by at least $\$ 20,000$, and the mean value of businesses or farms estimated as about half the value in other waves. 
The ownership underreporting problem did not happen to any other type of asset (e.g., real estate, vehicle, other assets, and debt). For those assets, both the ownership and mean value patterns are very consistent across waves, indicating that the AHEAD 1993 asset problems were the result of a problematic survey design unique to AHEAD 1993.

\section{The Correction Procedure}

Our procedure to correct these shortfalls is based on a presumed stability in the flow of asset ownership into and out of asset categories between waves. That is, we assume that if 5\% of respondents have the pattern: own stock in wave 2, don't own stock in wave 3, own stock in wave 4 ; then $5 \%$ will have that pattern in waves 1,2 and 3 . That this assumption is valid for AHEAD 1995-1998-2000 as compared to AHEAD 1998-2000-2002 can be seen in Table 2 (for ownership pattern indicators we use the numbers one for ownership and five for nonownership-e.g. 115 indicates the pattern own-own-don’t own). For example, Table 2 shows that $27.55 \%$ own stocks in at least one of the three waves 1995, 1998 or 2000 compared to roughly $26.95 \%$ in 1998,2000 or 2002. Similarly, the numbers for account ownership are $81 \%$ in AHEAD 1995, 1998 or 2000 and also 81\% in 1998, 2000 or 2002. Based on this assumption, we implement the following procedure:

Step 1. Determine the asset ownership patterns in the AHEAD cohort in 1995, 1998 and 2000. This relationship may be characterized as the following marginal distribution (Distribution B) in Table 3, where “ 1 ” indicates owning an asset in a wave, “5” not owning an asset in a wave, and the sum of the sample percentages $\left(\mathrm{P}_{\mathrm{i}}, \mathrm{i}=1,2, \ldots, 8\right)$ is equal to 100 .

\section{Table 2. AHEAD Three-Wave Ownership Distributions (\% of households)}

Panel A. Business/Farm and IRA 


\begin{tabular}{|c|c|c|c|c|c|}
\hline \multirow{2}{*}{\multicolumn{2}{|c|}{$\begin{array}{l}\text { Three-Wave Ownership } \\
\text { Pattern }\end{array}$}} & \multicolumn{2}{|c|}{ Business/Farm (\%) } & \multicolumn{2}{|c|}{ IRA (\%) } \\
\hline & & $\begin{array}{c}\text { 1995-1998- } \\
2000 \\
\end{array}$ & $\begin{array}{c}\text { 1998-2000- } \\
2002 \\
\end{array}$ & $\begin{array}{c}\text { 1995-1998- } \\
2000 \\
\end{array}$ & $\begin{array}{c}1998-2000- \\
2002 \\
\end{array}$ \\
\hline \multirow{5}{*}{$\begin{array}{l}\text { Owning } \\
\text { Asset in the } \\
\text { Base Year }\end{array}$} & 111 & 1.61 & 1.49 & 9.97 & 8.95 \\
\hline & 115 & 1.40 & 0.94 & 2.56 & 3.41 \\
\hline & 151 & 0.47 & 0.63 & 0.71 & 0.94 \\
\hline & 155 & 2.44 & 2.05 & 3.27 & 3.34 \\
\hline & Subtotal & 5.92 & 5.11 & 16.51 & 16.64 \\
\hline \multirow{4}{*}{$\begin{array}{c}\text { Not Owning } \\
\text { Asset in the } \\
\text { Base Year }\end{array}$} & 511 & 0.64 & 1.00 & 1.82 & 2.36 \\
\hline & 515 & 1.32 & 1.04 & 1.32 & 1.91 \\
\hline & 551 & 1.61 & 1.98 & 5.90 & 4.95 \\
\hline & 555 & 90.51 & 90.87 & 74.45 & 74.13 \\
\hline \multicolumn{2}{|c|}{ Grand Total } & 100.0 & 100.0 & 100.0 & 100.0 \\
\hline
\end{tabular}


Table 2 Panel B. Stock/Mutual Fund and Bond

\begin{tabular}{|c|c|c|c|c|c|}
\hline \multirow{2}{*}{\multicolumn{2}{|c|}{$\begin{array}{l}\text { Three-Wave Ownership } \\
\text { Pattern }\end{array}$}} & \multicolumn{2}{|c|}{ Stock/Mutual Funds (\%) } & \multicolumn{2}{|l|}{ Bond (\%) } \\
\hline & & \multirow{2}{*}{$\begin{array}{c}\begin{array}{c}1995-1998- \\
2000\end{array} \\
14.78\end{array}$} & \multirow{2}{*}{$\begin{array}{c}\text { 1998-2000- } \\
2002 \\
13.74\end{array}$} & \multirow{2}{*}{$\begin{array}{c}1995-1998 \\
2000 \\
1.80\end{array}$} & \multirow{2}{*}{$\begin{array}{c}1998-2000 \\
2002\end{array}$} \\
\hline \multirow{5}{*}{$\begin{array}{l}\text { Owning } \\
\text { Asset in the } \\
\text { Base Year }\end{array}$} & 111 & & & & \\
\hline & 115 & 5.78 & 6.65 & 1.86 & 1.60 \\
\hline & 151 & 2.24 & 1.78 & 0.94 & 1.00 \\
\hline & 155 & 4.75 & 4.78 & 3.78 & 3.13 \\
\hline & Subtotal & 27.55 & 26.95 & 8.38 & 7.25 \\
\hline \multirow{4}{*}{$\begin{array}{l}\text { Not Owning } \\
\text { Asset in the } \\
\text { Base Year }\end{array}$} & 511 & 4.19 & 4.20 & 1.29 & 1.81 \\
\hline & 515 & 2.06 & 3.89 & 2.50 & 2.92 \\
\hline & 551 & 7.67 & 6.84 & 4.04 & 3.79 \\
\hline & 555 & 58.52 & 58.11 & 83.78 & 84.22 \\
\hline \multicolumn{2}{|c|}{ Grand Total } & 100.0 & 100.0 & 100.0 & 100.0 \\
\hline
\end{tabular}

Table 2 Panel C. Checking/Savings Account and CD

\begin{tabular}{|c|c|c|c|c|c|}
\hline \multirow{2}{*}{\multicolumn{2}{|c|}{$\begin{array}{l}\text { Three-Wave Ownership } \\
\text { Pattern }\end{array}$}} & \multicolumn{2}{|c|}{ Checking/Savings Account (\%) } & \multicolumn{2}{|c|}{ CD (\%) } \\
\hline & & \multirow{2}{*}{$\begin{array}{c}\begin{array}{c}1995-1998- \\
2000\end{array} \\
61.57\end{array}$} & \multirow{2}{*}{$\begin{array}{c}1998-2000- \\
2002 \\
63.13\end{array}$} & \multirow{2}{*}{$\begin{array}{c}1995-1998- \\
2000 \\
10.93\end{array}$} & \multirow{2}{*}{$\begin{array}{c}1998-2000- \\
2002 \\
11.44\end{array}$} \\
\hline \multirow{5}{*}{$\begin{array}{l}\text { Owning } \\
\text { Asset in the } \\
\text { Base Year }\end{array}$} & 111 & & & & \\
\hline & 115 & 9.53 & 7.64 & 6.53 & 7.74 \\
\hline & 151 & 6.38 & 6.37 & 3.34 & 3.30 \\
\hline & 155 & 3.37 & 3.46 & 8.36 & 6.58 \\
\hline & Subtotal & 80.85 & 80.60 & 29.16 & 29.04 \\
\hline \multirow{4}{*}{$\begin{array}{l}\text { Not Owning } \\
\text { Asset in the } \\
\text { Base Year }\end{array}$} & 511 & 6.95 & 7.01 & 6.29 & 6.00 \\
\hline & 515 & 1.98 & 1.83 & 4.38 & 5.56 \\
\hline & 551 & 4.59 & 5.06 & 9.71 & 7.64 \\
\hline & 555 & 5.63 & 5.51 & 50.47 & 51.74 \\
\hline \multicolumn{2}{|c|}{ Grand Total } & 100.0 & 100.0 & 100.0 & 100.0 \\
\hline
\end{tabular}


Table 3. Cross-Wave Asset Ownership in AHEAD 1995-HRS 2000

$\begin{array}{lllll}\begin{array}{l}\text { Ownership } \\ \text { Category }\end{array} & \text { AHEAD 1995 } & \text { HRS 1998 } & \text { HRS 2000 } & \text { Sample \% } \\ 1 & 1 & 1 & 1 & \mathrm{P}_{1} \\ 2 & 1 & 1 & 5 & \mathrm{P}_{2} \\ 3 & 1 & 5 & 1 & \mathrm{P}_{3} \\ 4 & 1 & 5 & 5 & \mathrm{P}_{4} \\ 5 & 5 & 1 & 1 & \mathrm{P}_{5} \\ 6 & 5 & 1 & 5 & \mathrm{P}_{6} \\ 7 & 5 & 5 & 1 & \mathrm{P}_{7} \\ 8 & 5 & 5 & 5 & \mathrm{P}_{8}\end{array}$

Step 2. Determine the asset ownership patterns in the AHEAD cohorts of 1993, 1995, and 1998. Called "Distribution A", this relationship may be characterized as the marginal distribution in Table 4. Again, “ 1 ” indicates owning an asset in a wave, “5” not owning an asset in a wave, and the sum of the sample percentages $\left(R_{i}, i=1,2, \ldots, 8\right)$ is equal to 100 .

Table 4. Cross-Wave Asset Ownership in AHEAD 1993-HRS 1998

$\begin{array}{lllll}\begin{array}{l}\text { Ownership } \\ \text { Category }\end{array} & \text { AHEAD 1993 } & \text { AHEAD 1995 } & \text { HRS 1998 } & \text { Sample \% } \\ 1 & 1 & 1 & 1 & \mathrm{R}_{1} \\ 2 & 1 & 1 & 5 & \mathrm{R}_{2} \\ 3 & 1 & 5 & 1 & \mathrm{R}_{3} \\ 4 & 1 & 5 & 5 & \mathrm{R}_{4} \\ 5 & 5 & 1 & 1 & \mathrm{R}_{5} \\ 6 & 5 & 1 & 5 & \mathrm{R}_{6} \\ 7 & 5 & 5 & 1 & \mathrm{R}_{7} \\ 8 & 5 & 5 & 5 & \mathrm{R}_{8}\end{array}$


Step 3. Calculate the AHEAD 1993 ownership shortfall based on the difference between the marginal distributions in Tables 3 and 4. Assign a randomly selected set of households who did not report owning an asset to be households who should have reported owning the asset, based on the calculated shortfall.

Table 5. Determine the Ownership Shortfall in AHEAD 1993

$\begin{array}{llllll}\begin{array}{l}\text { Ownership } \\ \text { Category }\end{array} & \text { AHEAD 1993 } & \text { AHEAD 1995 } & \text { HRS } 1998 & \text { Sample \% } & \begin{array}{l}\text { Ownership } \\ \text { Shortfall \% }\end{array} \\ 1 & 1 & 1 & 1 & \mathrm{R} 1 & \mathrm{P}_{1}-\mathrm{R}_{1}=\mathrm{S}_{1} \\ 2 & 1 & 1 & 5 & \mathrm{R} 2 & \mathrm{P}_{2}-\mathrm{R}_{2}=\mathrm{S}_{2} \\ 3 & 1 & 5 & 1 & \mathrm{R} 3 & \mathrm{P}_{3}-\mathrm{R}_{3}=\mathrm{S}_{3} \\ 4 & 1 & 5 & 5 & \mathrm{R} 4 & \mathrm{P}_{4}-\mathrm{R}_{4}=\mathrm{S}_{4} \\ 5 & 5 & 1 & 1 & \mathrm{R} 5 & - \\ 6 & 5 & 1 & 5 & \mathrm{R} 6 & - \\ 7 & 5 & 5 & 1 & \mathrm{R} 7 & - \\ 8 & 5 & 5 & 5 & \mathrm{R} 8 & -\end{array}$

Because there was ownership underreporting in AHEAD 1993, the sum of $R_{1}, R_{2}, R_{3}$ and $R_{4}$ (those are the categories that indicate ownership in 1993) in Table 4 is less than the sum of $P_{1}$, $\mathrm{P}_{2}, \mathrm{P}_{3}$, and $\mathrm{P}_{4}$ (the categories that indicate ownership in 1995) in Table 3. The fundamental logic of the correction procedure is to retrieve the underreporting households in AHEAD 1993 based on the differences between $P_{i}$ and $R_{i}$. To do this, first identify those categories where $P_{i}>R_{i}(i=1$, 2, 3, and 4). Calculate the difference, or AHEAD 1993 ownership shortfall, $S_{i}=P_{i}-R_{i}$. Then notice the correspondence between categories 1 and 5, 2 and 6, 3 and 7, and 4 and 8: in each case, the ownership patterns are the same in the last two waves and different in the first wave. That is, category 1 is the same as category 5 except in the first wave. This means that to correct a shortfall in category 1 , we switch some respondents from category 5 to category 1 by imputing 
asset ownership to a sample of those respondents in 1993. Similarly, we switch some respondents from category 6 to category 2 and so forth. Therefore, find category $\mathrm{j}(\mathrm{j}=5,6,7$, and 8) where the AHEAD 1995 and HRS 1998 ownership pattern is the same as in i (i.e, $\mathrm{j}=5$ if $\mathrm{i}$ $=1, j=6$ if $i=2, j=7$ if $i=3$, and $j=8$ if $i=4)$. Convert $\left(S_{i}\right) \%$ of 5 's in the category $k$ into 1 's based on an appropriate imputation procedure.

The three-wave asset ownership distributions described in Tables 3 and 4 as well as the corrected AHEAD 1993 asset ownership distributions (conditional on the ownership pattern in AHEAD 1995 and 1998) are given in Table 6. Table 6 shows that in the original data there were significant asset ownership shortfalls and that in the corrected data, asset ownership proportions in 1993 yield three-wave ownership patterns that match closely the patterns in the subsequent three-wave period. For example, panel C shows that in the original data only $73 \%$ of respondents owned checking/savings accounts, as compared to $81 \%$ in the next wave. In the corrected data, $81 \%$ of respondents own checking/savings accounts. Similar results arise across all the corrected asset categories.

Step 4. Impute positive asset values for those retrieved households based on an appropriate imputation procedure. 
Table 6. Three-Wave Financial and Business/Farm Asset Ownership Distributions (\%) Before and After AHEAD 1993 Corrections

Panel A. Business/Farm and IRA

Three-Wave

Ownership Pattern

\begin{tabular}{|c|c|c|c|c|c|c|c|c|c|}
\hline \multicolumn{2}{|c|}{ Ownership Pattern } & $\mathrm{P}$ & $\begin{array}{c}\mathrm{R} \\
\text { Original }\end{array}$ & $\mathrm{S}$ & $\begin{array}{c}\mathrm{R} \\
\text { Corrected }\end{array}$ & $\mathrm{P}$ & $\begin{array}{c}\mathrm{R} \\
\text { Original }\end{array}$ & S & $\begin{array}{c}\mathrm{R} \\
\text { Corrected }\end{array}$ \\
\hline \multirow{5}{*}{$\begin{array}{l}\text { Owning } \\
\text { Asset in } \\
\text { the Base } \\
\text { Year }\end{array}$} & 111 & 1.61 & 1.03 & 0.58 & 1.61 & 9.97 & 8.98 & 0.99 & 9.97 \\
\hline & 115 & 1.40 & 0.56 & 0.84 & 1.39 & 2.56 & 1.73 & 0.83 & 2.55 \\
\hline & 151 & 0.47 & 0.29 & 0.18 & 0.46 & 0.71 & 0.73 & - & 0.73 \\
\hline & 155 & 2.44 & 1.56 & 0.88 & 2.44 & 3.27 & 2.06 & 1.21 & 3.27 \\
\hline & Sub-total & 5.92 & 3.44 & 2.48 & 5.90 & 16.51 & 13.50 & 3.03 & 16.52 \\
\hline \multirow{4}{*}{$\begin{array}{c}\text { Not } \\
\text { Owning } \\
\text { Asset in } \\
\text { the Base } \\
\text { Year }\end{array}$} & 511 & 0.64 & 1.74 & - & 1.16 & 1.82 & 2.98 & - & 1.99 \\
\hline & 515 & 1.32 & 1.93 & - & 1.09 & 1.32 & 2.25 & - & 1.43 \\
\hline & 551 & 1.61 & 1.86 & - & 1.68 & 5.90 & 3.71 & - & 3.71 \\
\hline & 555 & 90.51 & 91.04 & - & 90.16 & 74.45 & 77.56 & - & 76.35 \\
\hline \multicolumn{2}{|c|}{ Grand Total } & 100.0 & 100.0 & - & 100.0 & 100.0 & 100.0 & - & 100.0 \\
\hline
\end{tabular}


Table 6 Panel B. Stock/Mutual Fund and Bond

Three-Wave

Ownership Pattern

Not

Asset in

the Base

Year

\section{1}

Owning

Stock/Mutual Funds (\%)

\begin{tabular}{cccccccccc} 
Owning & 115 & 5.78 & 2.94 & 2.84 & 5.78 & 1.86 & 1.15 & 0.71 & 1.86 \\
$\begin{array}{c}\text { Asset in } \\
\text { the Base }\end{array}$ & 151 & 2.24 & 1.85 & 0.39 & 2.24 & 0.94 & 0.61 & 0.33 & 0.94 \\
$\quad$ Year & 155 & 4.75 & 2.94 & 1.81 & 4.75 & 3.78 & 2.20 & 158 & 3.78 \\
& Sub-total & 27.55 & 18.09 & 9.46 & 27.55 & 8.38 & 5.36 & 3.01 & 8.38 \\
$\quad$ Not & 511 & 4.19 & 8.65 & - & 4.23 & 1.29 & 1.89 & - & 1.49 \\
$\begin{array}{l}\text { Owning } \\
\text { Asset in }\end{array}$ & 515 & 2.06 & 4.97 & - & 2.13 & 2.50 & 3.73 & - & 3.02 \\
the Base & 551 & 7.67 & 5.81 & - & 5.42 & 4.04 & 3.42 & - & 3.09 \\
$\quad \begin{array}{r}\text { Year } \\
\text { Grand Total }\end{array}$ & 555 & 58.52 & 62.48 & - & 60.67 & 83.78 & 85.60 & - & 84.03 \\
\multicolumn{2}{l}{ Gran }
\end{tabular}

\section{Bond (\%)}

$\begin{array}{cccccccc}\mathrm{P} & \mathrm{R} & \mathrm{R} & \mathrm{R} & \mathrm{R} \\ \text { Original } & \mathrm{S} & \text { Corrected } & \mathrm{P} & \text { Original } & \mathrm{S} & \text { Corrected }\end{array}$

$\begin{array}{llllllll}14.78 & 10.36 & 4.42 & 14.78 & 1.80 & 1.40 & 0.40 & 1.80\end{array}$

14.78

10.36

4.42

14.78

1.80

1.40

0.70

1.80

1.86

0.94

3.78

8.38

1.49

3.02

3.09

84.03

100.0

Table 6 Panel C. Checking/Savings Account and CD

Three-Wave

Ownership Pattern

$\begin{array}{lllclcl}\mathrm{P} & \mathrm{R} & \mathrm{R} & \mathrm{R} & \mathrm{R} & \mathrm{R} \\ \text { Original } & \mathrm{S} & \text { Corrected } & \mathrm{Original} & \mathrm{S} & \text { Corrected }\end{array}$

\begin{tabular}{|c|c|c|c|c|c|c|c|c|c|}
\hline & 111 & 61.57 & 57.14 & 4.43 & 61.57 & 10.93 & 8.46 & 2.47 & 10.93 \\
\hline \multirow{4}{*}{$\begin{array}{c}\text { Owning } \\
\text { Asset in } \\
\text { the Base } \\
\text { Year }\end{array}$} & 115 & 9.53 & 7.49 & 2.04 & 9.53 & 6.53 & 4.46 & 2.07 & 6.52 \\
\hline & 151 & 6.38 & 5.80 & 0.58 & 6.38 & 3.34 & 2.91 & 0.43 & 3.34 \\
\hline & 155 & 3.37 & 2.44 & 0.93 & 3.37 & 8.36 & 5.31 & 3.05 & 8.36 \\
\hline & Sub-total & 80.85 & 72.87 & 7.98 & 80.85 & 29.16 & 21.14 & 8.02 & 29.15 \\
\hline \multirow{4}{*}{$\begin{array}{c}\text { Not } \\
\text { Owning } \\
\text { Asset in } \\
\text { the Base } \\
\text { Year }\end{array}$} & 511 & 6.95 & 12.65 & - & 8.22 & 6.29 & 8.39 & - & 5.92 \\
\hline & 515 & 1.98 & 3.21 & - & 1.16 & 4.38 & 8.02 & - & 5.95 \\
\hline & 551 & 4.59 & 4.05 & - & 3.48 & 9.71 & 8.83 & - & 8.40 \\
\hline & 555 & 5.63 & 7.22 & - & 6.30 & 50.47 & 53.63 & - & 50.58 \\
\hline \multicolumn{2}{|c|}{ Grand Total } & 100.0 & 100.0 & - & 100.0 & 100.0 & 100.0 & - & 100.0 \\
\hline
\end{tabular}


Note: Column "P” represents marginal distribution of the asset ownership in AHEAD 1995, 1998, and 2000, as defined in Table 1. Column "R Original” (or "R Corrected") represents marginal distribution of the asset ownership in AHEAD 1993 original (or corrected), 1995, and 1998. Column "S" represents ownership shortfall in AHEAD 1993 as compared to the ownership distribution in Column "P".

\section{$\underline{\text { Results }}$}

Tables 7 and 8 summarize preliminary results for the corrected AHEAD 1993 asset data based on the above procedure. Among other things, the major changes induced by the correction procedure include more consistent time-series patterns of asset ownership (Table 7), and more consistent time-series pattern of total asset value (Table 8). In particular, after corrections, the percentage of households owning stocks and mutual funds in AHEAD 1993 became 30, which turns out to be identical to those in AHEAD 1995 and HRS 1998, and very close to those in HRS 2000 and 2002. The mean value of the total non-housing assets in AHEAD 1993 became about $\$ 150,000$, which represented a $17 \%$ increase. 
Table 7. AHEAD Asset Ownership (\%) Before and After the Corrections

\begin{tabular}{|c|c|c|c|c|c|c|}
\hline Asset & $\begin{array}{l}\text { AHEAD93 } \\
\text { Original }\end{array}$ & $\begin{array}{l}\text { AHEAD93 } \\
\text { Corrected }\end{array}$ & AHEAD95 & HRS98 & HRS00 & HRS02 \\
\hline Real Estate & $\% 18$ & $\% 18$ & $\% 15$ & $\% 12$ & $\% 13$ & $\% 11$ \\
\hline Business/Farm & $\% 4$ & $\% 6$ & $\% 7$ & $\% 6$ & $\% 6$ & $\% 6$ \\
\hline IRA & $\% 17$ & $\% 20$ & $\% 20$ & $\% 20$ & $\% 22$ & $\% 22$ \\
\hline $\begin{array}{l}\text { Stock/Mutual } \\
\text { Funds }\end{array}$ & $\% 20$ & $\% 30$ & $\% 30$ & $\% 31$ & $\% 33$ & $\% 31$ \\
\hline Bond & $\% 6$ & $\% 9$ & $\% 9$ & $\% 8$ & $\% 9$ & $\% 9$ \\
\hline $\begin{array}{l}\text { Checking/Savings } \\
\text { Account }\end{array}$ & $\% 77$ & $\% 84$ & $\% 84$ & $\% 84$ & $\% 83$ & $\% 87$ \\
\hline $\mathrm{CD}$ & $\% 22$ & $\% 31$ & $\% 32$ & $\% 32$ & $\% 34$ & $\% 32$ \\
\hline Vehicle & $\% 72$ & $\% 72$ & $\% 69$ & $\% 68$ & $\% 69$ & $\% 68$ \\
\hline Other Assets & $\% 10$ & $\% 10$ & $\% 9$ & $\% 10$ & $\% 10$ & $\% 10$ \\
\hline Debt & $\% 14$ & $\% 14$ & $\% 13$ & $\% 12$ & $\% 11$ & $\% 10$ \\
\hline $\begin{array}{l}\text { Total Non- } \\
\text { Housing Assets }\end{array}$ & $\% 91$ & $\% 92$ & \%92 & \%92 & $\% 93$ & \%93 \\
\hline Net Worth & $\% 94$ & $\% 95$ & \%96 & \%96 & \%97 & \%96 \\
\hline
\end{tabular}

Note: Weighted results. "Total Non-Housing Assets" is equal to the sum of the first nine asset components minus "Debt". "Net Worth" is equal to "Total Non-Housing Assets" + "Housing Equity". The numbers in this table may be found from Appendix 1, the last row for each asset variable. The AHEAD 1993 asset corrections were made only for business/farm, IRA, stock/mutual fund, bond, checking/savings account, and CD. 
Table 8. Mean Value of AHEAD Assets Before and After the Corrections

\begin{tabular}{|c|c|c|c|c|c|c|}
\hline Asset & $\begin{array}{l}\text { AHEAD93 } \\
\text { Original }\end{array}$ & $\begin{array}{l}\text { AHEAD93 } \\
\text { Corrected }\end{array}$ & AHEAD95 & HRS98 & HRS00 & HRS02 \\
\hline Real Estate & $\$ 25,254$ & $\$ 25,254$ & $\$ 29,185$ & $\$ 29,804$ & $\$ 31,225$ & $\$ 24,497$ \\
\hline Business/Farm & $\$ 8,769$ & $\$ 9,173$ & $\$ 17,883$ & $\$ 17,638$ & $\$ 18,687$ & $\$ 18,821$ \\
\hline IRA & $\$ 10,582$ & $\$ 11,748$ & $\$ 15,091$ & $\$ 16,405$ & $\$ 16,875$ & $\$ 15,349$ \\
\hline $\begin{array}{l}\text { Stock/Mutual } \\
\text { Funds }\end{array}$ & $\$ 30,154$ & $\$ 42,603$ & $\$ 74,014$ & $\$ 68,171$ & $\$ 73,109$ & $\$ 56,084$ \\
\hline Bond & $\$ 6,403$ & $\$ 6,933$ & $\$ 13,057$ & $\$ 10,384$ & $\$ 8,264$ & $\$ 11,626$ \\
\hline $\begin{array}{l}\text { Checking/Savings } \\
\text { Account }\end{array}$ & $\$ 22,953$ & $\$ 23,228$ & $\$ 28,632$ & $\$ 24,132$ & $\$ 23,661$ & $\$ 26,368$ \\
\hline $\mathrm{CD}$ & $\$ 11,376$ & $\$ 16,221$ & $\$ 21,385$ & $\$ 21,741$ & $\$ 23,101$ & $\$ 20,254$ \\
\hline Vehicle & $\$ 8,837$ & $\$ 8,837$ & $\$ 8,013$ & $\$ 7,563$ & $\$ 7,223$ & $\$ 6,961$ \\
\hline Other Assets & $\$ 3,425$ & $\$ 3,425$ & $\$ 5,090$ & $\$ 7,270$ & $\$ 6,440$ & $\$ 4,374$ \\
\hline Debt & $\$ 1,152$ & $\$ 1,152$ & $\$ 815$ & $\$ 611$ & $\$ 689$ & $\$ 1,029$ \\
\hline $\begin{array}{l}\text { Total Non- } \\
\text { Housing Assets }\end{array}$ & $\$ 127,501$ & $\$ 149,707$ & $\$ 211,534$ & $\$ 202,495$ & $\$ 208,894$ & $\$ 183,126$ \\
\hline Net Worth & $\$ 219,860$ & $\$ 242,066$ & $\$ 311,135$ & $\$ 302,215$ & $\$ 312,375$ & $\$ 292,640$ \\
\hline
\end{tabular}

Note: Weighted results and in 2002 dollars. "Total Non-Housing Assets” is equal to the sum of the first nine asset components minus "Debt". "Net Worth" is equal to "Total Non-Housing Assets" + "Housing Equity". The AHEAD 1993 asset corrections were made only for business/farm, IRA, stock/mutual fund, bond, checking/savings account, and CD.

In addition to the revised asset measurements presented, we have implemented the imputation procedures for capital income described in detail in Appendix B. These procedures correct for under-reporting of financial asset income due to the capital income questions being separated from the asset questions in AHEAD 1993 (as well as HRS 1992 and HRS 1994, which are corrected in the previous reference).

Evidence for this under-reporting can be seen in Table 9. In AHEAD 1993, 40\% percent of respondents report income from financial assets as compared to approximately $60-65 \%$ in subsequent waves (a similar pattern is shown for the HRS in Appendix B). Full versions of all 
tables from Appendix B, but applied to the AHEAD sample are available on request. We do not reproduce them here as they show largely similar patterns to HRS.

To fix this problem we employ an imputation procedure that assumes that the rates of return to financial assets in AHEAD 1995 are unbiased, then we used three somewhat different strategies (labeled A, B and C and described in Appendix B) to apply rates of return to AHEAD 1993 asset measurements to obtain measurements of capital income. Strategies A, B and C are described extensively in the flow chart that is Figure 1 of Appendix B, but we describe them briefly here. In strategy A, anyone who reports financial income and financial assets in 1993 is left as is and anyone who reports financial assets, but no financial income receives a random rate of return imputation from the distribution of rates of return in the 1993 data segregated by financial asset percentile group (defined as those in percentiles 0-25, 25-50, 50-75, 75-90 and 90100). In strategy $B$, anyone with financial assets in 1993 receives a random rate of return imputation. Strategy $\mathrm{C}$ is the same as B, except that those individuals who have financial assets in both 1993 and 1995 and for whom their financial assets are in the same asset percentile group in both years get their 1995 rate of return applied to their 1993 assets and anyone who has financial assets, but no financial income in 1995 receives a rate of return of zero in 1993. In all three strategies, anyone with no financial assets in 1993 get a rate of return of zero and all returns are capped at $100 \%$ (placing a top value on returns is not done in Appendix B). Of course, using rates of return as a basis for imputation requires reliable estimates of assets themselves in order for the income measurements to be correct. Hence we apply the imputation procedure to the results of our asset correction above. 
The results are shown in Table 10. Average AHEAD income from financial assets is \$3,159 in 1993 as compared to approximately $\$ 6000$ in the next two waves, with a slow decline thereafter. Strategies A, B and C result in estimates of \$5179, \$4969 and \$4720, respectively.

Table 9. Financial Asset and Income Ownership in AHEAD

\begin{tabular}{|c|c|c|c|c|c|c|c|c|c|c|c|c|c|c|}
\hline \multirow[b]{2}{*}{ Financial Income } & \multicolumn{3}{|c|}{ |1993 } & \multicolumn{2}{|l|}{1995} & \multicolumn{3}{|l|}{1998} & \multicolumn{3}{|l|}{2000} & \multicolumn{3}{|c|}{2002} \\
\hline & Yes & No & Total & Yes & No & Yes & No & Tota & Yes & No & Total & Yes & No & Total \\
\hline Financial Assets & & & & & & & & & & & & & & \\
\hline Yes & 36.3 & 39.2 & 75.6 & 65.7 & 16.982 .6 & 62.9 & 19.1 & 82 & 58.2 & 23.5 & 81.8 & 57.1 & 26.4 & 83.5 \\
\hline No & 3.6 & 20.8 & 24.4 & 0.1 & 17.317 .4 & 0.1 & 17.9 & 18 & 0 & 18.2 & 18.2 & 0.1 & 16.4 & 16.5 \\
\hline $\begin{array}{l}\text { Total } \\
\text { Observations }\end{array}$ & $\begin{array}{l}39.9 \\
6047\end{array}$ & 60.1 & & $\begin{array}{l}65.8 \\
5216\end{array}$ & 34.2 & $\begin{array}{l}63 \\
4730\end{array}$ & 37 & & $\begin{array}{l}58.2 \\
4093\end{array}$ & 41.7 & & $\begin{array}{l}57.2 \\
3466\end{array}$ & 42.8 & 100 \\
\hline
\end{tabular}

Table 10. Corrected Financial Income in AHEAD by Financial Asset Percentile Group

\begin{tabular}{|c|c|c|c|c|c|c|c|}
\hline \multirow{6}{*}{$\begin{array}{l}\text { Year } \\
1993\end{array}$} & \multirow{2}{*}{$\begin{array}{l}\text { Imputation } \\
\text { Strategy } \\
\text { Method } \\
\end{array}$} & \multicolumn{6}{|c|}{ Financial Asset Percentile } \\
\hline & & $0-25$ & $25-50$ & $50-75$ & $75-90$ & $90-100$ & total \\
\hline & none & 1,218 & 1,062 & 3,117 & 6,116 & 16,146 & 3,959 \\
\hline & A & 126 & 1,686 & 5,003 & 8,560 & 23,614 & 5,179 \\
\hline & $\mathrm{B}$ & 62 & 1,062 & 3,817 & 8,853 & 25,768 & 4,969 \\
\hline & C & 57 & 1,010 & 3,873 & 8,585 & 22,575 & 4,720 \\
\hline 1995 & none & 55 & 776 & 3,821 & 9,643 & 32,210 & 6,138 \\
\hline 1998 & none & 55 & 611 & 3,224 & 10,812 & 35,627 & 6,453 \\
\hline 2000 & none & 85 & 579 & 2,692 & 9,997 & 33,304 & 5,960 \\
\hline 2002 & none & 43 & 661 & 2,297 & 6,753 & 24,778 & 4,449 \\
\hline
\end{tabular}

Note: Weighted results and in 2002 dollars.

\section{Appendix HRS/AHEAD Imputation Procedures}

Two alternative procedures have been used for generating HRS/AHEAD imputation data. The first is to rely on the information within a wave, imputing relevant variables by taking advantage of the bracket information collected. We call this procedure “cross-sectional imputation”. One of the most important features of this procedure is its independence from the information in other HRS waves, making the imputation process relatively straightforward. 
Cross-sectional imputations, however, have two inherent drawbacks. Because of their independence from the data in other waves, longitudinal consistency may not be achieved automatically. Moreover, when the bracket information contains problems, as found in AHEAD 1995, cross-sectional imputation lacks an effective way to correct the problems. To address these issues, a second imputation procedure goes beyond the information within a wave, imputing variables based on their potential relationships across waves. We call this procedure "longitudinal imputation”.

\section{The Immediate Neighbor Rule}

One key element of both cross-sectional and longitudinal imputation procedures is a so-called "immediate neighbor rule" (INR), which assigns to a missing value a cardinal or valid report that is immediately above or below in the sequence of the data. When multiple missing values are next to one another, however, a cardinal report immediately above or below a missing value may not be available. In those cases, a spatially closest cardinal report is assigned to the missing value.

Obviously, based on this rule, how to order data before imputation for the cardinal report assignment is critical. An imputation procedure is called "pure hotdeck" if data are ordered totally randomly. While the pure hotdeck procedure has been used here or there, ${ }^{3}$ in general, HRS imputations are not random imputations.

\section{Cross-Sectional Imputation}

The cross-sectional imputation procedure primarily uses the bracket information—if availablewithin a wave to determine the ordering of the data before imputation. To improve the quality of the imputation, one may also take into account other factors that are known to be important in

\footnotetext{
${ }^{3}$ This form of hotdeck was used for decades by the U.S.Census Bureau partly because it is easily implemented on a standard IBM keypunch machine and partly because it had known and quantifiable statistical properties.
} 
predicting the variables being imputed. When dealing with open-end brackets (i.e., the top bracket point is not known), for example, the HRS consistently uses several basic demographic variables to control the ordering of the data. These demographic variables include age, gender, educational attainment and marital status. In addition, when imputing for the income from a certain type of asset, the control variables also include the relevant asset.

The HRS imputation data publicly released so far are all cross-sectional imputations.

\section{Second Home Problems: Overview of Appendix D}

The treatment of second home equity has not been consistent in some of the early HRS and AHEAD waves. Ideally, questions regarding second home should be asked of all households who own second homes at the time of the interview. Parallel to the questions about the primary (or main) home, the question sequence about second home should be independent of the sequence about real estate investment, making second home equity distinguishable from real estate equity.

In AHEAD 1993, however, second home was explicitly treated as part of real estate investment. In both AHEAD 1995 and HRS 1996, second home was treated as independent of primary home and real estate investment. But due to a skip-pattern error, not all households with second homes were asked detailed questions about current market value, amount of mortgage, etc. Specifically, any respondents who had not lived in their second homes for at least two months of the year would not have been asked about their second home equity.

One way to fix these problems is to utilize cross-wave relationships in the second home ownership found among relevant HRS and AHEAD waves as well as the information on asset changes reported in HRS 1998. Based on the cross-wave relationships and the asset change 
information, we first correct misclassifications found in second home ownership in AHEAD 1993 and 1995, and HRS 1996, and then impute second home equity for those "misclassified" households. These adjustments are examined in detail in Appendix D.

Appendix A: Unfolding Brackets (JASA)

Appendix B: Rate of Return Adjustments (MRRC Working Paper)

Appendix C: Periodicity Adjustments, Rate of Return Analysis (JHR)

Appendix D: Second Home Adjustment (MRRC Working Paper) 
APPENDIX A 


\title{
Improving the Quality of Economic Data: Lessons from the HRS and AHEAD
}

\section{F. Thomas JUSTER and James P. SMITH}

\begin{abstract}
Missing data are an increasingly important problem in economic surveys, especially when trying to measure household wealth. However, some relatively simple new survey methods such as follow-up brackets appear to appreciably improve the quality of household economic data. Brackets represent partial responses to asset questions and apparently significantly reduce item nonresponse. Brackets also provide a remedy to deal with nonignorable nonresponse bias, a critical problem with economic survey data.

KEY WORDS: Imputation; Missing data: Nonignorable nonresponse
\end{abstract}

\section{INTRODUCTION}

In recent years, our understanding of what determines levels, rates of accumulation, and portfolios of wealth has greatly increased (see Hurd 1990 for an excellent summary). Encouraged by newly available data, analysts have focused theoretical models on fundamental hypotheses about why people save (Deaton 1992; Poterba 1994). Although the issues examined are extremely diverse, these models are linked by a common need: reasonably reliable wealth and savings data to test the basic implications of the models. Unfortunately, the quality of the survey data in many current wealth modules fails to meet that need.

Data quality is an issue of longstanding concern among researchers interested in wealth accumulation (Curtin, Juster, and Morgan 1988; Ferber 1959; Lansing, Ginsberg, and Braaten 1961). Recently, available wealth data have proliferated, as many surveys have incorporated wealth modules into studies whose major objectives were quite different than the measurement of wealth or savings. In this article we argue that some relatively simple survey extensions may significantly improve the quality of household economic data. The survey extensions are "follow-up brackets"--bracket categories offered to respondents who initially refused or were unable to provide an exact value for their assets or income. Brackets represent partial responses to asset questions and can significantly reduce uncertainty about the actual value.

Applied in this form to wealth modules, these extensions originated in the Panel Study of Income Dynamics (PSID) and were used extensively in the recently fielded Health and Retirement Survey (HRS) and the Asset and Health Dynamics Among the Oldest Old Survey (AHEAD). Their value is clearest in surveys with relatively short wealth modules. Although application of this methodology to surveys mainly concerned with wealth risks alienating respondents with an excessive number of follow-up questions, wealth surveys with extensive modules might also be able to use brackets successfully by tailoring brackets to specific assets or us-

F. Thomas Juster is Research Scientist. Survey Research Center. Un versity of Michigan, Ann Arbor, MI 48104. James P. Smith is Senior Economist. RAND, Santa Monica, CA 90407. This research was supported in part by grants 5PO1-AGO8291 and IRO1-AG12394 awarded by the National Institute on Aging. Department of Health and Human Services, to RAND. Excellent programming assistance was provided by Iva Maclennan ing them judiciously. Use of follow-up brackets appears to provide a partial remedy to deal with nonignorable nonresponse bias, a critical problem with economic survey data. Our estimates indicate that wealth imputations based on this methodology are typically higher by a factor of two compared to conventional "hot-deck" imputations made without these brackets. In the two surveys that we examine, the failure to use brackets understated population estimates of nonhousing wealth by $19 \%$ among those in their $50 \mathrm{~s}$ and by $9 \%$ among those over 70 . The effect of this methodology on behavioral models has yet to be assessed.

This article is organized as follows. Section 2 briefly describes why and how follow-up brackets are used, relying mainly on the HRS and AHEAD surveys. Section 3 documents the extent of nonresponse to asset questions and the brackets' ability to modify the consequences of initial nonresponse. Section 4 summarizes the results of our imputations for respondents with missing asset data. Section 5 contains a parallel analysis for the complete HRS and AHEAD samples. Section 6 summarizes our findings and points to directions for future research.

\section{BACKGROUND}

Assets are notoriously poorly reported on surveys. Nonresponse is pervasive, and other evidence (Curtin et al. 1989) suggested that the values may also be reported with errors. Although many prominent surveys have included wealth modules, their quality has been viewed with skepticism, due partly to large numbers of missing values. Three types of cognitive problems may help explain why missingdata rates are so high for many forms of household wealth. First, the respondent may simply not know the answer to the question, particularly if the answer requires adding several different accounts or placing a value on hard-to-measure assets like a business. Second, the respondent may have a rough idea of the amount but assumes that the interviewer wants a very precise figure. Third, the respondent may refuse to disclose the value of assets, because he or she regards it as too personal or intrusive.

These considerations may help explain why some wealth components are subject to higher missing-data rates than

(C) 1997 American Statistical Association Journal of the American Statistical Association December 1997, Vol. 92, No. 440, Applications and Case Studies 
others. For example, many individuals are quite inactive investors. They may have a much better idea of the amount in their checking account than in their common stock holdings. These households buy stock infrequently, do not check the price with any regularity, and have only a very general notion of their value. In contrast, households with checking accounts get a monthly statement from banks, which is often used to monitor expenditures. Housing equity offers another interesting contrast. Respondents are more willing to respond to questions about the market value of their homes, possibly because they may feel that anyone, including the interviewer, is able to make a pretty good guess about how much their quite-visible home is worth.

This research relies on data from two important new surveys fielded by the Institute for Social Research at the University of Michigan. The HRS is a national sample of about 7,600 households ( 12,654 individuals) with at least one person in the household born between 1931 and 1941 (51-61 years old at the interview date). At baseline, an in-home face-to-face interview of some 90 minutes was conducted starting in spring 1992 and extending into early 1993. The sample was obtained by screening for age eligibility from an area probability sample of some 70,000 household address listings. Given its focus on the preretirement years, the principal objective of HRS is to monitor economic transitions in work, income, and wealth, as well as changes in many dimensions of health status.

The companion survey to the HRS-AHEAD--includes 6,052 households $(8,204$ individuals) from the birth cohorts of 1923 or before, thus with at least one person age 70 or older in 1993. All AHEAD-sampled households with age-eligible respondents under age 80 were obtained by screening from the HRS area probability sample. To guard against underrepresentation of the extremely disabled in an area sample, AHEAD added a supplemental sample of respondents age 80 and above from the Health Care Financing Administration (HCFA) Medicare enrollment file. The baseline AHEAD interview was conducted in 1993 using computer-assisted telephone techniques for respondents age 70-79 and computer-assisted in-person interviews for persons age 80 and older. Given its older age span, AHEAD's objectives shift toward the relationship between changes in physical and cognitive health in old age, the maintenance of independent living arrangements, and asset decumulation. In both surveys, blacks, Hispanics, and residents of Florida were oversampled at a rate of two to one. Baseline response rates were $82 \%$ in HRS and $81 \%$ in AHEAD, and each survey plans follow-ups every 2 years.

Survey designers have tried various ways to mitigate the missing data problem in financial variables. One strategy, discussed in the early methodological literature (Ferber 1959), was to encourage respondents to reduce missing data by providing exact data from financial records. But records were often inaccessible and almost always incomplete, so additional information was always necessary. Another technique, used extensively in early waves of the Surveys of Consumer Finances (SCF), gives respondents a range card with letters corresponding to quantitative intervals (e.g., an amount between $\$ 5,000$ and $\$ 7,499$ would be represented by the letter E).

Unfolding brackets taking the form of simple questions that follow immediately after a "don"t know" or "refuse" response are another device to determine the interval in which the respondent's assets lie. Because the 1984 and 1989 PSID wealth modules had used similar unfolding brackets, HRS and AHEAD were not the first studies to use follow-up brackets for wealth questions. Although PSID respondents have been interviewed every year since 1968 , they may still be as sensitive to privacy concerns as other respondents.

Although SCF has historically used range cards for nonresponse, it has recently experimented with follow-up brackets. In the 1983, 1989, 1992, and 1995 SCFs, nonresponders to asset value questions were given the option of selecting category limits listed in range cards (with a more detailed list of categories in 1992 and 1995). The 1995 survey also allowed respondents to select their own limits and used the unfolding brackets techniques used in HRS and AHEAD. The Survey of Income and Program Participation (SIPP) also has made limited use of follow-up brackets to impute property income, but has not used them in its wealth module.

These various methods of mitigating missing-data problems all have pluses and minuses. First, any method of following up "don't know" or "refuse" responses is timeconsuming and runs some risk of annoying or badgering the respondent. Second, follow-ups that take the form of range cards can be used effectively only in personal interview surveys. Third, unfolding bracket questions provide a uniform stimulus and are generally easy to answer, but are necessarily limited to placing values into relatively few categories. Finally, failure to probe for exact answers may result in some loss of exact answer data.

The HRS and AHEAD methodology involved two main features. First, unfolding brackets (is the amount more than $x$ ?) placed the respondent's asset into one of a set of categories; second, interviewers were told not to extensively probe "don't know" or "refuse" responses, but rather to proceed to the first question in the unfolding bracket sequence. The design philosophy was that dropping the usual practice of probing for exact answers would shorten the survey and minimize chances of annoying respondents. The loss of data quality resulting from losing some exact answers (either by not probing or by learning to provide ranges rather than exact amounts) would hopefully be smaller than the gain resulting from converting completely missing data to categorical data. In HRS wave 1, the strategy used in the 1984 and 1989 PSID wealth module was adopted, where unfolding brackets were used for financial assets and debts. but range cards were used for housing assets and were also a possibility (on a voluntary basis) in the financial asset module. In later waves where telephones were the primary medium (AHEAD 1 and 2, HRS 2 and 3), range cards were not used, and all assets used unfolding brackets.

The HRS and AHEAD basic design is shown in Figure 1. First, ownership status is obtained with allowable responses of "yes," "no," "don't know," or "refuse." Next, 
Do you (or your spousefpartner) have any money in checking or savings uccounts or money market funds?

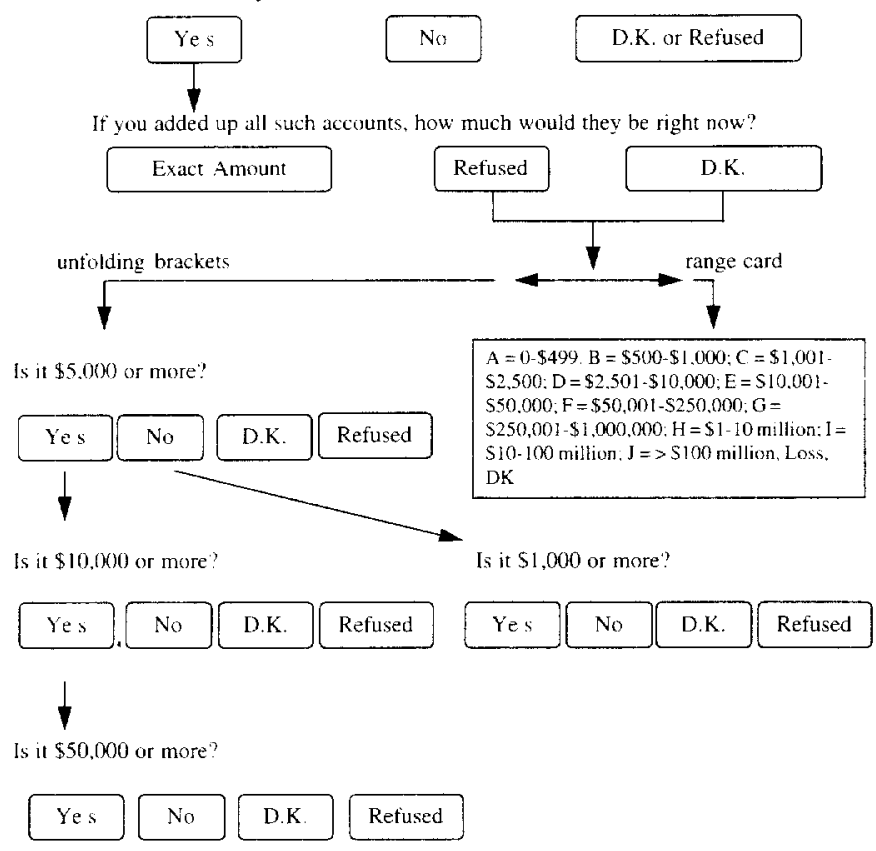

Figure 1. Illustrative Example of HRS Question Sequence on Checking Accounts, Savings Accounts, or Money Market Funds.

respondents reporting asset ownership are asked about total value; possible responses are a dollar amount, "don't know," or "refuse." Respondents in the last two categories were asked a set of "is it more than $x$ " questions that placed their asset values within categorical limits (unfolding brackets). Anytime in this sequence of bracket questions, respondents could give a "refuse" or a "don't know" response, thus ending the sequence. For housing values, HRS wave 1 nonrespondents were shown a range card. Range cards were occasionally used instead of unfolding brackets for assets other than housing in HRS wave 1, possibly because some respondents kept the range card after it was first used and routinely used it. In addition, respondents and interviewers may have felt that range cards shortened the interview.

To be more concrete, Figure 1 displays the HRS question flow for assets held in checking and savings accounts. Imputations were needed for the relatively small number of respondents who replied either do not know or refuse to the question about asset ownership. No further questions about this asset were asked of this group. Respondents who did not report an exact amount were asked up to three questions, starting with "Is this amount greater than $\$ 5,000$ ?", that ultimately yielded five bracket categories: $\$ 0-\$ 999, \$ 1,000-\$ 4,999, \$ 5,000-\$ 9,999, \$ 10,000-\$ 49,999$, and $\$ 50,000$ or more. At any point in this sequence of questions, a respondent could report don't know or refuse, producing additional bracket categories (e.g., $\$ 10,000$ or more). Alternatively, the range card option was used with intervals of $\$ 0-\$ 499, \$ 500-\$ 1,000, \$ 1,001-\$ 2,500, \$ 2,501-$ $\$ 10,000, \$ 10,001-\$ 50,000, \$ 50,001-\$ 250,000, \$ 250,001-$ $\$ 1,000,000,1-10$ million, 10 million-100 million, and more than 100 million. The range card intervals are the same for all assets, whereas the unfolding bracket intervals varied by asset type.
Our brief summary of the history of attempts to reduce the missing data problem in household wealth surveys suggests that a variety of early and contemporary experiments have been tried in an attempt to improve data quality. In the following sections, we examine the HRS and AHEAD experience using this unfolding bracket technique.

\section{MISSING VALUES AND DATA QUALITY}

This section documents the ability of follow-up brackets to limit the effects of initial nonresponse. Table 1 lists the prevalence of item nonresponse in the HRS and AHEAD asset modules; exact data nonresponse is shown in column 2. Housing yields the lowest nonresponse rates, with less than $5 \%$ of HRS respondents not providing an exact home value and almost twice as many having trouble with the mortgage. Missing values are considerably larger among the financial and tangible asset categories, often on the order of $30 \%$ or more. For example, 1 in 3 HRS business or common stock owners had initial nonresponses on the value of their businesses or stocks. In most cases, a larger fraction of AHEAD households than HRS households did not give an exact value to their assets. Among asset owners, 32\% of AHEAD ( $28 \%$ of HRS) households did not report the exact amount in their checking and savings accounts. In general, item nonresponse ran about 4-8 percentage points larger in AHEAD than in HRS. Because most AHEAD respondents are at least 70 years old and many are in their $80 \mathrm{~s}$, reasonable caution in the face of a stranger, minor forgetfulness, or other mild cognitive problems may account for AHEAD's somewhat higher item nonresponse rates. Severe cognitive problems were more likely to result in the use of a proxy respondent.

Nonresponse to asset questions is commonplace in all household surveys with wealth modules, and these problems are not unique to HRS and AHEAD. For example, $38 \%$ of the owners of common stock did not provide an exact value to the amount question in the 1986 SIPP; the comparable figure for the 1983 SCF was $25 \%$. Roughly one-third of respondents in both of these surveys did not respond with an exact amount about the value of their businesses.

This picture of large amounts of missing data changes dramatically if the categorical data obtained from unfolding brackets are considered. The value of brackets depends first on whether they induce sufficient numbers of respondents to provide range responses. Some believe that nonrespondents to asset questions are hard-nut cases, reluctant for privacy reasons to reveal their asset values. In this common view of nonresponse as dogmatic refusal, the cost of countering the initial nonresponse with more probing is thought to be high and the yield in new information low. But our experience in HRS and AHEAD suggests that convincing nonrespondents to provide bracketed responses is often easy. To illustrate, Table 1 separates missing-data responses on HRS and AHEAD into three subcategories: categorical data obtained from a range card, unfolding brackets, and the residualcases where the respondent refused to provide any information. The proportion of all missing data converted to range card or unfolding bracket responses is shown in the last column. 
Table 1. Response Rates (Percent of Total)

\begin{tabular}{|c|c|c|c|c|c|c|c|}
\hline \multirow[b]{2}{*}{ Variable } & \multicolumn{7}{|c|}{ Owners only } \\
\hline & $\begin{array}{c}\text { No asset } \\
\text { (1) }\end{array}$ & $\begin{array}{l}\text { Exact data } \\
\text { report }(2)\end{array}$ & $\begin{array}{l}\text { Exact data } \\
\text { missing (3) }\end{array}$ & $\begin{array}{c}\text { Range card } \\
\text { (4) }\end{array}$ & $\begin{array}{l}\text { Unfold brackets } \\
\text { (5) }\end{array}$ & $\begin{array}{c}\text { No information } \\
(6)\end{array}$ & $\begin{array}{c}(4)+(5) \\
3(7)\end{array}$ \\
\hline \multicolumn{8}{|l|}{ HRS } \\
\hline House* & 28. & 96 & 4 & 1 & $\mathrm{n} / \mathrm{a}$ & 3 & .25 \\
\hline First mortgage & 55 & 92 & 8 & 1 & $\mathrm{n} / \mathrm{a}$ & 7 & .12 \\
\hline Other real estate & 75 & 74 & 26 & 6 & 15 & 5 & .81 \\
\hline Vehicles & 0 & 86 & 14 & 3 & 9 & 2 & .83 \\
\hline Business equity & 82 & 68 & 32 & 5 & 20 & 7 & .76 \\
\hline IRA and Keoghs & 58 & 73 & 27 & 5 & 14 & 8 & .78 \\
\hline Stocks & 70 & 67 & 33 & 6 & 19 & 9 & .73 \\
\hline Checking-savings & 18 & 72 & 28 & 5 & 14 & 8 & .78 \\
\hline CDs, treasury bills & 73 & 70 & 30 & 6 & 14 & 10 & .68 \\
\hline Bonds & 92 & 69 & 31 & 6 & 12 & 13 & .43 \\
\hline Other savings & 83 & 71 & 29 & 5 & 15 & 8 & .62 \\
\hline Other debts & 60 & 86 & 14 & 3 & $\mathrm{n} / \mathrm{a}$ & 11 & .21 \\
\hline \multicolumn{8}{|l|}{ AHEAD } \\
\hline House* & 29 & 78 & 22 & $\mathrm{n} / \mathrm{a}$ & 20 & 2 & .91 \\
\hline First mortgage & 89 & 86 & 14 & $\mathrm{n} / \mathrm{a}$ & 13 & 2 & .87 \\
\hline Other real estate & 80 & 74 & 26 & $\mathrm{n} / \mathrm{a}$ & 21 & 4 & .84 \\
\hline Vehicles & 0 & 83 & 17 & $\mathrm{n} / \mathrm{a}$ & 15 & 2 & .88 \\
\hline Business equity & 95 & 59 & 41 & $\mathrm{n} / \mathrm{a}$ & 36 & 5 & .88 \\
\hline IRA and Keoghs & 83 & 74 & 26 & $\mathrm{n} / \mathrm{a}$ & 19 & 7 & .73 \\
\hline Stocks & 79 & 55 & 45 & $\mathrm{n} / \mathrm{a}$ & 37 & 8 & .82 \\
\hline Checking-savings & 24 & 68 & 32 & $\mathrm{n} / \mathrm{a}$ & 25 & 7 & .78 \\
\hline CDs, treasury bills & 77 & 62 & 38 & $\mathrm{n} / \mathrm{a}$ & 28 & 10 & .74 \\
\hline Bonds & 92 & 59 & 41 & $\mathrm{n} / \mathrm{a}$ & 31 & 10 & .76 \\
\hline Other savings & 88 & 70 & 30 & $n / a$ & 25 & 6 & .81 \\
\hline Other debts & 85 & 86 & 14 & $\mathrm{n} / \mathrm{a}$ & 12 & 2 & .86 \\
\hline
\end{tabular}

* Refers to house or apartment (not ranches, farms, or mobile homes).

Although we cannot know what information might have been obtained by direct probing, both surveys showed a substantial reduction in the amount of completely missing information with the unfolding technique. For example, the range categories converted a $33 \%$ item nonresponse for stocks in HRS to only $9 \%$ of cases for which we have no information on value. In many financial asset categories, brackets reduced HRS item nonresponse (defined as no information) by $75 \%$. Because we have only a partial response to a question and not an exact value, this reduction in item nonresponse is not the same as eliminating item nonresponse entirely for these cases. But although knowing that a value lies within some prespecified range does not equal knowing an exact value, it is extremely valuable for imputation.

Table 1 shows that brackets were even more successful in decreasing item nonresponse in AHEAD. For example, brackets converted a $45 \%$ full-item nonresponse in stock value to only $8 \%$ of cases with no information on value. On average, brackets reduced nonresponse for asset items by more than $80 \%$, a conversion rate that exceeds even HRS. In general, full item nonresponse (no information on value) in both surveys ends up in the single digits after the brackets are offered.

While providing some information about the distribution of asset values, a legitimate concern is whether unfolding brackets reduce the probability of reporting exact data. Unfolding brackets might encourage respondents to avoid the difficult cognitive task of counting up asset values in favor of the simpler one of providing "yes" or "no" answers to various threshold amounts. Although plausible, our evidence from these surveys actually goes in the opposite direction. We examined respondents who used unfolding brackets in the early parts of the survey to see whether they were also more likely to use brackets in answering questions in the later part of the survey. In fact, just the reverse is true-for all assets, respondents who use brackets early tended to provide exact responses later. Our speculation is that respondents may learn from the bracket questions that a rough approximation to asset value is of sufficient accuracy and use that insight to provide exact answer data (often in round numbers) later in the survey.

The HRS and AHEAD survey design also sheds some light on the motivation for nonresponse. In the initial question sequence, respondents who did not give an asset value were separated into two categories: those who refused to respond [refusals (REF)], and those who said that they did not know [don't knows (DK)]. This is an important distinction, not only for the eventual success rate in converting completely missing data into bracket responses, but also in estimating the distribution of the unknown-asset values. Although some respondents are reluctant to reveal the value of their assets, others may simply be unsure of precise values, an uncertainty that translates into nonresponse. It turns out that most of these unsure respondents can be persuaded to place their asset values within range limits, information that turns out to be very valuable indeed.

Table 2 provides some insight into this issue by listing the distribution of HRS cases originally recorded as "DK" or "REF" on asset questions. Respondents who went com- 
Table 2. Bracket Response Distributions, HRS Data (\% of Total)

\begin{tabular}{|c|c|c|c|c|c|c|}
\hline \multirow[b]{2}{*}{ Asset type } & \multicolumn{3}{|c|}{ Don't know response } & \multicolumn{3}{|c|}{ Refusal response } \\
\hline & $\begin{array}{c}\text { Complete } \\
\text { bracket }\end{array}$ & $\begin{array}{l}\text { Partial } \\
\text { bracket }\end{array}$ & DK Ref & $\begin{array}{c}\text { Complete } \\
\text { bracket }\end{array}$ & $\begin{array}{l}\text { Partial } \\
\text { bracket }\end{array}$ & DKRef \\
\hline Real estate & 84 & 6 & 10 & 40 & 11 & 49 \\
\hline Vehicles & 89 & 3 & 8 & 32 & 3 & 65 \\
\hline Business equity & 83 & 4 & 14 & 41 & 7 & 53 \\
\hline IRA and Keoghs & 82 & 7 & 10 & 42 & 12 & 46 \\
\hline Stock & 82 & 6 & 12 & 34 & 12 & 54 \\
\hline Checking and savings & 85 & 7 & 8 & 45 & 11 & 46 \\
\hline CD's, treasury bills & 80 & 10 & 11 & 35 & 8 & 58 \\
\hline Bonds & 71 & 5 & 24 & 19 & 7 & 74 \\
\hline Other & 83 & 5 & 13 & 28 & 5 & 67 \\
\hline
\end{tabular}

pletely through the bracket sequence are labeled complete bracket. Those who went partly through the bracket sequence, but refused at some later point, are called partial bracket. Finally, those who refused to respond to any of the bracket questions are labeled DK or REF. Data are shown separately for those who originally responded DK and for those who originally responded REF.

The data show a substantial difference in willingness to provide bracket responses between original DK and REF responses. Almost $90 \%$ of initial DK responses provided either complete or partial bracket data; the great majority typically $80 \%$ or more-gave complete bracket information. In contrast, more than half of those initially responding REF on a specific item typically refused to provide any additional information about that asset; only about $40 \%$ on average provided complete bracket information. Perhaps some respondents who are unsure of precise values may initially be polite refusals; these respondents are willing to provide some information about asset values with the follow-up brackets. This marked contrast in the behavior of DK and REF responses suggests that the two need to be handled separately when imputations are being done.

\section{IMPUTATION OF MISSING VALUES-METHODS}

Follow-up bracket questions persuaded many initial nonrespondents to provide ranges for their asset values. Without brackets, imputation would treat these converts as if they had the same assets as exact-answer respondents with similar personal attributes. It turns out that for both HRS and AHEAD, exact-answer cases are heavily weighted toward the lower end of the asset value distribution, whereas REF and DK cases are weighted more toward the upper end. As one example, just $8 \%$ of HRS households giving exact answers had business equity in excess of $\$ 500,000$, compared to $19(22) \%$ of those who gave initial don't know (refusal) responses, but who answered the bracket question sequence. In general, based on respondents who eventually used the brackets, REF cases are weighted more toward the upper end of the amount distribution than DK cases.

Although many imputation procedures are available, not all are equally appropriate for assets, where the distribution of possible values is inherently constrained. For example, most asset values cannot be less than 0 , and the frequent use of range values imposes varying upper and lower bounds.
To maintain the distribution in the population, imputation should also have variance-preserving properties.

In this article we use hot-deck algorithms to assign missing values. Like any method, hot-deck imputation has advantages and disadvantages (see Little-Rubin 1987). Its advantage is the absence of parametric assumptions about unobservables, relying implicitly on the functional form among the donors. A principal disadvantage is that it reduces to a fully saturated ANOVA model so that donor samples can quickly become thin if many covariates are used.

An important distinction in missing-data models is between ignorable and nonignorable nonresponse (Little and Rubin 1987). When nonresponse is nonignorable, there is response bias, because observationally equivalent respondents and nonrespondents will have different distributions of missing values. Although significant advances have been made recently on ignorable models for missing data (Fay 1996; Rubin 1996), progress on nonignorable nonresponse has been stymied, because inferences are sensitive to untestable assumptions about what generates differences between respondents and nonrespondents (Lillard, Smith, and Welch 1986). The difficulty with nonignorable response models is that there rarely is an external way of testing model assumptions. An important exception is the work of Greenlees, Reece, and Zieschang (1982), which used the CPS-IRS-SSA exact match file to model nonresponse in wages. While having some external source for missing values is unusual, follow-up brackets can be viewed as a self-reported external source for missing values. Instead of providing an exact number for the missing value (as with IRS-SSA values for missing CPS wages), follow-up brackets provide a range within which the missing value must lie. For this reason, follow-up brackets provide mileage in dealing with nonignorable nonresponse, an especially important issue for wealth.

There exists nontrivial estimation error in any imputation procedure, and hot deck is certainly no exception. The estimation error associated with any single set of imputations can make it difficult to distinguish with any confidence between differences that emerge because of bias and those due to random imputation estimation error. Multiple imputation methods (Rao 1996; Rao and Shao 1992; Rubin 1987), which acknowledge this underlying uncertainty by providing multiple estimates, can also be used productively with follow-up brackets. We minimized the effect of 
imputation estimation error by computing all hot-deck imputations across 25 independent trials. The means across these 25 trials are the imputations presented in this article. Because estimation error is proportional to the square root of $N$, estimation error associated with imputation should be reduced five-fold. The differences reported herein are simply far too large to be due to imputation estimation error.

As suggested by Figure 1, there are three distinct groups of respondents with missing values for whom imputations must be obtained. The first relatively small group involves those who did not know or refused to say whether they had the asset at all. For this group, hot-deck imputations are made using the complete sample-owners and nonowners of the assets-as potential donors. Given the small number of respondents in this group, how it is treated is not very important, and we ignore it in this article.

Brackets are critical, however, when assigning missing values to the other two groups. Our second group includes those who selected a bracket range for their asset value. The direct benefit from brackets is that they place an otherwise unknown asset value within a prespecified range. In making imputations for bracket respondents, we used as potential donors those exact-answer respondents whose asset values fell within the respondent's bracket range.

Our final group are those who provided neither an exact value nor a bracketed value for their assets. Brackets have the indirect benefit of providing a more relevant pool of donors for these cases. To make imputations for these complete nonresponse cases, only the pool of bracket responses is used as a source of potential donors, in contrast to standard imputation methods that traditionally use the entire sample. We would argue that respondents who use brackets are a more representative donor pool for complete nonresponse cases, because they share a common initial reluctance to answer wealth questions.

The following subsections summarize our imputations for nonhousing wealth, separately for bracket response cases and complete nonresponse cases. Section 5 combines these subsamples to derive the implications for the complete HRS and AHEAD samples. Whether brackets are used or not, we use an identical list of personal attributes for each hot-deck imputation in the article. The mose extensive list of covariates used included rate, ethnicity (Hispanic), education $(0-11,12-15,16$ or more years), married, law, M.D. or doctorate degree, and dummy variables for quintiles of household income and quintiles of housing equity (for nonhousing assets). As with most hot-deck procedures, the coarseness of the matching variables depends on the ability to find matches (Rubin 1987). The actual covariates used to impute specific assets vary depending on range width and thinness of the sample of potential donors.

\subsection{Bracket Respondents}

One way to establish the information value of brackets is to estimate missing values as though the bracketed data were not available. Accordingly, we imputed values under two assumptions for respondents who placed their assets within brackets. The first (brackets used) recognizes that the correct value must lie within self-reported limits and that only respondents with assets within those limits should serve as potential donors. The second (brackets ignored) uses the conventional procedure-all exact-answer respondents serve as potential donors. In both cases the full list of personal attributes described earlier is used in the imputation algorithm. Table 3 shows means and medians (averaged over 25 iterations) for each nonhousing asset. The

Table 3. The Effect of Ignoring Brackets for Imputation of Missing Nonhousing Values Among Respondents Providing Bracketed Responses

\begin{tabular}{|c|c|c|c|c|}
\hline \multirow[b]{2}{*}{ Asset } & \multicolumn{2}{|c|}{ HRS brackets } & \multicolumn{2}{|c|}{ AHEAD brackets } \\
\hline & Used & Ignored & Used & Ignored \\
\hline \multicolumn{5}{|l|}{ Mean Values } \\
\hline Real estate & 221,676 & 129,098 & 146,149 & 107,472 \\
\hline Vehicles & 18,079 & 12,539 & 6,606 & 6,141 \\
\hline Business & 348,600 & 165,986 & 219,580 & 99,872 \\
\hline IRA, Keoghs & 56,415 & 44,357 & 55,110 & 52,608 \\
\hline Stocks & 74,736 & 56,982 & 104,694 & 74,866 \\
\hline Checking, savings & 23,409 & 16,014 & 21,648 & 20,750 \\
\hline CDs, treasury & 47,665 & 27,253 & 34,823 & 39,852 \\
\hline Bonds & 67,846 & 47,447 & 90,208 & 54,275 \\
\hline Other assets & 78.711 & 41,885 & 21,671 & 29.684 \\
\hline Other debts & $-7,118$ & $-8,630$ & $-5,481$ & $-4,949$ \\
\hline Average value & 75,647 & 45,287 & 45,522 & 35,593 \\
\hline \multicolumn{5}{|l|}{ Median values } \\
\hline Real estate & 69,678 & 42,123 & 62,840 & 48,940 \\
\hline Vehicles & 10,000 & 7,800 & 4,272 & 2,024 \\
\hline Business & 98,000 & 24,260 & 110,400 & 15,960 \\
\hline IRA, Keoghs & 30,000 & 20,080 & 24,500 & 23,224 \\
\hline Stocks & 22,928 & 17,017 & 39,340 & 27,760 \\
\hline Checking, savings & 6,672 & 5,000 & 7,780 & 6,320 \\
\hline CDs, treasury & 10,000 & 9,760 & 13,440 & 19,400 \\
\hline Bonds & 24,220 & 14,340 & 41,540 & 31,060 \\
\hline Other assets & 20,000 & 13,980 & 8,050 & 9,950 \\
\hline Other debts & $-2,918$ & $-2,544$ & $-2,000$ & $-1,554$ \\
\hline
\end{tabular}


row labeled "average value" contains the weighted average of individual asset values where the weights are the fraction holding each asset among all bracketed assets.

The quantitative differences produced by these two imputation methods are substantial, especially for HRS households. For example, we estimate a mean HRS business asset of $\$ 348,600$ when brackets are used, with a standard deviation of that mean across the 25 iterations of $\$ 21,546$. This estimate is well in excess of the mean business asset of $\$ 165,986$ when bracket information is ignored. In virtually every case, the differences in means in Table 3 are well in excess of the standard errors of these estimates. Mean HRS nonhousing imputations are $67 \%$ higher when brackets are used than when brackets are ignored. The difference from using brackets appears somewhat greater for tangible than for financial assets; our estimate of mean business equity among HRS (AHEAD) respondents is more than $\$ 182,000$ $(\$ 120,000)$ greater when the brackets are used in imputation. Although not trivial, the bias is considerably smaller in AHEAD; our estimated average asset value using brackets was $29 \%$ higher than when they were ignored. Because these discrepancies are as great with medians, the higher mean values are not simply the consequence of a few very high values.

There are many plausible reasons for this difference between the two surveys. Most important, given the age difference between the samples, is that there are fewer AHEAD respondents with extremely high asset values. Second, relative to their total portfolio, AHEAD respondents have fewer assets in categories, such as business equity, where the bias is particularly large. Finally, HRS respondents use both unfolding brackets and range cards, whereas only unfolding brackets were used in AHEAD. The difference between using and ignoring brackets was larger with range cards. For example, average nonhousing asset values were about $50 \%$ higher for those who used unfolding brackets than for exact data responses, compared to about $100 \%$ higher for respondents who answered using range cards. The reason may be that range cards contain many more categories than unfolding brackets do, especially at very high asset values. Thus it is possible that the unfolding bracket categories may still understate respondents' asset values.

Our reliance on hot-deck methods is not an endorsement, because these methods are not inherently superior to the alternatives. We use them here to facilitate comparisons with Census imputation of missing wealth data, which relies almost exclusively on hot-deck methods. How sensitive are our main conclusions to our reliance on hot decks? The relatively few covariates in the hot-deck model may imply that correlations may be preserved only among a small subset of variables. In particular, our conclusions on bias may be sensitive to not including the values of other assets of respondents. For example, an excellent predictor of respondents' stock holdings may be the value of their bonds. The list of possible household assets is far too large to fit into a hot-deck procedure, so more explicit model-based approaches must be used.

To explore this issue, Table 4 lists two additional sets of HRS imputations alongside our hot-deck estimates, which
Table 4. Mean HRS Asset Imputations

Under Three Alternative Models

\begin{tabular}{lrrr}
\hline \multicolumn{1}{c}{ Asset } & $\begin{array}{c}\text { Hot-decks } \\
\text { (brackets-used) }\end{array}$ & OLS-simple & OLS-extended \\
\hline Real estate & 221,676 & 130,958 & 148,129 \\
Vehicles & 18,079 & 12,755 & 12,948 \\
Business & 348,600 & 133,206 & 160,825 \\
IRA, Keoghs & 56,415 & 43,544 & 45,627 \\
Stocks & 74,736 & 52,621 & 68,700 \\
Checking, savings & 23,409 & 15,086 & 16,127 \\
CD's, treasury & 47,665 & 24,075 & 29,589 \\
Bonds & 67,846 & 42,767 & 72,525 \\
Other assets & 78,711 & 47,011 & 50,646 \\
Other debts & $-7,118$ & $-9,797$ & $-9,964$ \\
Average value & 75,647 & 42,560 & 49,949 \\
\hline
\end{tabular}

are repeated in the second column. The third column contains mean imputations obtained from an ordinary least squares (OLS) regression model with the same list of covariates in the hot-deck model. The fourth column is also derived from an OLS regression on asset values, but now the covariates are expanded to include the presence and dollar value of each other asset held by the respondent. In both new models, predicted values are augmented by a random selection from the residual variance (using the estimated mean squared error from the regressions). To reduce the effect of imputation error, 25 different independent draws from this residual distribution are made. The numbers presented for the new models in Table 4 are also average values across the 25 iterations.

Comparing the third columns of Tables 3 and 4 , mean imputed values for bracketed cases are quite similar. This similarity implies that our imputations may not be overly sensitive to the type of imputation model (hot deck or regression) when the same covariates are used. With one notable exception, expanding the covariate list to include other assets does not have a great impact on the extent of nonignorable nonresponse bias, largely because exact dollar and bracketed respondents do not differ a great deal in their asset portfolios. The exception relates to stocks and bonds where mutual knowledge about their coexistence and values significantly raises estimates of missing values. The principal advantage of enlarging the list of covariates to include other assets is that it improves predictions of within-group allocations of asset values. Averaged across all assets, $R^{2}$ in the regressions average about .22 with the expanded covariate list, compared to .10 with the more limited list. Better within-group predictions are a good enough reason to include other assets in any imputation algorithm, but they apparently are not a substitute for brackets in dealing with nonignorable nonresponse bias. (See Kennickell 1979 for an application to $\mathrm{SCF}$.)

The problems entailed in accurate imputation when brackets are unavailable are succinctly summarized by calculating the percentage of cases in which imputation without brackets assigns values outside respondents' selfreported range. Table 5 indicates that only $35 \%$ of HRS missing values are correctly assigned to respondents' selfreported brackets when brackets are ignored. Ignoring 
Table 5. Fraction of HRS Misassigned Cases When Brackets Are Ignored

\begin{tabular}{lccc}
\hline \hline & $\begin{array}{c}\text { Below } \\
\text { brackets }\end{array}$ & $\begin{array}{c}\text { Within } \\
\text { brackets }\end{array}$ & $\begin{array}{c}\text { Above } \\
\text { brackets }\end{array}$ \\
\hline All Cases & 27.3 & 35.4 & 37.1 \\
$0-\$ 5,000$ & & 16.7 & 83.3 \\
Above $\$ 500,000$ & 88.7 & 11.3 & \\
\hline
\end{tabular}

brackets has particularly severe consequences at the extremes of the distribution. Among those HRS respondents who said that an asset was worth more then $\$ 500,000$, standard imputation using personal attributes predicted a value below that threshold in $89 \%$ of the cases. Similarly, when respondents indicated that an asset was less than $\$ 5,000$, a value larger than that threshold was assigned in $83 \%$ of the cases.

\subsection{Bracket Respondents: Refusals Versus Don't Knows}

We argued earlier that refusal (REF) and don't know (DK) responses may have different motives and consequently different distributions of asset values, other things equal. If refusals stem largely from the size of assets, then the imputed assets of REF cases will be greater than those of DK. Table 6 provides some evidence on this distinction by listing mean imputed assets separately for REF and DK respondents who gave unfolding bracket values. To conserve space, details for selected specific assets are provided for the HRS sample only.

REF responses show much higher asset values than DK responses. These sharp differences suggest that the distinction between REF and DK should be recorded in public use tapes to help researchers in making their own imputations. Whether a respondent was a REF or DK case was used as an attribute for all imputations in this article.

\subsection{Final Nonresponse Imputations}

More accurate estimates of missing data for respondents who gave bracketed responses are only part of the gain from the use of brackets. The indirect benefit is that bracketed respondents provide a more relevant donor pool for final nonresponse cases. Table 7 lists imputed mean values for all "final nonresponse cases" using two alternative donor pools. The first, more conventional pool consists of respondents who provided exact answers to asset questions. This pool corresponds to that used by many survey organizations when they conduct their imputations. In contrast, the second pool uses as donors only respondents who gave bracketed responses. We believe that the latter is more representative of the final nonresponse cases, because they share an initial reluctance to answer asset questions. If anything, the pool of bracketed respondents will still understate asset values of the final nonresponses, who are even more reluctant than bracket respondents to reveal their assets.

Table 7 demonstrates how critical the correct donor pool may be. The value of the average HRS (AHEAD) nonhousing asset is approximately 63 (42)\% larger using bracketed responses than exact answer responses as donors. Once again, the largest understatements occur in both surveys in the tangible asset categories (business and other real estate). For example, business equity in HRS is higher by roughly $\$ 130,000$ if we use the donor pool of unfolding bracket responses instead of the conventional donor pool of exact answer responses.

\section{COMPLETE SAMPLE IMPUTATIONS}

Although brackets make a substantial difference when imputing missing-data cases, the impact is obviously attenuated in the full sample, which includes respondents who gave exact answers to asset questions or those who did not possess the asset. Table 8 summarizes the effect of using brackets on total asset values for the complete HRS and AHEAD samples. In the full HRS sample, mean nonhousing wealth is $19 \%$ higher using bracket pools. This approximately $\$ 25,000$ in additional wealth is equivalent to ignoring all wealth in stocks, mutual funds, and checking and savings accounts. The size of the discrepancy in the full sample varies with the type of asset. Although there is little difference in housing equity, use of brackets increases total business and real estate equity by $37 \%$ and total financial assets by $17 \%$.

Because they vary systematically with age, these discrepancies may affect our views on such basic questions as the adequacy of savings for future retirement. Table 8 shows that mean nonhousing wealth is $9 \%$ larger when brackets are used in AHEAD. Although this is a nontrivial effect, it is much smaller than the $19 \%$ reported for HRS. On the basis of our estimates from these two samples, wealth imputations without brackets may understate by roughly $10 \%$ the asset holdings of those in their 50 s relative to those age 70 and older. Because the relative size of wealth in these two age groups is a critical part of any test of the life-cycle hypothesis (Deaton 1992), our results suggest that additional tests of the size of the bias across age groups should be conducted.

To this point, our discussion has concentrated solely on nonhousing assets. Nonresponse on housing was less severe in both surveys, so the ultimate impact of missing data on total household wealth is much smaller. In contrast to other assets, mean imputed home equity is little different in AHEAD and is actually slightly smaller in HRS when range

Table 6. Means of Nonhousing Assets for Unfolding Bracket Responses

\begin{tabular}{lrrr}
\hline \hline & $\begin{array}{c}\text { All } \\
\text { unfolding } \\
\text { brackets }\end{array}$ & $\begin{array}{c}\text { Refusal } \\
\text { unfolding } \\
\text { brackets }\end{array}$ & $\begin{array}{c}\text { Don't Know } \\
\text { unfolding } \\
\text { brackets }\end{array}$ \\
\hline HRS assets & & & \\
Other real estate & 184,458 & 254,047 & 176,033 \\
Equity in business & 361,009 & 448,285 & 351,145 \\
IRA, Keoghs & 49,360 & 66,013 & 43,781 \\
Stocks, mutual funds & 68,098 & 133,428 & 58,735 \\
Checking, savings & 19,502 & 23,908 & 17,619 \\
CD's, treasury & 32,389 & 45,021 & 28,414 \\
Bonds & 70,823 & 54,509 & 74,754 \\
Other assets & 52,071 & 78,788 & 48,743 \\
\hline
\end{tabular}


Table 7. Imputation of Mean Nonhousing Values for "Final Nonresponses"

\begin{tabular}{lccccr}
\hline \hline & \multicolumn{2}{c}{ HRS donor pool } & & \multicolumn{2}{c}{ AHEAD pool } \\
\cline { 2 - 3 } & $\begin{array}{c}\text { Exact data } \\
\text { responses }\end{array}$ & $\begin{array}{c}\text { Bracket } \\
\text { responses }\end{array}$ & & $\begin{array}{c}\text { Exact data } \\
\text { responses }\end{array}$ & $\begin{array}{c}\text { Bracket } \\
\text { responses }\end{array}$ \\
\hline Other real estate & 109,449 & 226,308 & & 91,108 & 165,454 \\
Vehicles & 11,209 & 20,684 & & 7,774 & 5,697 \\
Equity in business & 280,105 & 413,221 & & 43,429 & 251,780 \\
IRA, Keoghs & 37,554 & 61,272 & & 46,554 & 47,555 \\
Stocks, mutual funds & 63,258 & 98,055 & & 75,891 & 153,968 \\
Checking, savings & 16,823 & 24,585 & & 20,880 & 23,571 \\
CD's, Treasury & 24,805 & 46,259 & & 38,399 & 33,204 \\
Bonds & 45,681 & 51,747 & & 50,322 & 92,842 \\
Other assets & 51,683 & 106,653 & & 36,883 & 20,479 \\
Other debts & $-6,665$ & $-7,170$ & & $-6,211$ & $-4,635$ \\
Average value & 44,185 & 72,118 & & 40,297 & 57,156 \\
\hline
\end{tabular}

card respondents are used as the donors. The HRS result is a direct consequence of the distribution of range card responses compared to the distribution of respondents with exact data. HRS nonresponse cases who gave a range card answer were only one-third as likely as exact data cases to own a house worth more than $\$ 250,000$. Across many stratifications of economic status, including education and income, the less well-off are less likely to report their house value. For example, $7 \%$ of HRS households in the bottom family income quintile do not report house values, compared to $3 \%$ in the top quintile.

Why is the missing-data pattern for housing so different from all other missing asset values? Particularly among respondents who have lived in their current home for many years, unwillingness to report housing values may reflect uncertainty rather than sensitivity about value, especially among less-educated and lower-income respondents. In addition, housing prices exhibit significant regional variation, introducing disparities in the norm of what constitutes an expensive home. Respondent sensitivity about value may exist only relative to this norm, blurring the simple relation of reporting to actual value.

\section{REPORT ON SOME EXTENSIONS AND CONCLUSIONS}

Although unfolding brackets can improve the quality of financial data, research on their optimal design and implementation is just at the beginning stages. Three issues should be placed particularly high on the data quality research agenda (Sudman, Bradburn, and Schwarz 1966). These issues are complex and in need of additional research; their potential importance is briefly sketched here.
The first question concerns how to "optimally" select bracket categories. Practical survey constraints will always limit brackets to a small number of distinct categories. However, the breakpoints selected can still be chosen to maximize their predictive power in imputation. For example, if most of the missing cases had values over $\$ 1$ million, then the chosen brackets should be concentrated above that number. Because their empirical distributions are so diverse, the "best" brackets will vary across individual assets. The general idea behind selecting "optimal" breakpoints is that the chosen thresholds should maximize explained variance in a one-way ANOVA (Hill, Heeringa, and Howell 1994). The breakpoints actually used in HRS and AHEAD baselines were essentially the same as those in the 1984 and 1989 PSID wealth modules. Based on the optimal breakpoint strategy, these breakpoints were revised in subsequent waves of HRS and AHEAD. For example, the HRS wave-1 brackets for investment real estate were $\$ 1-\$ 4,999$; $\$ 5,000-\$ 49,999 ; \$ 50,000-\$ 149,999$, and $\$ 150,000$ or more. For wave 2, the analysis yielded optimized brackets of $\$ 1$ $\$ 2,499 ; \$ 2,500-\$ 124,999 ; \$ 125,000-\$ 499,999 ; \$ 500,000$ $\$ 999,999$ and $\$ 1$ million or more. Essentially, the optimal brackets involved finer partitions for very small and very large real estate values where many observations were concentrated.

Even if the best set of bracket thresholds are chosen, the issue of whether there exists an anchoring effect associated with the choice of an initial threshold in the sequence remains. Anchoring occurs when the content of the question itself conveys information about what the probable "correct" answer is. For example, if respondents are asked about the size of their checking accounts, responses may be influenced by whether the first question is at the $\$ 100$ level, the

Table 8. Value of Assets in Full HRS and AHEAD Samples

\begin{tabular}{lccccc}
\hline \hline & \multicolumn{2}{c}{ HRS } & & \multicolumn{2}{c}{ AHEAD } \\
\cline { 2 - 3 } \cline { 5 - 6 } & $\begin{array}{c}\text { Imputations using } \\
\text { brackets }\end{array}$ & $\begin{array}{c}\text { Imputations ignoring } \\
\text { brackets }\end{array}$ & & $\begin{array}{c}\text { Imputations using } \\
\text { brackets }\end{array}$ & $\begin{array}{c}\text { Imputations ignoring } \\
\text { brackets }\end{array}$ \\
\hline Housing & 75,459 & 75,864 & & 66,882 & 66,705 \\
Nonhousing & 162,253 & 136,904 & & 100,583 & 91,694 \\
All assets & 237,712 & 212,768 & & 167,465 & 158,399 \\
\hline
\end{tabular}


$\$ 1,000$, or the $\$ 10,000$ level, even if the final set of bracket categories are the same. Because respondents may assume that question designers know more than they do, the entry point may tell respondents something about what the "correct" answer is. A sequence that starts with $\$ 100$ will convey the impression that small numbers are more likely to be correct than large numbers, whereas a sequence starting with $\$ 10,000$ may give the opposite impression.

To address this question, a group of respondents in the second wave of AHEAD were asked to place their savings account values into bracket thresholds. While the final set of thresholds were the same, the initial threshold value varied randomly across respondents. The cumulative distribution of savings account values varied systematically with alternative initial entry points. For example, the cumulative fraction of cases less than $\$ 10,000$ was $49 \%$ when the initial entry point was $\$ 1,000$ compared to $37 \%$ when it was $\$ 20,000$. Anchoring effects produced less bias in mean values when the initial entry point was in the middle rather than at either end of the distribution. Because most HRS and AHEAD bracket sequences start toward the middle of the distribution, the bias in mean values in these surveys may be moderate.

The HRS and AHEAD unfolding bracket questions all had a common format where the initial bracket question is phrased: "Is it more than $x$ ?" But there are alternative ways to phrase the question, with some obvious possibilities being: "Is it $x$ or more?"; or "is it more than $x$, less than $x$, or about equal to $x$ ?" The distinction in these three questions is whether or not the rounded number specified by $x$ is associated with a "yes" or a "no" response (if the question is "more than $x$," then the rounded number calls for a "no" response), and whether the respondent can indicate that their asset holdings are just about the same amount as the rounded number. Based on analyses of some experimental data from HRS and AHEAD, there is little difference in the " $x$ or more" and "more than $x$ " versions, but the balanced question (is it more than $x$, less than $x$, or about equal to $x$ ) provides a somewhat different distribution of responses, with about $5-10 \%$ of respondents reporting that "about equal to $r$ " is the correct answer.

\section{CONCLUSIONS}

This article has investigated some survey techniques used in the HRS and AHEAD surveys. These techniquesfollow-up bracket responses-reduce the implications of initial nonresponse to wealth questions and narrow uncertainty about precise asset values. Because initial levels of item nonresponse in HRS and AHEAD are similar to those obtained in other household surveys, follow-up brackets may also lower the pervasiveness of complete item nonresponse in other surveys.

The potential value to other household surveys of followup brackets goes beyond simply reducing nonresponse. Our evidence suggests that missing wealth data involves nonignorable response bias, and that follow-up brackets provide a partial remedy to this problem. For example, our estimates imply that household surveys may distort the age-wealth profile by understating wealth in the preretirement years relative to the postretirement years by $10 \%$. Even if there were no effect on nonignorability, range brackets undoubtedly produce efficiency gains as the size of the imputation error is reduced. One must be careful in extrapolating our results to other household surveys that differ in many ways besides the use of brackets. But we think that our results are strong enough to recommend that multipurpose surveys with relatively short wealth modules try follow-up brackets to mitigate a serious problem of nonignorable nonresponse. In fact, based largely on the HRS and AHEAD experience, the new 1996 National Longitudinal Survey of Youth has already incorporated an extensive use of brackets in its wealth module.

[Received May 1995. Revised May 1997.]

\section{REFERENCES}

Curtin, R., Juster, F. T., and Morgan, J. (1989), "Survey Estimates of Wealth: An Assessment of Quality," in The Measurement of Saving, Investment, and Wealth, eds. R. E. Lipsey and H. S. Tice, Chicago: University of Chicago Press.

Deaton, A. (1992), Understanding Consumption, Oxford, U.K.: Clarendon Press.

Fay, R. E. (1996), "Alternative Paradigms for the Analysis of Imputed Survey Data," Journal of the American Statistical Association, 91, 490499.

Ferber, R. (1959), "Collecting Financial Data by Consumer Panel Techniques," report, University of Illinois-Urbana, Bureau of Economic and Business Research.

Greenlees, W. S., Reece, J. S., and Zieschang, K. D. (1982), "Imputation of Missing Values When the Probability of Response Depends on the Variable Being Imputed," Journal of the American Statistical Association, 77, 251-261.

Hill, D., Heeringa, H. S., and Howell, D. A. (1994), "Mixed Level Survey Measurement; Optimal Instrument Design and Efficient Analysis of Data," unpublished paper.

Hurd, M. D. (1990), "Research on the Elderly: Economic Status, Retirement, Consumption and Saving," Journal of Economic Literature, 27. 565-637.

Juster, F. T. (1977), "An Experiment in Data Collection: The Use of Financial Records," in Proceedings of the Social Science Section, American Statistical Association, pp. 504-510.

Juster, F. T., and Kuester. K. A. (1991), "Differences in the Measurement of Wealth, Wealth Inequality and Wealth Composition Obtained From Alternative U.S. Wealth Surveys," Review of Income and Wealth, 36, $33-62$.

Kennickell, A. B. (1991), "Imputation of the 1989 Survey of Consumer Finances," in Proceedings of the Section of Survey Research Methods, American Statistical Association, pp. 1-9.

___ (1997), "Using Range Techniques With CAPI in the 1995 Survey of Consumer Finances," Federal Reserve Board, Occasional Staff Studies-2.

Lansing, J., Ginsberg, G. B., and Braaten, K. (1961), "An Investigation of Response Error," Bureau of Economic and Business Research. University of Illinois-Urbana, June 1961

Lillard, L., Smith, J. P., and Welch, F. (1986), "What Do We Know About Wages; The Importance of Nonreporting and Census Imputation," Journal of Political Economy, 94, 489-506.

Little, R. J. A., and Rubin, D. B. (1987), Statistical Analysis With Missing Data, New York: Wiley.

Madow, W. G., Oklin, I., and Rubin, D. B. (1983), Incomplete Data in Sample Surveys. Vol. 2: Theories and Bibliographies, New York: Academic Press.

Meng, X. L. (1994), "Multiple-Imputation Inferences With Uncongenial Sources of Input," Statistical Science, 9, 538-573. 
Poterba, J. M. (1994a), "Personal Saving Behavior and Retirement Income Modelling: A Research Assessment," paper prepared for a meeting of the Committee on National Statistics Panel on Retirement Income Modelling Conference, National Academy of Sciences.

(1994b). Intemational Comparisons of Household Saving, Chicago: University of Chicago Press.

Rao, J. N. K., and Shao, J. (1992), "Jackknife Variance Estimation With Survey Data Under Hot Deck Imputation," Biometrika, 79, 811-822.
(1996), "On Variance Estimation With Imputed Survey Data," Journat of the American Statistical Association, 91. 499-506.

Rubin, D. B. (1987). Multiple Imputation for Non-Response in Surveys, New York: Wiley.

(1996). "Multiple Imputation After 18+ Years," Jommal of the American Statistical Association, 91. 473-490.

Sudman, S., Bradburn. N. M., and Schwarz. N. (1966), Thinking About Ansuers, San Francisco: Jossey-Bass. 
APPENDIX B 


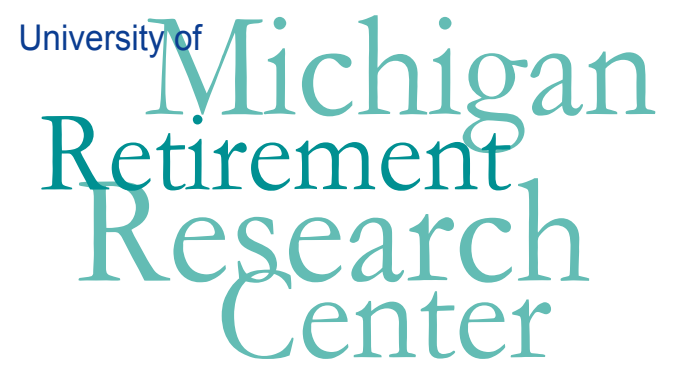

\section{Working Paper}

WP 2002-030

\section{Ensuring Time-Series Consistency in Estimates of Income and Wealth}

F. Thomas Juster, Joseph P. Lupton, and Honggao Cao

\begin{tabular}{|l|l|l|}
\hline $\mathrm{M}$ & $\mathrm{R}$ \\
$\mathrm{y}$ & $\mathrm{C}$ & Project \# UM02-Q3 \\
\hline
\end{tabular} 


\title{
"Ensuring Time-Series Consistency in Estimates of Income and Wealth"
}

\author{
F. Thomas Juster \\ University of Michigan \\ Joseph P. Lupton \\ University of Michigan \\ Honggao Cao \\ University of Michigan
}

\author{
July 2002 \\ Michigan Retirement Research Center \\ University of Michigan \\ P.O. Box 1248 \\ Ann Arbor, MI 48104 \\ www.mrrc.isr.umich.edu \\ (734) 615-0422
}

\section{Acknowledgements}

This work was supported by a grant from the Social Security Administration through the Michigan Retirement Research Center (Grant \# 10-P-98358-5). The opinions and conclusions are solely those of the authors and should not be considered as representing the opinions or policy of the Social Security Administration or any agency of the Federal Government.

\section{Regents of the University of Michigan}

David A. Brandon, Ann Arbor; Laurence B. Deitch, Bingham Farms; Daniel D. Horning, Grand Haven; Olivia P. Maynard, Goodrich; Rebecca McGowan, Ann Arbor; Andrea Fischer Newman, Ann Arbor; S. Martin Taylor, Gross Pointe Farms; Katherine E. White, Ann Arbor; Mary Sue Coleman, ex officio 


\section{Introduction}

The last decade has seen substantial progress in improving the quality of microdata on both income and wealth. Some of these developments are documented in recent papers by Juster and Smith (1997), Juster, Lupton, Smith and Stafford (under review, 2001), and Hurd, Juster and Smith (under review, 2001). These papers explore a number of quality enhancements: the use of unfolding brackets for income or wealth components that convert "don't know" or "refusal" responses into quantitative imputations that contain measurement error but little or no bias; the use of improved estimates of changes over time in wealth and active saving to generate measures of capital gains or losses; the use of a merged questionnaire sequence that integrates survey questions about asset holdings and income flows from these assets to reduce the bias in estimates of income from capital; and finally, matching of the periodicity specified in income questions to the actual periodicity of income receipts as a way to enhance the quality of reports for certain income categories.

These enhancements of survey data on income and wealth, while substantially improving the quality of the cross section data, do not come without a cost. A major problem associated with any change made to the methodology used in a panel survey is that they tend to produce time series inconsistencies. By definition, quality improvements reduce the bias and/or measurement error of the cross section point estimate but, by doing so, introduce a bias in the estimate of the change over time.

One way to avoid producing such a time series inconsistency is to freeze the

survey technology, thus eliminating any quality enhancement. As a long run strategy, this is clearly a bad idea - robust empirical findings cannot be obtained from poor data. A preferred alternative would be to develop methods of recovering time series consistency 
in the face of data enhancements. In this paper, we explore methods of recovering time series consistency in the measurement of income from capital in the Health and Retirement Survey (HRS).

Respondents in both Waves 1 (1992) and 2 (1994) of the HRS were asked to report all sources of income in a stand-alone series of questions. The conventional view is that these questions should be reported together since they all have the characteristic of being resource flows. In a separate set of questions, the value of household assets and liabilities were obtained. Again, the idea was that these are all stock values and thus should be grouped together. However, while this classification of flows and stocks into separate groups is useful from the perspective of the researcher, it may not be the optimum question structure from the viewpoint of the survey respondent. Given that the source of asset income is the asset itself, it makes sense to integrate stocks and flows in a way that allows the survey respondent to consider these dollar amounts at the same time. This innovation was implemented in the HRS beginning in Wave 3 (1996) and continues to be the methodology used in all following waves including Wave 4 (1998) and Wave 5 (2000). Hurd, Juster and Smith (2001) examine the effect of this data collection enhancement and find that the income from capital almost doubles between Waves 2 and 3 , suggesting the reduction of a serious bias resulting from the stock/flow separation of asset amounts and income. And as noted in that paper, other surveys, such as the Current Population Survey, also suggest a serious underestimate of income from assets using the conventional survey design that has income from assets reported in one module and the assets reported in a separate module.

Although clearly indicating a substantial improvement in the measurement of asset income, the mean doubling between Waves 2 and 3 of the HRS is problematic for 
researchers wishing to utilize the panel aspect of the survey. The results of any time series study of HRS asset income will be dominated by this technology change in data collection. To correct the problem we propose a strategy that utilizes the distribution of the rates of return obtained in the unbiased data. Random imputation of asset income rates of return in Waves 1 and 2, using Wave 3 as the donor distribution, are used with the asset values of Waves 1 and 2 to generate an estimate of asset income.

Two crucial assumptions are required if this strategy is to be successful. First, it is assumed that although there is a time series inconsistency in the estimate of asset income, the estimates of asset values are not contaminated by this bias. We provide evidence that the measurement of asset values is indeed consistent over time and that the major source of bias in the rate of return to assets stems from the measurement of asset income. Second, the donor distribution must be an adequate representation of the true distribution in the time period where the imputations are being made. To determine how robust our strategy is to this assumption, we provide imputed estimates based on donor distributions coming from HRS Waves 3, 4 and 5. The stability of the imputed estimates across donor distributions is noteworthy.

In the next section, we examine the HRS data on household financial wealth and income flowing from that wealth. We discuss the possibility of various sources of measurement error in the time series across Waves 1 through 5 and provide the mean rate of return to financial assets in these years. In Section 3, we outline three imputation procedures and discuss their relative advantages and disadvantages. These procedures are applied to the HRS asset income data and the results are reported in Section 4. The robustness of each procedure is examined as are the various imputation strategies. Concluding remarks are provided in Section 5. 


\section{Survey Structure Induced Bias in the HRS Financial Asset Income}

Financial wealth in the HRS is defined as the sum of four components: checking, saving and money market accounts; CD's, savings bonds and Treasury bills; publicly traded corporate equities and equity mutual funds; and corporate bonds. Each of these potentially yields some amount of asset income. Data from the 1992 and 1994 data are based on the conventional survey format while the 1996, 1998 and 2000 data are based on the revised format that integrates questions about asset holdings with questions about income from assets. In the conventional format, respondents are asked whether they own any of the four financial assets, or any investment real estate or business or farm equity, and how much they own if they report owning any. In a later section of the questionnaire, respondents are asked about income from a variety of sources (wages or salary, workers compensation, veterans benefits, business income, rent, Social Security, pensions, interest or dividends, etc.). In the revised question sequence, households are asked whether they have each of the four asset components noted above. If the respondent claims to own a particular asset, they are asked about its value and, if greater than zero, whether they received any dividend or interest income from that asset. If they claim to have asset income, they are ask how much and how often. Similar question sequences are asked for each of the four types of financial assets.

Gross differences in the reporting of financial assets and income from those assets across the five waves are enormous. These are shown in Table 1. In 1992 and 1994, only about a third of the sample reported income from financial assets while almost two-thirds reported zero income from assets. These proportions were approximately reversed in 1996, 1998 and 2000, with almost two-thirds reporting income from assets and a bit more than one-third reporting zero income from assets. Interestingly enough, the proportion of 
the sample reporting ownership of financial assets is essentially the same on all five waves: the fraction owning financial assets is a bit over $80 \%$ in 1992, and goes up slightly in each later year as one would expect during a vigorous economic expansion.

Another way to look at the linkage between assets and income from assets is to examine the proportion of the sample reporting zero income from assets within different asset percentiles across survey years. This is provided in Table 2. In the lowest asset category (zero to the $25^{\text {th }}$ percentile), the proportion of the sample reporting zero income from assets is over 90\% in all five survey years, although it is a bit higher in 1992 and 1994 than in 1996, 1998, or 2000. The differences by year become substantial when we look at higher asset percentiles. For example, in the $90^{\text {th }}$ percentile and above, the 1992 and 1994 proportions of households reporting zero income from assets are, respectively, $22 \%$ and $36 \%$, extraordinarily high numbers for households in the upper $10 \%$ of the financial asset distribution. Integrating the survey questions on asset income into the asset and liabilities module reduces the proportion of households reporting zero income from assets to about $3 \%$ in that percentile group. Substantial differences in the fraction of households reporting zero income from assets also show up in the $25^{\text {th }}-50^{\text {th }}$ percentile, in the $50^{\text {th }}-75^{\text {th }}$ percentile, and in the $75^{\text {th }}$ through the $90^{\text {th }}$ percentile. In the $25^{\text {th }}-50^{\text {th }}$ percentile, the fraction of households reporting zero income from assets goes from about $80 \%$ using the conventional survey format to between 40 and $50 \%$ using the revised format The fraction reporting zero goes from over $50 \%$ in the conventional mode to about $12 \%$ in the revised mode in the $50^{\text {th }}-75^{\text {th }}$ percentile, while going from about a third in 1992 and 1994 to around $5 \%$ in 1996,1998 and 2000 in the $75^{\text {th }}-90^{\text {th }}$ percentile.

Tables $3 \mathrm{a}, 3 \mathrm{~b}$ and $3 \mathrm{c}$ contain a more detailed picture of the change in income from financial assets and in asset holdings over the five survey years and over the percentile 
distribution of financial asset holdings. The pattern of the data in these tables is very consistent. In Table 3a, which has mean income from financial asset holdings by percentiles of financial asset holdings, the full sample means in 1992 and 1994 are roughly $50 \%$ of the means in 1996,1998 or 2000 . This across year mean difference stems largely from differences among households whose financial asset holdings are in the $75^{\text {th }}$ percentile or higher. For example, in the $90^{\text {th }}-100^{\text {th }}$ percentile, mean asset income is about $\$ 8,000$ in 1992 and 1994 , but about $\$ 18,000, \$ 22,000$ and $\$ 23,000$ in 1996,1998 and 2000 , respectively - roughly a three-fold increase. In contrast, in the $50^{\text {th }}-75^{\text {th }}$ percentile, the 1996, 1998 and 2000 data look to be about the same size as the 1992 data, all of which are higher than the 1994 mean.

Table $3 \mathrm{~b}$ contains mean financial asset holdings across asset holding percentile groups. No pattern difference is evident between the 1992-1994 data and the 1996-19982000 data. By year, the mean grows substantially, as one would expect during a period of economic prosperity with substantial capital gains. In the $50^{\text {th }}-74^{\text {th }}$ percentile, the mean grows from roughly $\$ 15,000$ to slightly over $\$ 22,500$ - a $50 \%$ increase over the eightyear period. In the $90^{\text {th }}+$ percentile group, the mean grows from around $\$ 300,000$ in 1992 to about $\$ 650,000$ in 2000 - roughly a two-fold increase. Thus the pattern that one would expect in the absence of any survey innovation is exactly what one finds in Table $3 \mathrm{~b}$. Mean financial asset holdings grows steadily and substantially over the 1992 to 2000 period with no indication that the growth rate is affected by the transition from conventional survey methods to the revised method. Generally speaking, the growth rates over the entire period tend to average about $9 \%$ per year with growth being larger in the higher percentiles than in the lower ones. 
The effect of the revised survey format conditioned on asset holdings is presented in Table $3 \mathrm{c}$ which provides the mean of the average rate of return to financial assets, defined as the ratio of financial asset income to financial assets. Note that this is a mean of individual rates rather then the ratio of the means from Tables $3 a$ and $3 b$. The mean average rate of return over all households increases by roughly $50 \%$ from the conventional format to the revised format. This pattern can be seen across the asset groups as well. For households with financial assets above the $90^{\text {th }}$ percentiles, the mean of the average rate of return jumps from 3.3\% and $2.4 \%$ in 1992 and 1994, respectively, to $4.6 \%$ in 1996 after which it stays relatively constant. As evident from Table 3c as well as Table 3a, the asset income data from 1994 seems to be particularly anomalous. One could also argue that the mean average rates of return in 1996 seem to be anomalously above the values in 1998 and 2000. This possibility is considered in more detail below.

The data displayed in Tables 1, 2 and 3 make it clear that time-series analysis of the effect of income change on various types of behavior would be greatly aided if the income component that reflected the return on financial assets could be adjusted to ensure consistency. The problem is that all datasets using the conventional HRS survey design (asking about a long set of income components, including dividends and interest income) will seriously underestimate income flows from financial assets and hence overstate the change across the conventional and revised survey years.

There are at least two potentially important ways in which biased measurement error is introduced into reported financial income from 1992 and 1994 - error in reporting having any asset income, and error in reporting the value of asset income conditional on having any at all. As indicated in Table 2, a striking features of the quality enhancement in measuring income from capital is that the merged question sequence converts the 
proportion of respondents who report zero asset income from $71 \%$ in Wave 2 to $38 \%$ in Wave 3. Even more striking is that the merged module converts the proportion of households with financial assets above the $90^{\text {th }}$ percentile who reported zero interest or dividend income from $36 \%$ in Wave 2 to $2.3 \%$ in Wave 3 . Thus, one possibility could be that the bias in reported financial income is generated solely by households who actually have but report no asset income. This would imply no bias among households who reported asset income and thus require the imputation of only those households who report owning assets but no asset income. If we limit comparisons to households reporting some asset income in each year we might find the same degree of time series consistency that we find in the level of asset holdings from Table $3 \mathrm{~b}$. If that were true, we could focus on devices for imputing values to households that reported owning financial assets with no asset income in Waves 1 and 2 based on relationships observed in wave 3 .

To examine this hypothesis, Table 4 reproduces Table $3 \mathrm{c}$ for households who report positive income from financial assets. Among all households, the mean average rate of return for 1992 and 1994 seems much more in line with those from the later waves. However, this masks some remaining time series inconsistencies across the financial asset distribution. The average rate of return for households with financial assets above the $90^{\text {th }}$ percentile, households with by far the most asset income on average (Table 3a), remains roughly 40\% lower in 1992 and 1994 than in 1996, 1998 or 2000. Thus, while the elimination of households who report no asset income alleviates some of the time series inconsistency, it fails to do so for the most relevant households, i.e. households with significant asset income. This is strong evidence against the hypothesis that the only survey induced bias is among households reporting no asset income. The 
existence of survey structure induced bias appears to be present both in households reporting positive asset income as well as in those reporting zero asset income.

\section{Imputation Strategy}

The average rates of return reported in Table $3 c$ are not only evidence of the measurement error in asset income from Waves 1 and 2 of the HRS, but also suggest a possible solution to correcting the problem. As noted above, there is a high degree of consistency in financial wealth across all waves in the HRS. The time series consistency is a product of the fact that the survey instrument did not change over the years. Furthermore, the use of a follow-up sequence of unfolding bracket questions for respondents reporting 'don't know' or 'refuse' in the collection of asset and liability data, combined with random imputation within brackets, greatly minimizes any bias in the measurement of financial wealth. The result is that, while the time series consistency of financial asset income is clearly suspect, the reliability of measured financial wealth is strong. ${ }^{1}$ It is thus possible to use the rates of return computed for the 1996 data to assign a rate of return to households in 1992 and 1994. These rates of return can then be combined with the financial wealth data for those households to impute a reliable measure of financial asset income.

To implement this strategy, a number of issues must first be resolved. The first issue involves specifying which households should be assigned a new rate of return. Throughout, we restrict attention to those households who report owning some financial assets. While this neglects households who may have owned financial assets at some point over the survey year but sold them prior to the survey date these cases are likely to be rare and we see no simple way of handling them. We consider two strategies for

\footnotetext{
${ }^{1}$ Note that unfolding brackets were implemented in the collection of asset income in all waves except Wave 1. This makes the reliability of asset income in Wave 1 even more suspect.
} 
imputing financial asset income to households with positive financial assets. As suggested above, one strategy (A) would be to assign a new rate of return only to those who report no asset income. However, this does nothing about the survey induced bias for households who do report asset income. An alternative strategy (B) would be to impute a rate of return to all households including those that report asset income. This completely replaces the asset income from Waves 1 and 2 with imputed data. Strategies (A) and (B) represent two extremes. We present results from both.

The second issue is what rate of return to assign each household. The simplest imputation method is to assign the mean or median rate of return from Wave 3 households to households in Waves 1 and 2 using either strategy (A) or (B). However, this has at least one serious drawback. Assigning the same rate of return eliminates all heterogeneity in the rate of return. The average rate of return to financial wealth is a product of portfolio choice across different asset groups (equities, bonds, checking and saving) as well as the choice and performance of the chosen individual assets within each asset group. Assigning the mean rate of return neglects this important individual choice variation. A better approach is to assume that individual choice regarding portfolio selection remains relatively constant and to apply each individual household's financial asset income rate of return in Wave 3 to the financial assets held in Wave 1 and 2. This is problematic for households that have financial assets in Wave 1 or 2 but do not in Wave 3. To impute a rate of return to these households while still maintaining the empirical heterogeneity of the donor distribution, a rate of return is randomly drawn (with replacement) from the donor distribution for each household. This is the approach we take. For strategies (A) and (B), all households being imputed receive a randomly drawn rate of return. A third strategy $(\mathrm{C})$ is to impute a rate of return to all households as in (B) 
but use the household's actual rate of return from Wave 3 if one is available and randomly impute if no Wave 3 rate of return is available.

The implementation of a random imputation procedure raises the issue of what donor distribution to use. The imputation procedure used to impute missing values for assets and liabilities relies on the donor distribution from the bracket in which the respondent claims their asset value resides. ${ }^{2}$ No such information is available regarding the rate of return to financial assets. One approach is to use the entire rate of return distribution from Wave 3. However, this is problematic for several reasons. Foremost is the fact that along with actual rates of return, the zero's must be included in the donor distribution since households reporting zero asset income in Waves 1 and 2 are a large source of the bias that needs to be corrected. The probability of having zero asset income is larger for households with small amounts of financial wealth since this wealth is less likely to have large fractions of high yielding assets such as equities and bonds. Furthermore, the result of classical measurement error is greatly magnified for low financial wealth households since these values are in the denominator of the variable of interest, i.e. the average rate of return. Imputing a high rate of return to a large asset value would grossly overestimate the true asset income value. Finally, one could make a behavioral argument that households with higher levels of financial wealth are more likely to have portfolios dominated by equities and bonds, both of which have higher yields than checking and savings accounts. For these reasons and for the fact that reliable financial wealth data is observable in all waves of the data, donor distributions of the rate of return are computed for various financial wealth groups and applied to the same groups in the data to be imputed. The asset groups considered in this paper are the first

\footnotetext{
${ }^{2}$ The number of households refusing to not knowing the bracket information is surprisingly low. See Juster and Smith (1997) for more details.
} 
three quartiles of financial wealth along with the $75^{\text {th }}$ to $90^{\text {th }}$ and $90^{\text {th }}$ and above percentile groups. ${ }^{3}$ As a result of the donor distributions varying by asset level, strategy (C) only uses the household's actual Wave 3 rate of return if its asset value in Wave 1 or 2 falls in the same asset group as Wave 3 .

The fourth issue that needs to be considered is the treatment of outliers. Although our results rest on the assumption that the reported financial wealth from all waves and asset income values from Waves 3 and later are unbiased, classical measurement error is still a problem. These errors yield unrealistic rates of return in Wave 3 which could, in turn, get imputed to households in Waves 1 and 2. The standard treatment of outliers in empirical work is to trim. In the present case, this would entail dropping some values from the top of each financial asset group's donor distribution. However, by trimming the donor distribution, the result will yield yet another time series inconsistency since the donor data have not been trimmed in any such way. Since the goal is to achieve time series consistency, we make no attempt to treat outliers and thereby keep them in the donor distributions. An alternative which we also consider is to trim the donor distributions and apply them for the imputation of not only Waves 1 and 2 but also the dropped outliers of Waves 3 and later.

The final issue is robustness. As noted in the introduction, a crucial assumption for the validity of the imputation procedure is that the rate of return distribution, within financial asset groups, is the same over time. This may not be true for several reasons. First, there have been changes in the way in which certain assets pay out income. For instance, there has been a trend for equities to pay out less in dividends in favor of capital gains. This suggests a shift downward in the rate of return distribution. Second,

\footnotetext{
${ }^{3}$ Note that these donor groups require that households with no financial wealth in the donor wave be dropped since it is not possible to compute a rate of return.
} 
households could be changing the way in which they allocate their financial wealth among assets. The increased household participation in financial markets over the past decade suggests a shift up in the rate of return distribution. Conversely, if this increase has been the result more of a shift from bonds to equities than from checking and savings accounts to either bonds or equities, then this would imply a shift downward in rates of return. Finally, the past decade has experienced tremendous growth. Although most of this has been reflected in large capital gains, returns to capital in all forms has increased suggesting higher rates of return. The net effect of these phenomena is ambiguous. While it seems most plausible to use the donor distribution from data collected nearest the collection date of the data requiring imputation, i.e. Wave 3 data, robustness is verified by applying the same imputations using donor data from Waves 4 and 5 of the HRS.

An outline of the imputation strategies and procedures considered in this paper are provided in Figure 1. We now turn to the results of implementing these procedures.

\section{Imputation Results}

The imputation procedures used in this paper rely heavily on the distribution of the rate of return in 1996. The central assumption is that the rate of return distributions for Wave 1 and 2 of the HRS are biased downward while the Wave 3 distribution, although not free of measurement error, has no such bias. The rate of return distribution for Waves 1, 2 and 3 are provided in Table $5 \mathrm{a}, 5 \mathrm{~b}$ and $5 \mathrm{c}$, respectively. These rates are computed only for households who have financial assets. However, it is important to note that there are many households who have a zero average rate of return.

The survey induced bias is clear by comparing the Wave 3 distribution with that of Wave1 and 2. The median rate of return for all households in 1996 is $2.4 \%$. This value is zero for households in 1992 and 1994. Moving up the rate of return distribution, the 
bias remains. The average rate of return in 1996 is $5.7 \%$ at the $75^{\text {th }}$ percentile while only being 3.3\% and 1.5\% in 1992 and 1994, respectively. Not surprisingly, average rates at a given percentile are smaller for lower values of financial assets. This is largely a result of the fact that the number of households with zero asset income increases. Households with small amounts of financial assets are more likely to have a portfolio that yields little to no asset income. For households in the lowest asset group, the median rate of return is zero in all years of the survey. Nevertheless, the pattern of the bias is consistent. The median rate of return for households with financial assets in the $50^{\text {th }}$ to $75^{\text {th }}$ percentile is $3.1 \%$ in 1996. In 1992 and 1994, this value remains at zero.

The importance of stratifying by financial assets is also made clear by Table 5 . The distributions vary quite substantially by asset group within each year. As noted, this is largely influenced by households with zero asset income. This is the dominant effect in the distributions across financial asset levels up through the $75^{\text {th }}$ rate of return percentile. However, by the $90^{\text {th }}$ percentile of the average rate of return, classical measurement error in the denominator is seen to dominate. Financial assets are unlikely to yield estimates of income flows in the neighborhood of $25 \%$ or more, and the cases that fall into these categories are almost certainly ones in which there is a very small amount of assets combined with a moderate amount of income flow, resulting in an extremely high estimate of the rate of return. If one were to look at the details of the cases falling into the $25 \%$ or more rate of return category, one would find a great many cases where the average rate of return amounted to several hundred percent or even several thousand percent - cases where asset holdings were reported to be a small number like $\$ 10$, and income flows reported to be a moderate amount like $\$ 500$ or $\$ 1000$. In general, errors that take the form of incorrect recording of the number of zeros are quite likely to result 
in extremely high rate of return estimates. In 1996 , the $90^{\text {th }}$ percentile of households in the lowest asset group is $20 \%$. This is more than twice as large as the $90^{\text {th }}$ percentile for households in the top asset group. The rate of return triples for the lowest group at the $95^{\text {th }}$ percentile while only increasing by less than $50 \%$ for the highest asset group. Clearly, imputing a $60 \%$ rate of return to households with large levels of financial assets would lead to gross outliers in imputed asset income. These large differences in the empirical rate of return distribution across financial assets make it crucial that the random imputations stratify on financial assets.

The main results of this paper are found in Table 6 . This table reports mean financial asset income by financial asset group using each of the three imputation strategies outlined in Figure 1. The un-imputed means are reported in the first row of each data year from Table $3 a$ for the purposes of comparison. The imputation method for these values is labeled as 'None'. Recall that Strategy (A) randomly imputes a rate of return only to households who report positive financial assets and zero income from those assets. The effect on the mean across all households is substantial. Financial asset income increases by $36 \%$ in 1992 from $\$ 1,876$ to $\$ 2,543$. The effect is even larger for the 1994 data. Imputation strategy (A) increases reported asset income in 1994 by $76 \%$ from $\$ 1,481$ to $\$ 2,600$. Not surprisingly, the largest gains from the imputation in both 1992 and 1994 go to those with the most financial asset wealth. However, the proportionate increase is roughly the same for households with financial assets above the $25^{\text {th }}$ percentile - between 70 and $90 \%$.

The third row of each data year in Table 6 reports the results of implementing Strategy (B). All households with positive financial assets are randomly imputed an average rate of return within financial asset groups. This argument for Strategy (B) over 
Strategy (A) rests on the results from Table 4 which indicated a bias in the mean average rate of return time series even among households who reported some financial income. Given our priors that the survey induced bias acts to reduce reported asset income, it is not surprising that the implementation of Strategy (B) increases mean financial asset income from that of Strategy (A). However, the results are not that different for the mean across all households. Mean financial asset income is only increased an additional 3.5\% in 1992 from $\$ 2,543$ under Strategy (A) to $\$ 2,633$ under Strategy (B). The 15\% increase in 1996 is slightly larger.

The dominant effect of the imputations on the overall mean appears to be a result of imputing an average rate of return to households who report zero asset income. However, as in Table 4, the overall means mask large differences across the financial wealth distribution. The largest difference between Strategy (A) and (B) is evident for households with financial wealth above the $90^{\text {th }}$ percentile. For both 1992 and 1994 , mean imputed asset income for high wealth households is $31 \%$ larger under strategy (B). Clearly, the survey induced bias not only increases the number of households reporting zero asset income but also significantly reduces the amount of reported asset income. It is interesting to note however, that while the imputations under Strategy (B) increase mean income by 9\% in 1994 over Strategy (A) for households with financial wealth in the $75^{\text {th }}$ to $90^{\text {th }}$ percentile, the procedure actually reduces the mean in 1992 . Of course, both strategies increase the mean from the value with no imputations.

Strategies (A) and (B) reflect two extremes in the way measurement error enters reported asset income over the five waves of the HRS. While (A) assumes a reporting error only among households that report no asset income and leaves reports of positive asset income unchanged, (B) assumes reported asset income of all households is 
contaminated. While Strategy (C) is closer to (B) in that it imputes asset income for all households (with positive financial assets), it uses each particular households rate of return from 1996 under the assumption that this rate of return reflects the portfolio allocation behavior of the household. The household's 1996 rate of return is used only if they have asset income in both 1996 and the imputation year and if the levels of financial wealth in both years are in the same asset group. Otherwise, the method of random imputation within asset groups is used. Within each asset group, roughly $50 \%$ of the cases under Strategy (C) utilize the households' own 1996 rate of return to impute an asset income value in either 1992 or 1994.

The results from implementing Strategy (C) are reported in the fourth row of each data year in Table 6. Relative to the increase from the original data, there is little difference between any of the strategies in the overall means of imputed financial asset income. The imputation strategies increase the mean by roughly 35-50\% in 1992 and by 75-100\% in 1994. Within asset groups, Strategy (B) and (C) are more similar with each other than with Strategy (A). The higher the level of financial wealth, the more the results for Strategy (A) differ from Strategies (B) and (C). Given the presumed theoretical advantages of using the within household portfolio allocation information along with the relatively stability between Strategies (B) and (C), Strategy (C) is the imputation procedure of choice.

The goal of the exercise in this paper is to create time series consistency in the values of reported financial asset income. The biennial overall mean change in the original data over the eight-year period is $-21 \%, 115 \%, 17 \%$ and $7.6 \%$, respectively between 1992 and 2000. The seam problem between 1994 and 1996 is glaring. In addition, the large fall in asset income between 1992 and 1994 also seems anomalous. 
Focusing on Strategy (C), the biennial overall mean change of the imputed data between 1992 and 2000 is $2.6 \%, 7.7 \%, 17 \%$ and $7.6 \%$. This general upward trend is much more consistent with the upward trend in financial assets than is the original data.

The results presented in Table 6 rely on random imputations using the 1996 distribution as the donor distribution. To verify the robustness of these results, the same imputation strategies are re-done using either the 1998 data or 2000 data as the donor distribution. These results are found in Table 7. The table reports the percentage difference using the 1998 or 2000 donor distribution from the respective value using the 1996 donor distribution. Differences in the means across all households are small for strategy (A) and (B) but are on the order of 10 to $18 \%$ in 1992. The differences are trivial in 1994 for the overall mean. The differences become larger for lower asset levels. This is to be expected as the base values become smaller. Overall the imputation results appear quite robust to the donor distribution. Nevertheless, using the imputations based on the 1996 distribution seems most advisable since it is the year closest to the years being imputed.

Finally, it is over a broader macroeconomic interest to examine the time series of financial asset income net of the effects of outliers. Outliers are handled by dropping the top five percent of the donor distributions used in the random imputations. To maintain time series consistency, outliers that are trimmed also get imputed using the donor distribution from the respective year. The results of this exercise are reported in Table 8 . Mean financial asset income across all households under Strategies (A) and (B) appear less consistent than under Strategy (C). The mean under Stategy (B) in 1992 is $\$ 2,080$ and then increases by $2.3 \%, 42.9 \%, 10.3 \%$ and $2.4 \%$ biennially over the following eight years. The seam problem still seems apparent between the 1994 to 1996 survey years. 
Using individual household rate of return information in Strategy $(\mathrm{C})$, mean income in 1992 is $\$ 2,177$ and then rises by $9.1 \%$ to $\$ 2,376$ in 1994 and then by an additional $10.3 \%$ to $\$ 2,584$ in 1996 . There is much more heterogeneity across the financial wealth distribution but the conclusion seems to be same: the seam problem introduced by the new survey technology in 1996 is eliminated most effectively in the imputed and cleaned data under Strategy (C).

\section{Conclusion}

In this paper we note the substantial effects of asking survey respondents about asset income in a merged asset/income module in which the income question sequences directly followed after the asset sequences rather than being asked in a separate income module. The inability of many surveys to ascertain accurate asset income data is certainly a product of this phenomenon. We go on to note that the improvements made by correcting this survey flaw do not come without a cost. This cost is a substantial seam problem between the years in which the survey technology is improved. In an attempt to improve cross-year consistency in the financial asset income series of the Health and Retirement Survey, we propose a number of imputation strategies that take advantage of the fact that cross-year consistency is maintained in the levels of financial assets.

Using various schemes to impute an average rate of return to households in 1992 and 1994, we are able to establish a time series of financial asset income with similar consistency to that of financial wealth. The strategy that yields the best results is one which combines a household's own portfolio allocation information from later waves of the data with random imputation of rates of return within various financial asset groups where the donor distributions come from the 1996 survey year. These results are notably robust to replacing the 1996 donor distribution with that of either the 1998 or 2000 
survey years. A version of this imputation procedure that also accounts for gross outliers in the average rate of return yields a time series of financial asset income that is consistent with macroeconomic trends.

Future work will include correcting the income from privately owned business farms and real estate. Income from these two assets shares the same time series inconsistency as the financial asset income examined in this paper since it was also asked in a separate model from the value of the assets. The bias in business, farm and real estate asset returns is more difficult to correct since the rates of return are far more idiosyncratic than they are for financial wealth. Nonetheless, once these issues are adequately resolved, a superiod measure of total household income will be made available.

Until then, the results presented here should be a warning to surveyors that respondents provide far more accurate measures of financial asset income when preceded by questions regarding the assets which generate that income.

\section{Reference List}

Hurd, Michael F., Juster, Thomas, Smith, James P., "Ehancing the Quality of Data on Income: Recent Innovations from the HRS." RAND Working Paper, 2001.

Juster, Thomas F., Lupton, Joseph P., Smith, James P., Stafford, Frank P., "The Decline in Household Saving and the Wealth Effect." University of Michigan Working Paper, May 1999.

Juster, Thomas F., Smith, James P., "Improving the Quality of Economic Data: Lessons from HRS and AHEAD." Journal of the American Statistical Association, 1997, 92 (440), 1268-1278. 
Table 1: HRS Financial Income and Asset Ownership Across Waves: Percent Reporting Income from Financial Assets

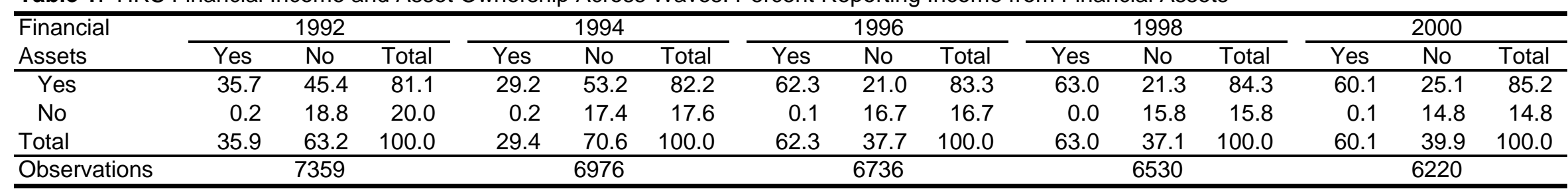


Table 2: Percent Reporting Zero Income from Assets by Asset Percentiles

\begin{tabular}{ccccccc}
\hline \multirow{2}{*}{ Year } & \multicolumn{5}{c}{ Percentile Group of Financial Assets } & All \\
\cline { 2 - 5 } & {$[0-25 \%)$} & {$[25-50 \%)$} & {$[50-75 \%)$} & {$[75-90 \%)$} & {$[90-100 \%]$} & Households \\
\hline 1992 & 98.0 & 79.1 & 51.5 & 32.0 & 26.2 & 63.2 \\
1994 & 97.7 & 81.9 & 61.1 & 47.6 & 36.3 & 70.6 \\
1996 & 93.7 & 42.5 & 11.1 & 5.2 & 4.5 & 37.7 \\
1998 & 92.8 & 43.7 & 10.8 & 5.8 & 1.3 & 37.1 \\
2000 & 92.9 & 45.7 & 16.3 & 6.7 & 2.3 & 39.9 \\
\hline
\end{tabular}


Table 3a: Mean Income from Financial Assets by Percentiles of Financial Asset Holdings (1996 Dollars)

\begin{tabular}{rcccccc}
\hline \multirow{2}{*}{ Year } & \multicolumn{5}{c}{ Financial Asset Percentile } & \multirow{2}{*}{ All Households } \\
\cline { 2 - 5 } & {$[0-25 \%)$} & {$[25-50 \%)$} & {$[50-75 \%)$} & {$[75-90 \%)$} & {$[90-100 \%]$} & \\
\hline 1992 & 25 & 360 & 1,081 & 2,882 & 8,776 & 1,876 \\
1994 & 16 & 311 & 706 & 1,883 & 7,683 & 1,481 \\
1996 & 11 & 143 & 1,070 & 4,680 & 18,451 & 3,190 \\
1998 & 6 & 163 & 1,057 & 4,643 & 22,545 & 3,740 \\
2000 & 31 & 284 & 1,015 & 4,889 & 23,307 & 4,024 \\
\hline
\end{tabular}

Table 3b: Mean Financial Asset Holdings in Dollars by Percentiles of Financial Asset Holdings (1996 Dollars)

\begin{tabular}{rcccccc}
\hline \multirow{2}{*}{ Year } & \multicolumn{5}{c}{ Financial Asset Percentile } & \multirow{2}{*}{ All Households } \\
\cline { 2 - 5 } & {$[0-25 \%)$} & {$[25-50 \%)$} & {$[50-75 \%)$} & {$[75-90 \%)$} & {$[90-100 \%]$} & \\
\hline 1992 & 13 & 1,960 & 14,723 & 62,493 & 318,749 & 51,197 \\
1994 & 34 & 2,793 & 19,047 & 71,070 & 369,886 & 60,887 \\
1996 & 41 & 2,479 & 19,335 & 80,113 & 454,030 & 70,656 \\
1998 & 30 & 2,190 & 18,909 & 85,009 & 589,991 & 88,957 \\
2000 & 54 & 2,674 & 22,550 & 100,480 & 649,099 & 100,539 \\
\hline
\end{tabular}

Table 3c: Mean Average Rate of Return by Percentiles of Financial Asset Holdings (Percent)

\begin{tabular}{ccccccc}
\hline \multirow{2}{*}{ Year } & \multicolumn{5}{c}{ Financial Asset Percentile } & \multirow{2}{*}{ All Households } \\
\cline { 2 - 6 } & {$[0-25 \%)$} & {$[25-50 \%)$} & {$[50-75 \%)$} & {$[75-90 \%)$} & {$[90-100 \%]$} & 3.7 \\
1992 & 1.3 & 3.3 & 4.7 & 4.1 & 3.3 & 2.3 \\
1994 & 0.6 & 2.3 & 2.7 & 2.4 & 2.7 & 5.0 \\
1996 & 3.9 & 5.0 & 5.2 & 5.8 & 4.6 & 4.6 \\
1998 & 3.0 & 5.0 & 5.0 & 4.6 & 4.5 & 4.2 \\
2000 & 2.8 & 4.5 & 4.3 & 4.6 & 4.1 & \\
\hline
\end{tabular}

Note: Table 3c presents the mean of individual average rates of return, defined as the ratio of financial asset income to financial assets. This requires all households with no financial wealth to be dropped from the sample. In addition, ratios above one are trimmed in the calculation. This drops roughly one percent of the sample in each year with most coming from the first quartile (about $3 \%$ dropped in the first quartile). 
Table 4: Mean Average Rate of Return by Percentiles of Financial Asset Holdings,

Only Households with Positive Asset Income (Percent)

\begin{tabular}{ccccccc}
\hline \multirow{2}{*}{ Year } & \multicolumn{7}{c}{ Financial Asset Percentile } & \multirow{2}{*}{ All Households } \\
\cline { 2 - 6 } & {$[0-25 \%)$} & {$[25-50 \%)$} & {$[50-75 \%)$} & {$[75-90 \%)$} & {$[90-100 \%]$} & 3.2 \\
1992 & 14.5 & 9.0 & 6.0 & 4.8 & 3.3 & 6.4 \\
1994 & 11.3 & 6.0 & 4.4 & 5.1 & 4.6 & 6.6 \\
1996 & 9.4 & 5.9 & 6.0 & 5.8 & 4.6 & 6.3 \\
1998 & 9.6 & 5.9 & 5.2 & 4.8 & 4.3 & 5.8 \\
2000 & 8.6 & 5.3 & 4.9 & 4.6 & \\
\hline
\end{tabular}

Note: Table 4 presents the mean of individual average rates of return, defined as the ratio of financial asset income to financial assets.

This requires all households with no financial wealth to be dropped from the sample. 
Table 5a: Distribution of Rate of Return to Financial Assets (Percent), HRS Wave I (1992)

\begin{tabular}{ccccccc}
\hline \multirow{2}{*}{ Precentile } & \multicolumn{5}{c}{ Financial Asset Percentile } & All \\
\cline { 2 - 6 } & {$[0-25 \%)$} & {$[25-50 \%)$} & {$[50-75 \%)$} & {$[75-90 \%)$} & {$[90-100 \%]$} & Households \\
\hline 5th & 0.0 & 0.0 & 0.0 & 0.0 & 0.0 & 0.0 \\
10th & 0.0 & 0.0 & 0.0 & 0.0 & 0.0 & 0.0 \\
25th & 0.0 & 0.0 & 0.0 & 0.0 & 0.0 & 0.0 \\
50th & 0.0 & 0.0 & 0.8 & 1.6 & 1.7 & 0.0 \\
75th & 0.0 & 1.7 & 4.7 & 5.0 & 4.5 & 3.3 \\
90th & 2.6 & 10.8 & 13.9 & 10.0 & 7.4 & 10.0 \\
95th & 44.4 & 35.7 & 25.0 & 16.3 & 10.0 & 23.1 \\
\hline
\end{tabular}

Table 5b: Distribution of Rate of Return to Financial Assets (Percent), HRS Wave II (1994)

\begin{tabular}{ccccccc}
\hline \multirow{2}{*}{ Precentile } & \multicolumn{5}{c}{ Financial Asset Percentile } & All \\
\cline { 2 - 5 } & {$[0-25 \%)$} & {$[25-50 \%)$} & {$[50-75 \%)$} & {$[75-90 \%)$} & {$[90-100 \%]$} & Households \\
\hline 5th & 0.0 & 0.0 & 0.0 & 0.0 & 0.0 & 0.0 \\
10th & 0.0 & 0.0 & 0.0 & 0.0 & 0.0 & 0.0 \\
25th & 0.0 & 0.0 & 0.0 & 0.0 & 0.0 & 0.0 \\
50th & 0.0 & 0.0 & 0.0 & 0.4 & 0.8 & 0.0 \\
75th & 0.0 & 0.8 & 2.4 & 2.5 & 2.9 & 1.5 \\
90th & 0.0 & 8.0 & 7.1 & 5.7 & 5.7 & 5.8 \\
95th & 10.0 & 16.3 & 12.5 & 8.8 & 8.9 & 12.0 \\
\hline
\end{tabular}

Table 5c: Distribution of Rate of Return to Financial Assets (Percent), HRS Wave III (1996)

\begin{tabular}{ccccccc}
\hline \multirow{2}{*}{ Precentile } & \multicolumn{5}{c}{ Financial Asset Percentile } & \multicolumn{2}{c}{ All } \\
\cline { 2 - 6 } & {$[0-25 \%)$} & {$[25-50 \%)$} & {$[50-75 \%)$} & {$[75-90 \%)$} & {$[90-100 \%]$} & Households \\
\hline 5th & 0.0 & 0.0 & 0.0 & 0.0 & 0.1 & 0.0 \\
10th & 0.0 & 0.0 & 0.0 & 0.6 & 0.4 & 0.0 \\
25th & 0.0 & 0.1 & 1.0 & 2.0 & 1.8 & 0.0 \\
50th & 0.0 & 1.8 & 3.1 & 4.0 & 3.6 & 2.4 \\
75th & 3.0 & 5.3 & 6.2 & 6.2 & 6.0 & 5.7 \\
90th & 20.0 & 12.9 & 12.0 & 11.9 & 9.8 & 12.1 \\
95th & 60.0 & 21.8 & 17.0 & 16.9 & 14.1 & 21.5 \\
\hline
\end{tabular}


Table 6: Mean Income from Financial Assets by Imputation Method (1996 dollars)

\begin{tabular}{|c|c|c|c|c|c|c|c|}
\hline \multirow{2}{*}{$\begin{array}{l}\text { Data } \\
\text { Year }\end{array}$} & \multirow{2}{*}{$\begin{array}{c}\text { Imputation } \\
\text { Method }\end{array}$} & \multicolumn{5}{|c|}{ Financial Asset Percentile } & \multirow{2}{*}{$\begin{array}{c}\text { All } \\
\text { Households }\end{array}$} \\
\hline & & {$[0-25 \%)$} & {$[25-50 \%)$} & {$[50-75 \%)$} & {$[75-90 \%)$} & [90-100\%] & \\
\hline \multirow{4}{*}{1992} & None & 25 & 360 & 1,081 & 2,882 & 8,776 & 1,876 \\
\hline & (A) & 11 & 565 & 1,446 & 4,011 & 11,675 & 2,543 \\
\hline & (B) & 2 & 272 & 734 & 3,745 & 15,306 & 2,633 \\
\hline & (C) & 19 & 202 & 958 & 4,443 & 18,901 & 2,886 \\
\hline \multirow{4}{*}{1994} & None & 16 & 311 & 706 & 1,883 & 7,683 & 1,481 \\
\hline & $(\mathrm{A})$ & 11 & 524 & 1,293 & 3,622 & 12,960 & 2,600 \\
\hline & (B) & 4 & 252 & 996 & 3,976 & 17,010 & 2,984 \\
\hline & (C) & 6 & 240 & 993 & 3,693 & 17,256 & 2,961 \\
\hline 1996 & None & 11 & 143 & 1,070 & 4,680 & 18,451 & 3,190 \\
\hline 1998 & None & 6 & 163 & 1,057 & 4,643 & 22,545 & 3,740 \\
\hline 2000 & None & 31 & 284 & 1,015 & 4,889 & 23,307 & 4,024 \\
\hline
\end{tabular}


Table 7: Alternative Donor Distributions, Percent Difference from Results Using 1996 Donor Distribution

\begin{tabular}{|c|c|c|c|c|c|c|c|c|}
\hline \multirow[b]{2}{*}{$\begin{array}{l}\text { Data } \\
\text { Year }\end{array}$} & \multirow[b]{2}{*}{$\begin{array}{c}\text { Baseline } \\
\text { Distribution }\end{array}$} & \multirow[b]{2}{*}{$\begin{array}{c}\text { Imputation } \\
\text { Method }\end{array}$} & \multicolumn{5}{|c|}{ Financial Asset Percentile } & \multirow{2}{*}{$\begin{array}{c}\text { All } \\
\text { Households }\end{array}$} \\
\hline & & & {$[0-25 \%)$} & {$[25-50 \%)$} & {$[50-75 \%)$} & {$[75-90 \%)$} & [90-100\%] & \\
\hline \multirow{6}{*}{1992} & \multirow{3}{*}{1998} & (A) & 9.1 & 14.3 & -1.0 & 7.3 & 2.3 & 5.3 \\
\hline & & (B) & 50.0 & 38.2 & -4.1 & 25.5 & -6.7 & 2.3 \\
\hline & & (C) & 5.3 & -30.7 & 7.5 & 20.4 & 19.8 & 18.0 \\
\hline & \multirow{3}{*}{2000} & $(\mathrm{~A})$ & -81.8 & -12.0 & 2.8 & 6.7 & 2.8 & 2.9 \\
\hline & & (B) & -450.0 & -6.6 & 5.7 & 14.5 & -2.9 & 1.8 \\
\hline & & (C) & -31.6 & -260.9 & 5.5 & 19.1 & 15.5 & 10.8 \\
\hline \multirow{6}{*}{1994} & \multirow{3}{*}{1998} & (A) & 18.2 & 16.4 & 2.9 & 5.9 & -1.7 & 1.7 \\
\hline & & (B) & 25.0 & 31.0 & 2.4 & 16.8 & -16.8 & -6.4 \\
\hline & & (C) & 50.0 & 29.2 & -2.4 & 9.7 & -1.5 & 1.4 \\
\hline & \multirow{3}{*}{2000} & $(\mathrm{~A})$ & -336.4 & -28.1 & 4.9 & 5.9 & 0.5 & 0.7 \\
\hline & & (B) & -925.0 & -60.3 & 11.0 & 12.6 & -3.4 & 0.1 \\
\hline & & (C) & -66.7 & -94.6 & 13.2 & 1.5 & -3.2 & -2.6 \\
\hline
\end{tabular}


Table 8: Mean Income from Financial Assets by Imputation Method, Imputed Outliers (1996 dollars)

\begin{tabular}{cccccccc}
\hline \multirow{2}{*}{$\begin{array}{c}\text { Data } \\
\text { Year }\end{array}$} & $\begin{array}{c}\text { Imputation } \\
\text { Method }\end{array}$ & {$[0-25 \%)$} & {$[25-50 \%)$} & {$[50-75 \%)$} & {$[75-90 \%)$} & All \\
\cline { 3 - 7 } & {$[90-100 \%]$} & Households \\
\multirow{2}{*}{1992} & (A), trim & 6 & 135 & 802 & 3,114 & 10,855 & 1,811 \\
& (B), trim & 5 & 110 & 742 & 3,176 & 13,642 & 2,080 \\
& (C), trim & 4 & 112 & 755 & 3,273 & 14,419 & 2,177 \\
\hline \multirow{2}{*}{1994} & (A), trim & 2 & 115 & 763 & 2,685 & 9,614 & 1,808 \\
& (B), trim & 2 & 94 & 742 & 3,215 & 11,681 & 2,128 \\
& (C), trim & 2 & 98 & 775 & 3,056 & 13,967 & 2,376 \\
\hline \multirow{2}{*}{1996} & trim & 1 & 84 & 769 & 3,455 & 15,732 & 2,584 \\
1998 & trim & 0 & 67 & 706 & 3,206 & 17,996 & 2,850 \\
2000 & trim & 1 & 72 & 666 & 3,611 & 17,805 & 2,917 \\
\hline
\end{tabular}




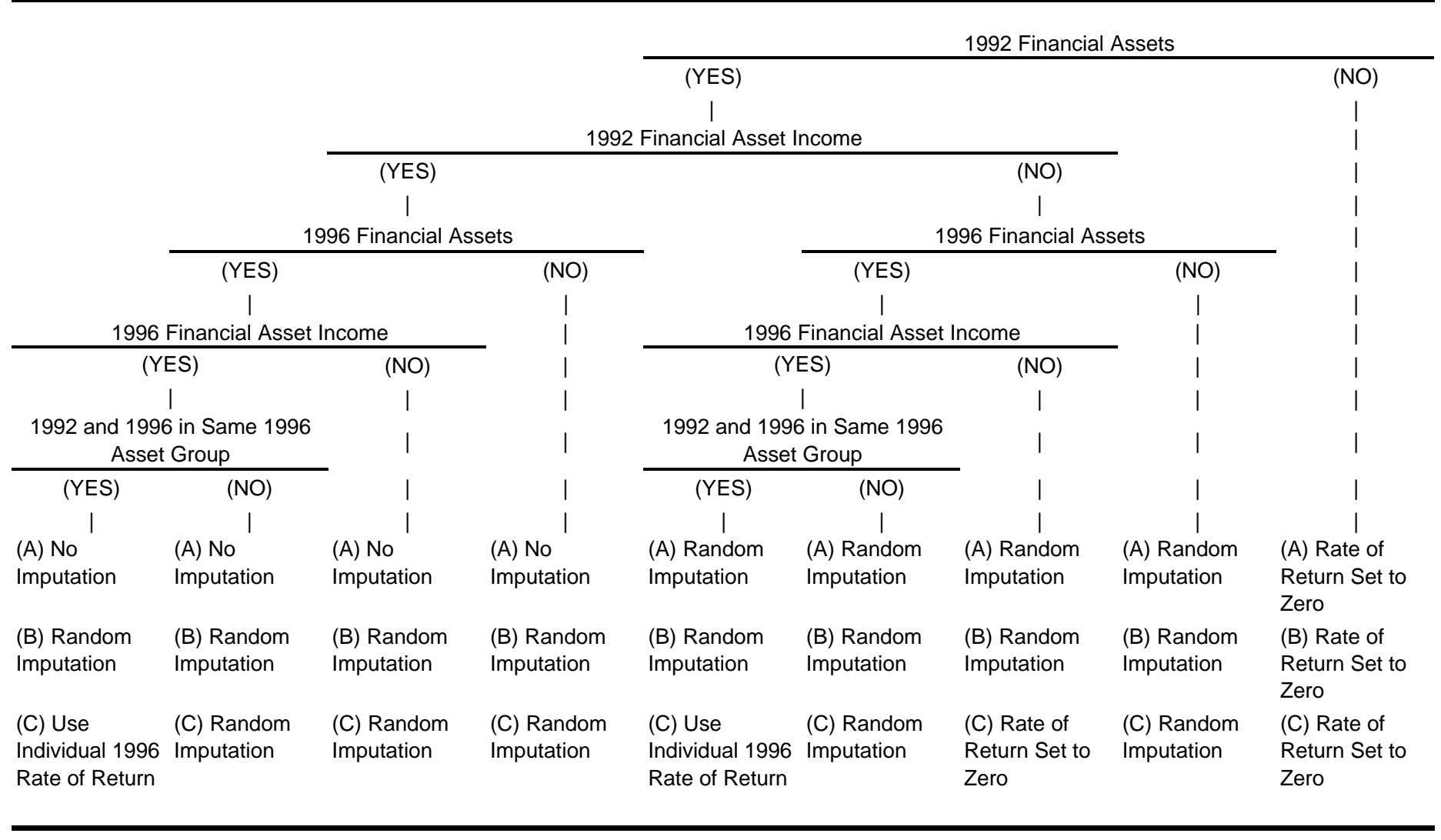




\section{APPENDIX C}


In the Journal of Human Resources Summer 2003; 38(3): 758-72

\section{ENHANCING THE QUALITY OF DATA ON INCOME: RECENT INNOVATIONS FROM THE HRS}

Michael Hurd, F. Thomas Juster and James P. Smith

Hurd and Smith are Senior Economists at RAND and Juster is a Research Scientist, Survey Research Center, University of Michigan. We would like to thank Tim Marshall, Greg Weyland, and Charles Nelson of the Department of Labor for their excellent help and cooperation in using the Current Population Survey files. Iva Maclennan and David Rumpel provided superb programming assistance. The research was supported by grants from the National Institute on Aging to RAND and by funds provided by the Survey Research Center at Michigan. 


\section{Introduction}

There has been concern about the reliability of survey estimates of income and wealth ever since such measures began to be collected systematically in the 1940s and 1950s (Sudman and Bradburn (1974); Radner (1982)). Obtaining accurate and unbiased household wealth measures has been problematic due to the reluctance of the extremely wealthy to participate in social science surveys at all, and the widespread prevalence of item non-response to wealth questions in particular. Ironically, using new survey innovations, there has been considerably greater progress in mitigating problems for wealth measurement than for income. For example, given the extreme skew in wealth distributions, the bias resulting from the substantially higher non-response rates among very wealthy households has been dealt with in the various Surveys of Consumer Finances conducted since 1983 by the use of special sampling frames (such as tax files) that over-sample the super-wealthy. Similarly, the growing use of unfolding bracket techniques to handle missing data problems have resulted in reduced measurement error and lower bias due to non-ignorable item non-response to wealth questions (Juster and Smith (1997)). To date, no parallel progress has been documented for income measurement.

In this paper, we attempt to remedy this situation by evaluating two survey innovations aimed at improving income measurement. These innovations are (1) integrating the question sequences for income and wealth which may elicit more accurate estimates of income from capital than has been true in the past, and (2) changes in the periodicity over which income flows are measured, which may provide a closer match between what the survey respondent knows best and the periodicity contained in survey measurement. These innovations have been introduced into both the Health and Retirement Study (HRS) and the study of Asset and Health 
Dynamics Among the Oldest Old (AHEAD). Based on the results reported in this paper, the potential return in quality of income measurement from these innovations is substantial.

The paper is organized as follows. In the next section, we document the extent of income under-reporting in household surveys and discuss the data on which this research will rely. In Section II, we investigate the implications of integrating questions about income from capital with questions about household wealth. Section III explores the implications of changes in the reference period for certain types of income flows.

\section{Section 1: Data Sources and Bias in Income Reporting}

Questions about income rank among the most difficult to answer in household surveys (Sudman and Bradburn (1974); Coder and Scoon-Rogers (1995)). Besides any reluctance respondents may have in revealing information they consider private and sensitive, significant cognitive issues exist that may make it difficult for respondents to accurately report their incomes. Especially when asked about the incomes of other family members, their knowledge about the actual income amounts may be quite limited. Some incomes are received on an irregular basis so that accuracy of reports may depend on how soon after the last receipt the survey questions are asked. Similarly, the dollar amounts involved may be variable from period to period, or taxes and other expenses may or may not be deducted. Finally, respondents may be asked to report their incomes over a time span that is different than how their incomes are received or remembered. These factors may result both in a significant bias (typically underreporting) or in mis-reporting or random measurement error.

Table 1 gives some indication about the extent of income under-reporting by comparing Current Population Survey (CPS) estimates of various types of income relative to external 
benchmark estimates according to CPS validation studies. Across all income sources, CPS income reports are 89 percent of the benchmark indicating an 11 percent under-report on average. However, there exists considerable variation around that average. There is little bias in CPS wage and salary incomes which are 98 percent of the benchmark. Social Security Income contains more bias (95 percent of the benchmark), but appears to be less understated than the other major source of retirement incomeCprivate pensions. But private pensions may be a case where the benchmark is too high since it includes lump sum withdrawals and rollovers to other accounts such as IRAs and Keoghs. Excluding such lump sum payments places the CPS pension income at about 84 percent of the benchmark (Woods (1996); Schieber (1995)). By far, the most severe under-reporting occurs in interest and dividends, where CPS reports are about half the external benchmarks. Even when these income sources are reported without bias, there remains the problem of substantial measurement error in reports of amounts (Ferber (1966), Moore, Stinson, and Welniak (1997)).

Our research will rely on data from three well known surveysCthe Health and Retirement Survey (HRS), the Asset and Health Dynamics of the Oldest Old (AHEAD), and the Current Population Surveys (CPS). HRS is a national sample of about 7,600 households $(12,654$ individuals) with at least one person in the household born between 1931 and 1941 (51-61 years old at the interview date). At baseline, an in-home, face-to-face interview of some 90 minutes was conducted starting in the spring of 1992 and extending into early 1993. Given its focus on the pre-retirement years, the principal objective of HRS is to monitor economic transitions in work, income, and wealth, as well as changes in many dimensions of health status.

AHEAD has 6,052 households (8,204 individuals) from the birth cohorts of 1923 or 
before, thus with at least one person aged 70 or over in 1993. The baseline AHEAD interview was done in 1993 using computer-assisted telephone techniques for respondents 70-79 and computer-assisted in-person interviews for those aged 80 and over. Given its older age span, AHEAD's objectives shift toward the relationship between economic status and changes in physical and cognitive health in old age, the maintenance of independent living arrangements, and dis-savings and asset decline. ${ }^{1}$

HRS and AHEAD are both longitudinal surveys with data collected every other year. Both surveys obtained extensive information about the economic situation of the households, including a complete accounting of assets stock and income flows. In addition to housing equity (with separate detail for the first and second home), assets were separated into the following categories in HRS and AHEAD: other real estate; vehicles; business equity; IRAs or Keoghs; stocks or mutual funds; checking, savings, or money market accounts; CD's, government savings bonds, or treasury bills; other bonds; trusts and estates; other assets; and other debt. Similarly, separate questions were asked in both surveys about a long list of income sources for both the respondent and spouse: wages and salaries, self-employment income, tips and bonuses, unemployment compensation, workers= compensation, Social Security income, supplemental security income, private pension income, welfare, disability income, veterans benefit or military pension. In addition, questions were asked at the household level about rental income, income from business, interest and dividends, annuities, and food stamps.

There are two specific enhancements implemented in HRS and AHEAD aimed at improving the quality of income measurementCthe integration of income from asset questions with questions about the assets from which such income is derived, and the use of periodicity 
questions that for certain income sources more closely reflect the frequency with which such income is received. We discuss these enhancements in detail below. HRS and AHEAD income and asset modules are given to the $>$ knowledgeable financial respondent $=\mathrm{C}$ the eligible respondent most knowledgeable about the household=s financial situation. Especially in AHEAD, proxy respondents are occasionally used if the financial respondent is not physically able to respond or suffers from severe cognitive problems. Because the integration of asset and income questions took place between the second and third waves of HRS and the first and second waves of AHEAD, across-wave comparisons of reports of income from capital provide a convenient way of evaluating the impact of this integration. Since AHEAD did not vary the periodicity of income reporting, on that issue we must turn to another survey for a comparison.

The Current Population Surveys (CPS) are the most widely used source to monitor labor force and income changes by year in the United States, and thus represent a useful standard of comparison to HRS and AHEAD. CPS conducts interviews each month with the number of households interviewed varying from 47,000 to 57,000 households during the 1990s (Current Population Reports). CPS households are interviewed for four successive months, are not interviewed for the next eight months, and then are interviewed once again for four successive months. Annual incomes from many sources are obtained during the March interview. Consequently, although CPS is normally not thought of as a panel, approximately half the respondents are interviewed across two adjacent March interviews.

Since no questions are asked about the value of household assets, the CPS cannot be used to evaluate the merit of integrating asset and income questions. However, CPS does ask questions about a long list of income sources using varying reporting periodicities. CPS income 
sources include wages and salaries, self-employment income, tips and bonuses, unemployment compensation, workers = compensation, Social Security income, supplemental security income, private pension income, welfare, veterans benefit or military pension. In addition, questions were asked at the household level about rental income, income from business, interest and dividends, annuities, and food stamps. CPS questionnaires are typically answered by one household member who may or may not be the most knowledgeable about its financial affairs.

\section{The Measurement of Income from Assets}

Table 1 indicated that the most serious under-reporting of income takes place in measures of income from capital. Some of this under-reporting no doubt stems from the positive skew in ownership of assets from which these income flows derive, but we will demonstrate here that this is far from the whole story. One enhancement implemented in HRS and AHEAD involves the measurement of income from assets. How do the better social science surveys typically attempt to measure income from assets? As in CPS, toward the end of the income sequence, there is likely to be a series of questions asked in close proximity to each other about rental income, interest and dividend income, and income from ownership of a business or farm. There are either no survey questions about the underlying assets that yield the income, or questions about those assets appear in a different part of the survey module (the wealth module). ${ }^{2}$ Therefore, the normal feature of economic modules in surveys is that all the asset questions are strung together in one section, and all the income questions are strung together in another section. The fact that the assets and the income are closely related is not exploited as a way to enhance data quality by jogging the respondent=s memory.

The cleanest case is interest and dividend income, since the underlying sources of the 
Hurd, Juster, and Smith 7

income flowsCholdings of common stock, bonds, CDs, checking and savings accounts, money market funds, etc.Care more likely to be reliably reported by the household than the income generated from these assets. But a comparison of the fraction of households who report holding an asset and the fraction who report receiving any interest or dividend income from that asset strongly suggests that survey estimates of income from assets are badly underestimated. In the typical survey, the fraction of households reporting interest or dividend income is much smaller than the percentage reporting ownership of assets that might yield an interest or dividend income flow. To illustrate, 75 percent of HRS wave 2 households report holding some financial assets, but less than 30 percent report having any interest or dividend income.

In light of this gross inconsistency in income and asset reports, we revised in the third wave of HRS and the second wave of AHEAD the way income questions were asked. Essentially, we created a Amerged@ asset and income module in which questions about particular types of assets were followed immediately by questions about income from that asset. The key to this entire sequence is the way in which income-yielding assets are handled. The standard question sequence we developed asked first about ownership of the asset; for those households reporting ownership we then asked about the value of the assets; we next asked whether any income was received from the asset and, if so, about the periodicity and whether or not about the same amount was received every period. For households reporting ownership, value, some income, and a monthly periodicity, with about the same amount received every month, the idea was to calculate last year=s income from the periodic amount and the periodicity. For households reporting that the amount received every period wasn=t always the same, we branched to a question about the amount of income received from the asset in the prior 
calendar year. This question sequence was used for the four types of financial assets included on HRS and AHEAD (checking, savings, and money market accounts; CDs, savings bonds and Treasury Bills; stocks; and bonds), as well as for real estate investment equity and business and farm equity.

Comparisons of results from this new way of asking about income from assets (used in HRS 3 and AHEAD 2) with estimates of income from assets produced by the conventional survey methodology (as reflected by HRS 2 and AHEAD 1) show dramatic differences in income amounts reported. Table 2 highlights the impact by listing mean income and the value of asset holdings by source in HRS 2 and 3 and AHEAD 1 and 2. The effects of the integration are quite dramatic. Between HRS 2 and HRS 3, income from these financial assets, real estate investments, and business and farm equity combined increased from $\$ 5,669$ a year to $\$ 9,266$ a year. Some of this increase in income may be due to the growing asset values common to the 1990s, but this can explain only a small part of the increase. While the value of assets goes up by about 14 percent between HRS 2 and 3, income from assets increased by 63 percent. While the integration of asset and income questions affected all income sources, the impact was largest in income amounts from the four financial assets (a greater than two-fold increase), and smallest in income from business and farm (a 32 percent increase). Following the integration of the asset and income questions, capital income increases of an even larger magnitude (over $\$ 8$ thousand compared to about 3.5 thousand) appear between AHEAD 1 and 2.

The failure to report interest or dividend income using the conventional survey format, while in an absolute sense related to the size of asset holdings, appears to apply throughout the full range of asset holdings. Table 3 provides the relevant data for HRS 2 and 3, dividing the 
Hurd, Juster, and Smith 9

sample into asset categories ranging from none to more than a quarter of a million, and then subdividing income into categories starting with none and going up to $\$ 25,000$ or more. Examine first the relationship between asset holdings and income flows for the sum of the four financial assets contained in the surveys. Ninety percent plus of households in HRS 2 who report a small amount of financial assets (\$1-\$2499) also report zero interest or dividend income. In contrast, 63 percent of HRS 3 households in the same asset group report zero interest or dividend income.

But the most dramatic results occurs among those with a great deal of these assets. For example, 31 percent of HRS 2 households who had more than $\$ 250,000$ of financial assets still reported that they received no income at all from these assets. That result is not plausible and indicates that without tying the income questions to the presence and amount of the asset there is a substantial understatement of the prevalence and level of income from assets. The integration of the asset and income question resulted in a substantial decrease in the inconsistency between asset and income reports. In HRS 3 among those with more than $\$ 250,000$ in these financial assets, only 3 percent did not report any income from this source.

Similar but less dramatic results show up in analysis of the value of real estate holdings compared to reports of rental income, and the value of owned businesses or farms compared to income from those businesses or farms. Of those reporting more than $\$ 250,000$ in investment real estate holdings, 52 percent reported zero rental income in HRS 2 compared to 28 percent in HRS 3. Among those with more than one-quarter million dollars in farm or business assets, 58 percent reported no income in HRS 2 while only 21 percent did so in HRS 3.

It is not surprising if people with a few dollars of interest or dividend income report that 
they had zero interest and dividend income. It is quite surprising that many people with more than a quarter of a million dollars of financial asset holdings report zero interest or dividend income when the question is asked in the conventional format relative to what they report when the question is asked in the merged format. We believe that the better quality income reports are obtained with the merged format as a respondent has just been asked to think about the existence and size of asset holdings. This merged format makes it difficult to report zero income having just reported substantial asset holdings. Whatever the explanation, the merged income/asset format produces a dramatic improvement in the reporting of income flows from assets.

There are also some income distribution consequences to the enhanced reporting of income from capital. This income tends to be held by wealthier households so that underreporting of income may simultaneously understate the extent of income inequality in the population. This issue is examined in Table 4 which stratifies households into quintiles by the amount of their total household income in HRS1, and within each quintile, lists the amount of total capital income reported in HRS 2 and HRS3. While HRS 3 numbers indicate that much more capital income is reported in the aggregate, the increased reporting of income from capital had very little impact on those households in the bottom fifth of the income distribution whose income declined relative to incomes in all other quintiles. In contrast, those households in the top quintile registered an increase in capital income of over $\$ 7000$ between HRS2 and HRS3. In general, the size of the increase in capital income between waves 2 and 3 grew across income quintiles. This pattern implies that the absolute income gap of the well-to-do relative to the poor is understated by conventional survey methods of obtaining household income.

\section{The Effect of Income Periodicity}


The second survey innovation we evaluate concerns the time span or periodicity over which income is reported. For simplicity, many surveys have respondents report all income sources in the same periodicity even though periodicity and regularity of payments may vary a great deal by source. Yet, especially for income sources which are not variable, respondents may know and answer best if the question refers to the time interval at which they normally and most recently receive that income. (Tourangeau, Rips, and Rasinki (2000)). When respondents are requested to report in a periodicity different than that of usual receipt, we may be asking them to perform quickly some difficult cognitive and computation tasks. The value of a specific periodicity may be highest for income flows that tend to continue indefinitely, to change slowly (perhaps due a COLA adjustment), and to arrive with uniform periodicity (typically a month).

Given these specifications, the most likely income flows to gain from alternative periodicities may be income sources generally received by older and retired households. The most common source in this category is Social Security benefits, which are received monthly, are adjusted annually for Cost of Living changes, do not have taxes withheld, and involve withholding only to the extent that respondents select Medicare Part B as an option (more than 90 percent do). In this case, asking the amount of last month=s Social Security check may produce better estimates of Social Security income than asking, as is the usual case, for Social Security benefits paid during the most recent calendar year. Thus, it seems better to estimate Social Security benefits by asking about last month=s Social Security check, multiplying it by twelve for respondents who began to receive Social Security payments prior to the beginning of the most recent calendar year (and multiplying it by the appropriate number of months for households who began to receive payments sometime during the prior calendar year). 
SinceCat least for sub-populations of recipientsCthe $>$ truth $=$ is known, Social Security may also represent the ideal income source to gauge respondents = ability to report their income accurately. By age 70 when there are no earnings tests or Social Security disability income, Social Security income is fixed legislatively by a formula that depends on the history of past earnings and on family composition. If there are no changes in family composition due to divorce, separation, or death, Social Security income is only revised across calender years by a universal Cost of Living Adjustment (COLA) first given in the January check each year. To eliminate such demographic reasons for changes in Social Security income, we restricted our AHEAD sample to households where both respondents were at least 70 years old in the first wave and where no marital status changes or deaths occurred between the first and second wave. We also required both respondents to have received some Social Security income in each wave so that there is no ambiguity that we are dealing with program beneficiaries. Finally, cases were deleted when Social Security income was imputed in either wave of the panel.

Given these sample restrictions, Social Security income in our remaining sample should only change due to a COLA. To compare reports of Social Security income across successive waves, we adjusted the wave one report by any COLA that would have taken place given the month and year of interviews. Between waves, most (86.5 percent) AHEAD respondents had two COLA adjustments, but 8.4 percent had only one while 5.1 percent had three. If all respondent reports were completely accurate, these adjusted wave one and actual wave two reports of Social Security income would be identical. Differences between them therefore reflect reporting error.

The first column in Table 5 displays percentile distributions of arithmetic differences in 
wave one Social Security income (adjusted for subsequent $\mathrm{COLA}=\mathrm{s}$ ) and wave two Social Security income. While respondents report monthly incomes, for comparison with other surveys, we list differences on an annual basis for the year 1995. The specific year chosen does not affect the results. The median difference in Social Security income is smallcthe COLA adjusted wave 1 report is $\$ 57$ higher per year greater than the wave 2 report of Social Security income. Half of respondents give reports that are no more than $\$ 200$ apart, 80 percent give reports within roughly $\$ 800$ of each other, and 90 percent lie no more than $\$ 1,500$ (or 23 percent) apart. Reporting errors appear to be symmetric so that each wave is equally likely to be higher than the other.

Are these AHEAD income reporting errors large or small? The answer depends on the context in which the data are used. For cross-sectional analyses since mean Social Security incomes were about $\$ 9600$ in 1995, Table 5 indicates that AHEAD reporting errors are nine percent or more for one in five respondents. But for analysis relying on the panel nature of the data (within person changes in Social Security income, the problem is far more serious. To illustrate, all within person variation in Social Security income in our sample in Table 5 represents measurement error by construction.

Another way to answer this question is to compare AHEAD income reports to those obtained from other prominent surveys that rely on different methodologies to obtain data on income. The Current Population Surveys (CPS) provide such a comparison. During the 1990s, CPS made several revisions in the way it asks income questions, including Social Security income. Before 1994, CPS respondents were asked to report Social Security income for the last calender year. Starting in 1994, respondents first selected the periodicity (monthly, quarterly, or annual) in which they wanted to report and then gave a dollar amount for this periodicity. There 
is a clear preference for a monthly interval for Social Security income. For example, in 1996, 77 percent of CPS respondents selected monthly as the easiest way of reporting Social Security income while 23 percent selected yearly. No matter which periodicity was chosen, the income still referred to the last calender year. For example, if the respondent chose monthly, they were asked to give their monthly income during an average month last year. CPS staff would then convert all incomes to an annual basis which is the way income is available on public use tapes.

We matched respondents across two successive March panels for 1992 and 1993 (when CPS asked for annual Social Security income) and 1996 and 1997 when the new CPS reporting system had been in place for a while. Individuals were matched based on their sex, race, age, education, and line number. Matches had to be exact on sex, race, and line number and no more than two years apart in age and at most one year of schooling apart. We then imposed the same sample deletions used in the AHEAD sample. That is, we retained only cases in which each respondent (and spouse) were at least 70 years old in the first March survey, no deaths or marital changes occurred between March interviews, Social Security incomes were not imputed in either interview, and there was a positive report of Social Security income in both March interviews.

The second and third columns in Table 5 list percentile differences in Social Security income from the second March CPS interview minus the COLA adjusted Social Security income from the previous March CPS. Once again, the median difference was smallcless than 50 dollars a year. However, differences in CPS reports of Social Security income are considerably larger than those in AHEAD. For example, the $90^{\text {th }}$ and $10^{\text {th }}$ percentiles in the CPS were about plus and minus $\$ 1,900$ compared to approximately $\$ 800$ in AHEAD. Alternatively, roughly one fifth of CPS respondents had measurement errors in their Social Security incomes of 20 percent or more. 
Hurd, Juster, and Smith 15

In general, reporting errors appear to be about twice as large in CPS as in AHEAD. Moreover, the size of these CPS reporting errors seem to be about the same when the new reporting methodology of March of 1996 and 1997 is used as when the old CPS annual income methodology was used in March of 1992 and 1993. Apparently, these revised CPS methods did not lead to any overall improvement in the quality of income reports for Social Security income.

Why then are the quality of AHEAD reports on Social Security income apparently superior to those obtained in CPS? Several factors could produce these differences. In particular, CPS does not necessarily interview the most $>$ knowledgeable financial respondent,$=$ a problem that may be compounded by interviewing someone else other than the older person or his/her spouse. However, when we restricted our analysis to single person households (where there were no options about whom to interview), we found that reporting errors were still about twice as large in CPS as in AHEAD. A more likely explanation is that CPS respondents do not report in the form in which they received their most recent checkCa monthly check which excludes the deduction of the Medicare Part B premium.

To see this, the penultimate column in Table 5 lists differences in CPS Social Security income among those reporting in a monthly interval in both 1996 and 1997. CPS errors in Social Security incomes are much smaller when consistent monthly units reporting is employed. In fact, more than 60 percent of the difference between CPS and AHEAD reporting errors is explained by the use of a monthly interval. The final column in Table 5 indicates some additional quality improvement is obtained by limiting CPS respondents to those reporting in a monthly interval and after Medicare premium deductions in both 1996 and 1997. Much of the remaining difference with AHEAD is likely a consequence of the fact that, even using monthly intervals, 
CPS is asking respondents to perform the more difficult computational task of calculating what they received in an average month last year while AHEAD is simply asking them to remember the last check. Requiring those respondents who said they found it easier to report in an yearly interval to report monthly instead is likely to result in improved reports as the preference for yearly reporting has little conviction behind it. Even among respondents who reported in a yearly interval in 1996, two-thirds of them reported in a monthly interval one year later. ${ }^{3}$

\section{Conclusion}

Although under-reporting of income is often thought to be a problem for those at the bottom of the economic strata, the results presented in this paper indicate that at least for some sources of income it is more of a problem for those at the top of the heap. These income sources include income from financial assets, rental income from property, and income from business. These income sources are understated by a factor of two in conventional household surveys. Fortunately, this appears to be a problem with a solution at handCintegration of asset and income modules in surveys. Such an integration was introduced into the third wave of the Health and Retirement Survey and second wave of AHEAD. The net result was an almost doubling of these income components as well as a much more consistent reporting by households of their income and their assets.

Can the benefits of this innovation carry over to other surveys? The merged income/asset module will work best for surveys like PSID, NLS and SIPP which are designed to collect information about asset holdings and about income flows and which have about the same number of asset categories as HRS. But the merged module may work less well in studies like the SCF, which has very detailed asset holdings (roughly 100 categories in all) so that a merger 
of the income and asset modules is impractical.

The interesting case involves surveys like CPS that do not currently obtain data on asset holdings in part because data on assets are thought to be sensitive (thereby encouraging refusals) and also to take too much survey time to administer. To deal with these concerns, an interesting possibility is to experiment randomly with modified versions of the merged income/asset module design that may be less sensitive and less time consuming than the full HRS treatment. One idea would be to ask about the presence or absence of asset holdings, but not about amounts. If assets were present, one would next ask whether there is any income associated with those assets and the periodicity and amount of income flows. Asking simply about the presence of assets is unlikely to be as sensitive or time consuming, but may produce some of the data quality benefits of associating income flows with assets. Another possibility is to ask about asset values but only within very broad intervals. Such knowledge may be sufficient to remind respondents of the likely income amounts they receive from these assets.

Similarly, asking respondents to answer using a time interval consistent with how income is received significantly improves the quality of resports about income. This is certainly the case with Social Security, where the same amount is received many times in a regular periodicity. The same rationale may hold for many major sources of income. Pension payments are much like Social Security payments, except that some fraction of pension payments will involve tax withholding, and many pensions are not adjusted for Cost of Living changes. But question sequences that ask about tax withholding and about Cost of Living changes should handle this problem quite well. A similar situation is likely to be the case for Veterans= Benefit payments which have the same features as Social Security or Pension paymentsConce they start, they 
continue until the death of the recipient, and may continue beyond that depending on demographic circumstances 


\section{References}

Coder, John, and L. Scoon-Rogers. 1995. AEvaluating the Quality of Income Data Collected in the Annual Supplement to the March CPS and the SIPP.@ SIPP Working Paper Series No. 215. Washington, DC: U.S. Bureau of the Census.

Current Population Reports. Consumer Income. Series P-60. Washington, DC: U.S. Bureau of the Census.

Ferber, Robert. 1966. The Reliability of Consumer Reports of Financial Assets and Debts. Urbana, IL: University of Illinois Bureau of Economic and Business Research.

Juster, F.T., and J. P. Smith. 1997. AImproving the Quality of Economic Data: Lessons from HRS and AHEAD.@ Journal of the American Statistical Association 92: 1268-78.

Moore, Jeffrey, Linda Stinson, and Edward J. Welniak. 1997. AIncome Measurement Error in Surveys: A Review,@ Washington, DC: U.S. Bureau of the Census. S.M. 97/5.

Radner, D. 1982. ADistribution of Family Income: Improved Estimates.@ Social Security Bulletin. 45: 13-21.

Schieber, Sylvester J. 1995. AWhy Do Pension Benefits Seem So Small.@ Benefits Quarterly, 11(4): $57-70$.

Sudman, Sydney, and Norman Bradburn. 1974. Response Errors in Surveys. Chicago. Aldine. Tourangeau, Roger, Lance Rips, and Kenneth Rasinki. 2000. The Psychology of Survey Response. Cambridge University Press Cambridge U.K.

Woods, John R. 1996. APension Benefits Among the Aged: Conflicting Measures, Unequal Distributions.@ Social Security Bulletin,. 59( 3): 3-30. 
Table 1

CPS Income as a Percent of Independent Sources

Wages and Salaries

98.2

Social Security and Railroad Retirement

94.8

Interest

51.3

Dividends

Net Rents and Royalties

81.3

Private Pensions and Annuities

70.6

All Income

89.2

Derived from Current Population Reports Consumer Income Series P-60. Money Income of Households, Families, and Persons in the United States. Department of Commerce, Bureau of Census. Numbers produced here are averages of Volume No 180 and 184. 
Table 2

Weighted Means of Assets and Income of HRS and AHEAD

\begin{tabular}{|c|c|c|c|c|}
\hline Categories & HRS-3 & HRS-2 & AHEAD-2 & AHEAD-1 \\
\hline Asset Values, Four Financial Flows & 73,139 & 56,771 & 91,929 & 50,766 \\
\hline Income from Four Financial Flows & 3,218 & 1,502 & 6,740 & 2,991 \\
\hline Real Estate Value & 49,527 & 41,700 & 25,591 & 24,231 \\
\hline Rental Income & 2,592 & 1,564 & 1,399 & 554 \\
\hline Asset Value, Own Business or Farm & 22,064 & 28,839 & NA & NA \\
\hline Income from Own Business or Farm & 3,456 & 2,603 & NA & NA \\
\hline Total Non-housing Asset Values, \$ & 144,730 & 127,310 & 117,520 & 82,010 \\
\hline Total Income from Assets, \$ & 9,266 & 5,669 & 8,138 & 3,545 \\
\hline
\end{tabular}


Table 3

Distribution of Income from Assets

\begin{tabular}{|c|c|c|c|c|c|c|c|c|}
\hline & \multicolumn{8}{|c|}{ A. Interest or Dividend Income from Four Financial Assets } \\
\hline & Total & None & $<\$ 50$ & $\$ 50-$ & $\$ 250-$ & $\$ 1 K-$ & \$5K- & $>\$ 25 K$ \\
\hline \multicolumn{9}{|l|}{ HRS-3 } \\
\hline None & 1243 & 97.2 & 0.8 & 0.8 & 0.9 & 0.2 & 0.1 & 0.0 \\
\hline$\$ 1-2499$ & 1351 & 63.1 & 17.2 & 11.6 & 6.5 & 1.3 & 0.4 & 0.0 \\
\hline$\$ 2500$ - 9999 & 956 & 27.0 & 15.6 & 28.8 & 19.6 & 8.5 & 0.5 & 0.1 \\
\hline \$10K - 49,999 & 1520 & 10.0 & 6.8 & 17.6 & 29.8 & 32.1 & 3.6 & 0.1 \\
\hline \$50K - 249,999 & 1275 & 6.7 & 2.0 & 4.0 & 8.8 & 43.2 & 31.8 & 3.5 \\
\hline$>\$ 250 \mathrm{~K}$ & 371 & 3.0 & 0.8 & 1.1 & 1.1 & 16.7 & 48.8 & 28.6 \\
\hline Total N & 6716 & 38.2 & 7.8 & 11.4 & 12.7 & 17.9 & 9.7 & 2.3 \\
\hline \multicolumn{9}{|l|}{ HRS-2 } \\
\hline None & 1322 & 98.5 & 0.2 & 0.5 & 0.5 & 0.2 & 0.2 & 0.0 \\
\hline$\$ 1-2499$ & 1294 & 91.8 & 2.1 & 3.1 & 1.6 & 1.4 & 0.1 & 0.0 \\
\hline$\$ 2500$ - 9999 & 1123 & 76.6 & 2.0 & 8.8 & 8.5 & 3.7 & 0.5 & 0.0 \\
\hline$\$ 10 K-49,999$ & 1703 & 60.0 & 1.1 & 7.0 & 16.4 & 12.6 & 2.5 & 0.4 \\
\hline \$50K - 249,999 & 1217 & 43.1 & 0.9 & 2.6 & 10.9 & 26.9 & 14.3 & 1.2 \\
\hline$>\$ 250 \mathrm{~K}$ & 278 & 30.6 & 0.7 & 2.5 & 6.1 & 15.1 & 30.9 & 14.0 \\
\hline \multirow[t]{3}{*}{ Total N } & 6937 & 71.8 & 1.2 & 4.4 & 7.9 & 9.3 & 4.5 & 0.9 \\
\hline & \multicolumn{8}{|c|}{ B. Rental Income } \\
\hline & Total & None & $<\$ 50$ & $\$ 50-$ & $\$ 250-$ & $\$ 1 K-$ & $\$ 5 K-$ & $>\$ 25 K$ \\
\hline \multicolumn{9}{|l|}{ HRS-3 } \\
\hline None & 5153 & 99.8 & 0.0 & 0.0 & 0.0 & 0.1 & 0.1 & 0.0 \\
\hline$\$ 1$ - 2499 & 22 & 77.3 & 0.0 & 0.0 & 4.6 & 13.6 & 4.6 & 0.0 \\
\hline$\$ 2500$ - 9999 & 123 & 86.2 & 0.0 & 1.6 & 0.8 & 7.3 & 4.1 & 0.0 \\
\hline \$10K - 49,999 & 483 & 64.0 & 0.0 & 1.2 & 1.5 & 20.1 & 13.0 & 0.2 \\
\hline \$50K - 249,999 & 641 & 40.6 & 0.0 & 0.3 & 0.3 & 16.2 & 38.1 & 4.5 \\
\hline$>\$ 250 \mathrm{~K}$ & 294 & 27.9 & 0.0 & 0.3 & 1.0 & 8.5 & 29.9 & 32.3 \\
\hline Total N & 6716 & 88.1 & 0.0 & 0.2 & 0.2 & 3.7 & 6.1 & 1.9 \\
\hline \multicolumn{9}{|l|}{ HRS-2 } \\
\hline None & 5299 & 95.5 & 0.0 & 0.0 & 0.6 & 2.3 & 1.6 & 0.1 \\
\hline$\$ 1-2499$ & 50 & 88.0 & 0.0 & 0.0 & 0.0 & 8.0 & 4.0 & 0.0 \\
\hline$\$ 2500$ - 9999 & 141 & 90.8 & 0.0 & 0.7 & 2.1 & 4.3 & 2.1 & 0.0 \\
\hline \$10K - 49,999 & 539 & 73.1 & 0.0 & 0.7 & 2.4 & 13.2 & 10.2 & 0.4 \\
\hline$\$ 50 K$ - 249,999 & 666 & 51.5 & 0.0 & 0.6 & 1.8 & 15.3 & 26.4 & 4.4 \\
\hline$>\$ 250 \mathrm{~K}$ & 242 & 51.7 & 0.0 & 0.0 & 0.8 & 5.8 & 25.6 & 16.1 \\
\hline Total N & 6937 & 87.8 & 0.0 & 0.1 & 0.9 & 4.6 & 5.5 & 1.1 \\
\hline
\end{tabular}




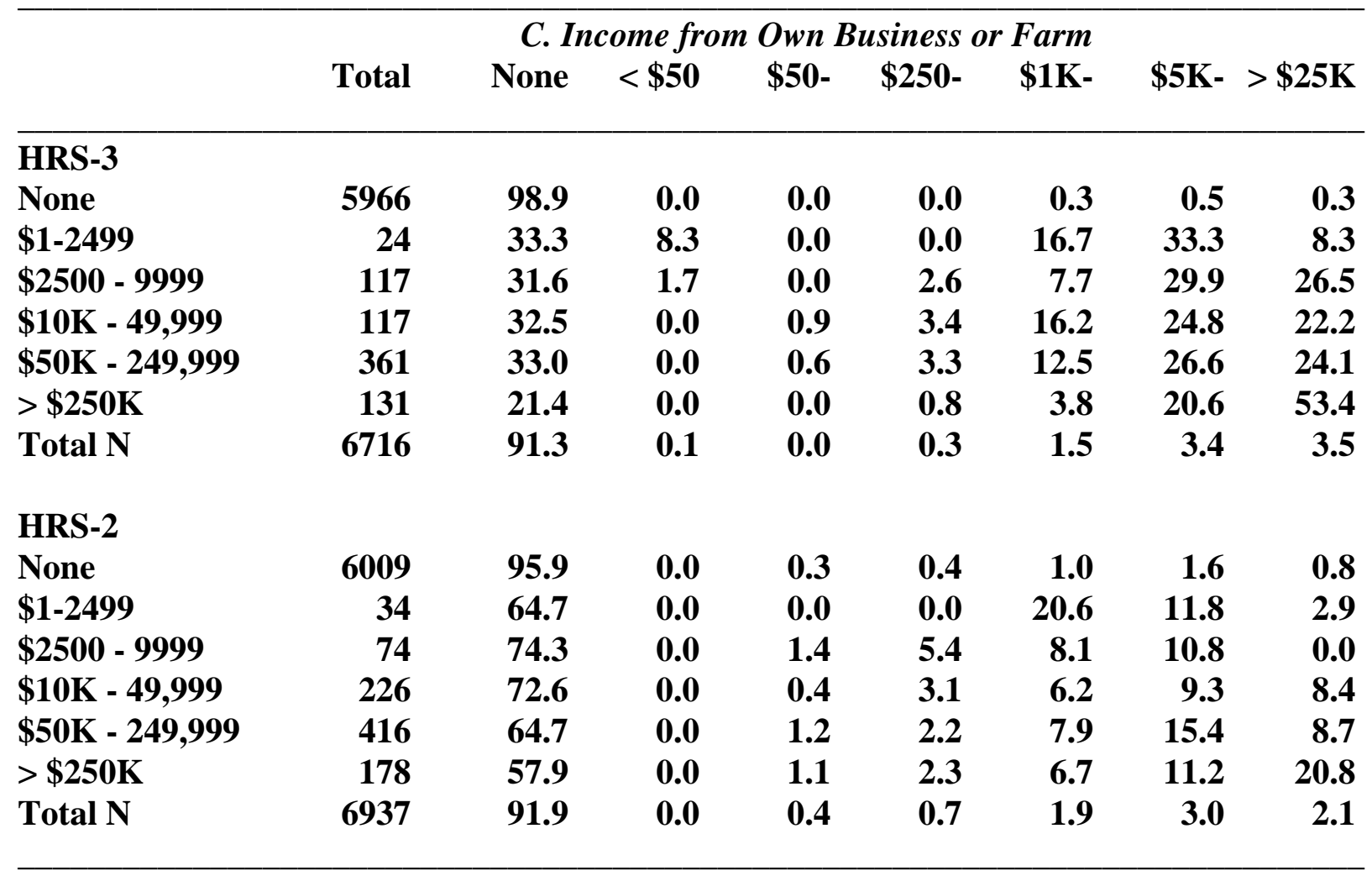


Table 4

Weighted Means of Capital Income Flows by HRS-1 Total Household Income Quintiles

HRS-1

Total Household Income

Quintile

Mean Value

HRS-2

Capital Income
Weighted Means

HRS-3 Change in

Capital Income Capital Income

\begin{tabular}{lrrrr}
\hline & & & \\
First & 9,886 & 1,652 & 2,003 & 351 \\
Second & 25,428 & 2,107 & 4,366 & 2,259 \\
Third & 40,762 & 3,571 & 5,371 & 1,800 \\
Fourth & 59,660 & 5,018 & 10,193 & 5,175 \\
Fifth & 116,397 & 16,757 & 23,956 & 7,199 \\
\end{tabular}


Table 5

Percentiles of Differences in Annual Social Security Income

\begin{tabular}{|c|c|c|c|c|c|}
\hline \multirow[b]{3}{*}{ Percentile } & \multirow{3}{*}{$\frac{\text { AHEAD }}{1994-1995}$} & \multirow{3}{*}{ 1992-1993 } & & \multicolumn{2}{|c|}{ CPS } \\
\hline & & & \multirow[b]{2}{*}{ All } & \multicolumn{2}{|c|}{ 1996-97 } \\
\hline & & & & Monthly $1^{\mathrm{a}}$ & Monthly $2^{b}$ \\
\hline 95 & 1563 & 3415 & 3799 & 2682 & 2167 \\
\hline 90 & 863 & 1965 & 1948 & 1271 & 1134 \\
\hline 75 & 208 & 545 & 435 & 301 & 256 \\
\hline 50 & -57 & 46 & -36 & -49 & -47 \\
\hline 25 & -263 & -405 & -540 & -369 & -310 \\
\hline 10 & -807 & -1973 & -1921 & -1161 & -1034 \\
\hline 5 & -1578 & -4062 & -3956 & -2499 & -2232 \\
\hline
\end{tabular}

a. Based on CPS respondents using monthly reporting intervals.

b. Based on CPS respondents using monthly reporting intervals and after Medicare deduction. 
Endnotes

1. In both surveys, African-Americans, Hispanics, and residents of Florida were over sampled at a rate of two to one. Baseline response rates were 82 percent in HRS and 81 percent in AHEAD, and each survey conducted follow-ups at approximately two- year intervals. Attrition rates for these surveys averaged about 7 percent per wave.

2. The Census and CPS are good examples of surveys without a wealth module that ask questions about income in this way. The PSID, SCFs, SIPP and the set of National Longitudinal Surveys are examples of surveys with separate wealth and income modules where the income questions are not integrated with the questions on wealth categories that generate that income.

3. A monthly reporting interval is not the only factor influencing the quality of income reports. Using a proportional error model of the absolute difference of in reports of Social Security income, the difference in reports are about 4 percent smaller when the financial respondent is answering questions about his (her) own Social Security income than when the report is about the spouse $=\mathrm{s}$ income. Similarly, the use of a proxy respondent leads to a 5 percent greater discrepancy in Social Security reports. The most troubling situationCespecially for longitudinal analysisCoccurs. In the fortunately rare case when the financial respondent changes between survey waves, the discrepancy in income reports is 25 percent. The cognitive ability of respondents is also important for the quality of income reports. For example, each remembered word in the AHEAD word count measure reduces the across wave discrepancy in Social Security income by one percent. Finally, the more important Social Security is a source of family income 
the more accurately Social Security income is reported. Individuals whose standard of living during retirement largely depends on their monthly Social Security check are more likely to remember the numbers printed on it. 
APPENDIX D 


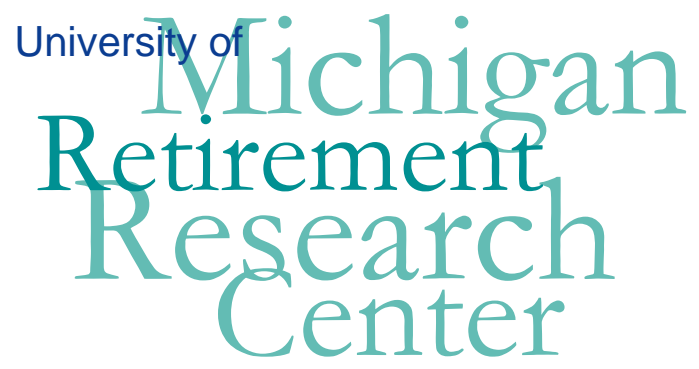

Working Paper

WP 2004-081

\section{Correcting Second Home Equity in HRS/AHEAD: the Issues, a Method, and Preliminary Results}

Honggao Cao and F. Thomas Juster

\begin{tabular}{|c|c|}
\hline $\mathrm{M}$ & $\mathrm{R}$ \\
\hline $\mathrm{R}$ & $\mathrm{C}$ \\
$\mathrm{y}$
\end{tabular}$\quad$ Project \#: UM03-Q3 


\title{
"Correcting Second Home Equity in HRS/AHEAD: The Issues, a Method, and Some Preliminary Results”
}

\author{
Honggao Cao \\ University of Michigan \\ F. Thomas Juster \\ University of Michigan
}

June 2004

\author{
Michigan Retirement Research Center \\ University of Michigan \\ P.O. Box 1248 \\ Ann Arbor, MI 48104
}

\section{Acknowledgements}

This work was supported by a grant from the Social Security Administration through the Michigan Retirement Research Center (Grant \# 10-P-98358-5). The opinions and conclusions are solely those of the authors and should not be considered as representing the opinions or policy of the Social Security Administration or any agency of the Federal Government.

\section{Regents of the University of Michigan}

David A. Brandon, Ann Arbor; Laurence B. Deitch, Bingham Farms; Olivia P. Maynard, Goodrich; Rebecca McGowan, Ann Arbor; Andrea Fischer Newman, Ann Arbor; Andrew C. Richner, Grosse Pointe Park; S. Martin Taylor, Gross Pointe Farms; Katherine E. White, Ann Arbor; Mary Sue Coleman, ex officio 


\title{
Correcting Second Home Equity in HRS/AHEAD: The Issues, a Method, and Some Preliminary Results
}

\author{
Honggao Cao and F. Thomas Juster
}

\begin{abstract}
Second home equity is an important component of both housing equity and net worth for the old population. It has been covered, implicitly or explicitly, across all waves of HRS and AHEAD surveys. But due to a skip-pattern error, not all households with second homes were asked detailed questions about current market value, amount of mortgage, etc... The negative impact of the inconsistent treatment of second home on the estimation of housing equity and net worth is substantial. When the second home information is not collected for all the households who own second homes (as in AHEAD 1995 and HRS 1996), the second home equity measure based on the partial data is likely to suffer from selection bias, rendering vulnerable both measures of total housing equity and total net worth. This paper reports on an imputation method to correct for this bias that we demonstrate and find effective.
\end{abstract}

\section{Authors’ Acknowledgements}

We thank Dan Hill for comments on an earlier version of this memo. All errors are our own. 


\section{The Issues}

Second home equity is an important component of both housing equity and net worth for the old population. It has been covered, implicitly or explicitly, across all waves of HRS and AHEAD surveys. The treatment of second home equity, however, has not been consistent. Questions regarding second home should be asked for all households who have second homes at the time of the interview. Parallel to the questions about the primary (or main) home, the question sequence about second home should be independent of the sequence about real estate investment, making second home equity distinguishable from real estate equity. HRS92, HRS94, and HRS98 and after are the only survey waves that have exactly followed these rules.

In AHEAD93, second home was explicitly treated as part of real estate investment. When asked about their real estate assets, a household was directed to include "any real estate (other than its main home), such as land, a second home, rental real estate, a partnership, or money owed to you on a land contract or mortgage" (see Question K2, AHEAD93 Codebook). In both AHEAD95 and HRS96, second home was correctly treated as independent of primary home and real estate investment. But due to a skip-pattern error, not all households with second homes were asked detailed questions about current market value, amount of mortgage, etc. Specifically, any respondents who had not lived in their second homes for at least two months of the year would not have been asked about their second home equity (see Questions CS31, CS35, and F40 for the relevant question flow in the AHEAD95 and HRS96 Codebooks). Since most people do not live in their second homes for two months or more of the year, this problem has skipped most second-home owners, and effectively past the detailed questions about value, mortgage, etc, misclassified most second home owners as not owning second homes.

The negative impact of the inconsistent treatment of second home on the estimation of housing equity and net worth is substantial. Based on results from HRS 1992, 1998, 2000, and 2002, second home equity in the aggregate accounts for more than $10 \%$ of total housing equity, more than $3 \%$ of total net worth for the HRS cohort (Table 1), and about $8 \%$ of total housing equity, about $3 \%$ of the total net worth for the AHEAD cohort (Table 2). When second home equity is combined with real estate investment (as in AHEAD 1993), there is no direct way to get an accurate measure of second home-and thus, total housing-equity. On the other hand, when the second home information is not collected for all the households who own second homes (as in AHEAD 1995 and HRS 1996), the second home equity measure based on the partial data is 
likely to suffer from selection bias, rendering vulnerable both measures of total housing equity and total net worth.

Table 1. The Role of Second Home Equity in Total Housing Equity and Total Net Worth: the HRS Cohort, HRS 1992-2002

\begin{tabular}{|l|c|c|c|c|c|c|}
\hline & $\begin{array}{l}\text { HRS } \\
\mathbf{1 9 9 2}\end{array}$ & $\begin{array}{l}\text { HRS } \\
\mathbf{1 9 9 4}\end{array}$ & $\begin{array}{l}\text { HRS } \\
\mathbf{1 9 9 6}\end{array}$ & $\begin{array}{l}\text { HRS } \\
\mathbf{1 9 9 8}\end{array}$ & $\begin{array}{l}\text { HRS } \\
\mathbf{2 0 0 0}\end{array}$ & $\begin{array}{l}\text { HRS } \\
\mathbf{2 0 0 2}\end{array}$ \\
\hline \% 2 $\mathbf{2}^{\text {nd }}$ Home Ownership & 13.9 & 13.0 & 4.0 & 13.2 & 13.1 & 13.3 \\
\hline Second Home Equity & 15,140 & 11,515 & 4,735 & 12,528 & 14,372 & 17,855 \\
\hline Primary Home Equity & 82,566 & 88,207 & 90,512 & 99,428 & 110,248 & 114,780 \\
\hline Total Housing Equity & 97,707 & 99,723 & 95,248 & 111,956 & 124,621 & 132,635 \\
\hline Total Net Worth & 274,366 & 310,365 & 319,485 & 378,375 & 418,389 & 410,450 \\
\hline $\begin{array}{l}\text { \% of 2 } 2^{\text {nd }} \text { Home Equity in } \\
\text { Total Housing Equity }\end{array}$ & 15.5 & 11.5 & 4.9 & 11.2 & 11.5 & 13.5 \\
\hline $\begin{array}{l}\text { \% of 2 } \mathbf{2}^{\text {dnd }} \text { Home Equity in } \\
\text { Total Net Worth }\end{array}$ & 5.5 & 3.7 & 1.4 & 3.3 & 3.4 & 4.3 \\
\hline
\end{tabular}

Note: Total net worth is a combination of the total housing equity and non-housing assets, which exclude "trusts not reported earlier". All the housing equity and net worth variables are weighted means in 2002 dollars. The HRS 1996 results contain obvious errors in the percentage of second home ownership and second home equity.

Table 2. The Role of Second Home Equity in Total Housing Equity and Total Net Worth: the AHEAD Cohort, AHEAD 1995-2002

\begin{tabular}{|l|l|l|l|l|l|}
\hline & $\begin{array}{l}\text { AHEAD } \\
\mathbf{1 9 9 3}\end{array}$ & $\begin{array}{l}\text { AHEAD } \\
\mathbf{1 9 9 5}\end{array}$ & $\begin{array}{l}\text { HRS } \\
\mathbf{1 9 9 8}\end{array}$ & $\begin{array}{l}\text { HRS } \\
\mathbf{2 0 0 0}\end{array}$ & $\begin{array}{l}\text { HRS } \\
\mathbf{2 0 0 2}\end{array}$ \\
\hline \% 2 $\mathbf{2}^{\text {nd }}$ Home Ownership & - & 5.0 & 7.7 & 10.8 & 10.9 \\
\hline Second Home Equity & - & 4,845 & 8,591 & 7,956 & 11,032 \\
\hline Primary Home Equity & 87,159 & 90,351 & 91,128 & 95,499 & 95,129 \\
\hline Total Housing Equity & - & 95,197 & 99,719 & 103,455 & 106,161 \\
\hline Total Net Worth & 217,933 & 307,000 & 302,214 & 312,356 & 304,137 \\
\hline $\begin{array}{l}\text { \% of 2 } \\
\text { Total Housing Equity in }\end{array}$ & - & 5.1 & 8.6 & 7.7 & 10.4 \\
\hline $\begin{array}{l}\text { \% of 2 } \\
\text { Total Not Wome Equity in }\end{array}$ & - & 1.6 & 2.8 & 2.5 & 3.6 \\
\hline
\end{tabular}

Note: Total net worth is a combination of the total housing equity and non-housing assets, which exclude "trusts not reported earlier". All the housing equity and net worth variables are weighted means in 2002 dollars. The AHEAD 1995 results contain obvious errors in second home equity. The AHEAD 1993 total net worth is apparently also flawed, an issue to be addressed elsewhere.

In this memo, we intend to correct — at least partially — the second-home data. The plan is to use the information in HRS98 as the gold standard, imputing second home equity for HRS96 
and AHEAD95 from data in later waves on ownership and data of purchase. Section II explores the cross-wave relationship in second home ownership between HRS98 and HRS96, and between HRS98 and AHEAD95. Based on these connections, Section III proposes a simple method for correcting the second-home errors in HRS96 and AHEAD95, and Section IV reports some preliminary results after the data corrections. The memo concludes with an extension of our simple correction method to the second home problem for AHEAD93, where the problem is that second-home equity is combined with real estate investment.

\section{HRS98, HRS96, and AHEAD95: Building Cross-Wave Connections}

Two facts in HRS98 about housing and assets make it feasible to correct second home equity for HRS96 and AHEAD95. First, information on the year of purchase for second home is available in HRS98. This allows one to be able to predict second home ownership in a previous wave. If a second-home-owning household reported in HRS98 that it had purchased its second home in 1994, for example, it should also have a second home in HRS96 or AHEAD95.

Conversely, if the purchase year was 1997, the household would usually have no second home in HRS96 or AHEAD95.

HRS98 also has information on housing transactions. In Section N (Widowhood and Divorce), each household was asked if it had bought or sold any home (main or second) since the last interview. While this information may not help us identify all previously mis-classified second home owners, it would help us separate a previously mis-classified second home owner from an owner who had bought his/her second home after his/her previous interview. We shall elaborate this point as we proceed.

There are four possible answers to a question whether a household owned a second home in HRS98 and/or in a previous wave, say, HRS96: it owned a second home in both waves, it owned a second home in neither waves, and it owned a second home in only one of the waves. Figure 1 depicts the four potential scenarios generated from the question.

Cell A represents all households who owned second homes in both waves. Theoretically, it includes second-home-owning households who made no housing transactions since the HRS96 interview, and households who sold and bought second homes after the HRS96 interview. The 
information on second home equity is available in both waves for these households, and this information will be the backbone in our exercise of second home equity imputation.

Figure 1. Second Home Ownership in HRS98 and HRS96:

A Theoretical Model

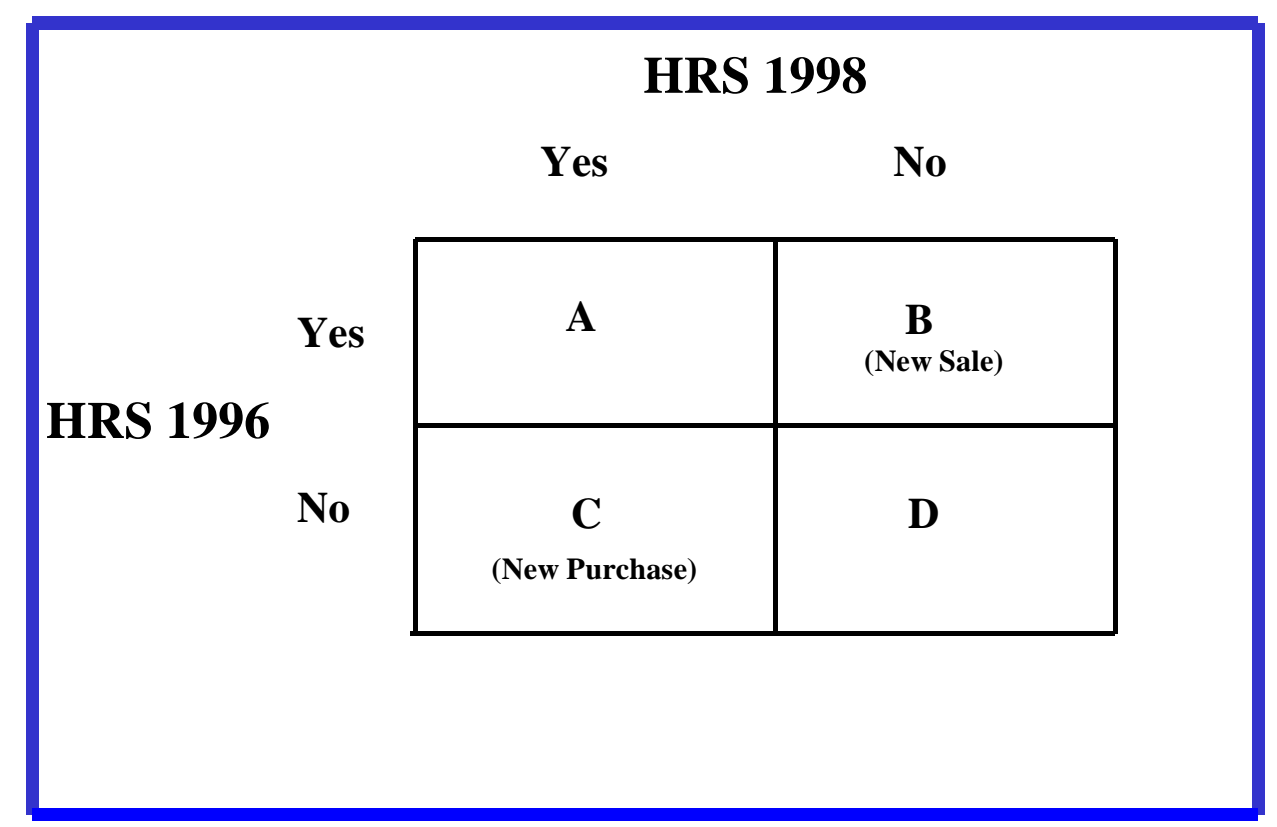

Cell D represents all households who did not own second homes in HRS98 and HRS96. For these households, second home transactions are possible, but unlikely. (They could, in principle, have both bought and sold a second home in 1997.)

Cells B and C include most of the households who made housing transactions after the HRS96 interview. A household without a second home in HRS96 would be in Cell C if it purchased one after the interview, while a household with a second home in 1996 would be in Cell B if it sold the home after the interview. Information on second home equity is available only in HRS98 for the households in Cell C, and in HRS96 for the households in Cell B.

One consequence of the inconsistent treatment of second home equity described earlier is that a great number of the households who are supposed to be in Cell A are mis-classified into Cell C, thereby reducing the percentage of households who had second homes in both waves (Cell A). As evidenced in Tables 3 and 4, the percentages of second-home owning households in 
HRS96 and AHEAD95 were, respectively, 3.4 and 4.1, both substantially lower than their counterparts in HRS98 (12.4 for the HRS96 households, and 6.9 for the AHEAD95 households).

Table 3. Second Home Ownership in HRS98 and HRS96: Empirical Results before Correction

\begin{tabular}{|c|c|c|c|c|}
\hline & \multicolumn{5}{|c|}{ HRS 1998} \\
\hline & & Yes & No & \multicolumn{1}{|c|}{ Total $(\%)$} \\
\cline { 2 - 6 } & Yes & 163 & 47 & $210 \quad(3.4)$ \\
\cline { 2 - 6 } & No & 612 & 5,343 & $5,955 \quad(96.6)$ \\
\cline { 2 - 6 } & Total & 775 & 5,390 & $\begin{array}{c}6,165 \quad(100) \\
(\%)\end{array}$ \\
\cline { 2 - 6 } & $(12.6)$ & $(87.4)$ & $(100)$ \\
\hline
\end{tabular}

Note: Only the households interviewed in both HRS96 and HRS98 are listed in this Table.

Table 4. Second Home Ownership in HRS98 and AHEAD95: Empirical Results before Correction

\begin{tabular}{|l|c|c|c|c|}
\hline & \multicolumn{5}{|c|}{ HRS 1998 } \\
\hline \multirow{4}{*}{$\begin{array}{l}\text { AHEAD } \\
1995\end{array}$} & Yes & 101 & No & Total $(\%)$ \\
\cline { 2 - 6 } & No & 192 & 3,892 & $169 \quad(4.0)$ \\
\cline { 2 - 6 } & $\begin{array}{c}\text { Total } \\
(\%)\end{array}$ & $\begin{array}{c}293 \\
(6.9)\end{array}$ & $\begin{array}{c}3,960 \\
(93.1)\end{array}$ & $\begin{array}{r}4,253 \\
(100)\end{array}$ \\
\hline
\end{tabular}

Note: Only the households interviewed in both AHEAD95 and HRS98 are listed in this Table.

\section{The Correction Method}

Our method of correcting second home equity consists of two stages. In the first stage, we identify the mis-classified households in Cell C, assigning them back to Cell A. This may be done based on the following two sequential rules ---

(a) If a HRS (or AHEAD) household in Cell C reported in HRS98 that it had purchased its second home before 1996 (or 1995), this household will be treated as misclassified, and assigned to Cell A; and 
(b) If the first rule fails to assign the household to Cell A, but records in HRS98 show that the household did not sell any home after the HRS96 (or AHEAD95) interview, the household will still be assigned to Cell A. ${ }^{1}$

For simplicity, a household who can be identified as mis-classified through these rules will be called as identifiable mis-classified household. Our second home equity corrections are limited to such households. Any households in Cell C who cannot be identified as mis-classified will remain in that cell, and we will not correct second home equity in HRS96 or AHEAD95.

The second stage of our correction method involves an estimation of the second-home equity for the identifiable mis-classified households in HRS96 or AHEAD95, based on the information available for the households in Cell A that are identified in Tables 3 and 4.

Obviously, there are various ways to do this. The method presented below seems to be one of the simplest.

Let second-home equity as reported in HRS98 and HRS96 (or AHEAD95) be, respectively, $\mathrm{X}$ and $\mathrm{Y}$. The relationship between the two is assumed to be (1),

$$
\mathrm{Y}=\mathrm{Xg}+\Gamma^{\prime}
$$

where $я$ is a factor related to the rate of appreciation of second-home equity, ${ }^{2}$ and $\Gamma$ is a random error term.

Equation (1) may be estimated by least squares. Based on this equation, we then generate predicted value for each household in HRS96 (or AHEAD95) for which a reported X is available in HRS98. The final estimate of the second home equity for each identifiable mis-classified household may then be determined by a hotdeck imputation procedure that is based on the predicted value of $\mathrm{Y}$.

\footnotetext{
${ }^{1}$ We understand that these rules cannot identify all mis-classified households in Cell C (for example, a household who had made multiple housing transactions after the HRS96 (or AHEAD95) interview), nor can they prevent some households in Cell $\mathrm{C}$ from being mis-identified (for example, a household who reported in HRS98 inaccurate information on the purchase year of its second home or its housing transaction history). But we believe that these rules should be able to correctly identify most of the mis-classified households.

${ }^{2}$ To be exact, if the rate of appreciation of the second-home equity is $r$, then $\mathrm{g}=1 /(1+r)$.
} 


\section{Preliminary Results}

The effect of the corrections on the HRS/AHEAD second home data may be best seen in Tables 5 and 6. Before the corrections, only 3.4\% of HRS96 and 4.0\% of AHEAD95 households have reported to have second homes, and have non-missing information on their second-home equity. After the corrections, the number increases to $13.1 \%$ for the HRS96 households, and $8.4 \%$ for the AHEAD95 households.

\section{Table 5. Second Home Ownership in HRS98 and HRS96: The Effect of Corrections}

\begin{tabular}{|l|c|c|c|c|}
\hline \multirow{3}{*}{ HRS 1996 } & \multicolumn{5}{|c|}{ HRS 1998 } \\
\cline { 2 - 6 } & & Yes & No & Total $\quad \%)$ \\
\hline \multirow{3}{*}{ Pre-Correction } & Yes & 163 & 47 & $210 \quad(3.4)$ \\
\cline { 2 - 6 } & No & 612 & 5,343 & $5,955 \quad(96.6)$ \\
\hline \multirow{3}{*}{ Post-Correction } & Yes & 763 & 47 & $810 \quad(13.1)$ \\
\cline { 2 - 6 } & No & 12 & 5,343 & $5,355 \quad(86.9)$ \\
\hline & $\begin{array}{c}\text { Total } \\
(\%)\end{array}$ & $\begin{array}{c}775 \\
(12.6)\end{array}$ & $\begin{array}{c}5,390 \\
(87.4)\end{array}$ & $\begin{array}{r}6,165 \quad(100) \\
(100)\end{array}$ \\
\hline
\end{tabular}

Note: Only the households interviewed in both HRS96 and HRS98 are listed in this Table.

Since the percentages of second home ownership in HRS96 and AHEAD95 are significantly increased after corrections, one can imagine that the mean values of the second home equities in the two waves will be increased significantly as well. The only question is: With the new second home equity results, is the data quality for the housing equities and net worth really improved?

In Tables 7 and 8 we have replicated Tables 1 and 2 with the corrected information on the second home equity for HRS 1996 and AHEAD 1995. The time-series patterns of second home ownership and equity are more consistent now for both the HRS and AHEAD cohorts. In HRS 1996, 13.1\% of the households owned second homes, compared to $13.9 \%$ in HRS 1992, 13.0\% in HRS 1994, 13.2\% in HRS 1998, 13.1\% in HRS 2000, and 13.3\% in HRS 2002. In AHEAD 
$1995,8.2 \%$ of the households owned second homes, compared to $7.7 \%$ in HRS $1998,10.8 \%$ in HRS 2000, and $10.9 \%$ in 2002.

With the corrections, the mean value of the second home equity in HRS 1996 has increased by about $165 \%$, from $\$ 4,735$ to $\$ 12,590$, while the mean value of the second home equity in AHEAD 1995 has increased by about $90 \%$, from $\$ 4,845$ to $\$ 9,262$. The second home equity now comprises $12.2 \%$ of total housing equity and $3.8 \%$ of total net worth in HRS 1996, and $9.3 \%$ of total housing equity and 3.0\% of total net worth in AHEAD 1995. All these numbers are quite comparable to the counterpart data in other HRS or AHEAD waves, suggesting that our corrections have indeed improved the data quality.

Table 6. Second Home Ownership in HRS98 and AHEAD95: The Effect of Corrections

\begin{tabular}{|c|c|c|c|c|c|}
\hline \multirow[b]{2}{*}{ AHEAD 1995} & \multicolumn{5}{|c|}{ HRS 1998} \\
\hline & & Yes & No & Total & $(\%)$ \\
\hline \multirow{2}{*}{ Pre-Correction } & Yes & 101 & 68 & 169 & $(4.0)$ \\
\hline & No & 192 & 3,892 & 4,084 & (96.0) \\
\hline \multirow{3}{*}{ Post-Correction } & Yes & 290 & 68 & 358 & $(8.4)$ \\
\hline & No & 3 & 3,892 & 3,895 & (91.6) \\
\hline & $\begin{array}{r}\text { Total } \\
(\%)\end{array}$ & $\begin{array}{l}293 \\
(6.9)\end{array}$ & $\begin{array}{l}3,960 \\
(93.1)\end{array}$ & $\begin{array}{r}4,253 \\
(100)\end{array}$ & (100) \\
\hline
\end{tabular}

Note: Only the households interviewed in both AHEAD95 and HRS98 are listed in this Table.

It is interesting to note that the households who were mis-classified in both AHEAD 1995 and HRS 1996 appeared to have lower values on their second home equities. For those misclassified households in AHEAD 1995, the mean value of their second home equities was $\$ 100,852$, compared to $\$ 126,656$ for those reported to own second homes. In HRS 1996 , the two numbers were $\$ 81,525$ and $\$ 109,137$, respectively. Since a mis-classified household was one who lived in second home for less than two months of the year, the results seem to suggest a positive correlation between the duration of second home stay and the quality of the second home. 
Table 7. The Role of Second Home Equity in Total Housing Equity and Total Net Worth after the Second Home Equity Problem in HRS 1996 Corrected: the HRS Cohort, HRS 1992-2002

\begin{tabular}{|l|l|l|l|l|l|l|}
\hline & $\begin{array}{l}\text { HRS } \\
\mathbf{1 9 9 2}\end{array}$ & $\begin{array}{l}\text { HRS } \\
\mathbf{1 9 9 4}\end{array}$ & $\begin{array}{l}\text { HRS } \\
\mathbf{1 9 9 6}\end{array}$ & $\begin{array}{l}\text { HRS } \\
\mathbf{1 9 9 8}\end{array}$ & $\begin{array}{l}\text { HRS } \\
\mathbf{2 0 0 0}\end{array}$ & $\begin{array}{l}\text { HRS } \\
\mathbf{2 0 0 2}\end{array}$ \\
\hline \% 2 $\mathbf{2}^{\text {nd }}$ Home Ownership & 13.9 & 13.0 & 13.1 & 13.2 & 13.1 & 13.3 \\
\hline Second Home Equity & 15,140 & 11,515 & 12,590 & 12,528 & 14,372 & 17,855 \\
\hline Primary Home Equity & 82,566 & 88,207 & 90,512 & 99,428 & 110,248 & 114,780 \\
\hline Total Housing Equity & 97,707 & 99,723 & 103,102 & 111,956 & 124,621 & 132,635 \\
\hline Total Net Worth & 274,366 & 310,365 & 327,340 & 378,375 & 418,389 & 410,450 \\
\hline $\begin{array}{l}\text { \% of 2 } \mathbf{2}^{\text {nd }} \text { Home Equity in } \\
\text { Total Housing Equity }\end{array}$ & 15.5 & 11.5 & 12.2 & 11.2 & 11.5 & 13.5 \\
\hline $\begin{array}{l}\text { \% of 2 } \mathbf{2}^{\text {nd }} \text { Home Equity in } \\
\text { Total Net Worth }\end{array}$ & 5.5 & 3.7 & 3.8 & 3.3 & 3.4 & 4.3 \\
\hline
\end{tabular}

Note: Total net worth is a combination of the total housing equity and non-housing assets, which exclude "trusts not reported earlier". All the housing equity and net worth variables are weighted means in 2002 dollars. Both the second home ownership and equity now show more consistent timeseries patterns.

Table 8. The Role of Second Home Equity in Total Housing Equity and Total Net Worth after the Second Home Equity Problem in AHEAD 1995 Corrected: the AHEAD Cohort, AHEAD 1995-2002

\begin{tabular}{|l|l|l|l|l|l|}
\hline & $\begin{array}{l}\text { AHEAD } \\
\mathbf{1 9 9 3}\end{array}$ & $\begin{array}{l}\text { AHEAD } \\
\mathbf{1 9 9 5}\end{array}$ & $\begin{array}{c}\text { HRS } \\
\mathbf{1 9 9 8}\end{array}$ & $\begin{array}{c}\text { HRS } \\
\mathbf{2 0 0 0}\end{array}$ & $\begin{array}{c}\text { HRS } \\
\mathbf{2 0 0 2}\end{array}$ \\
\hline \% 2 $\mathbf{2}^{\text {nd }}$ Home Ownership & 7.8 & 8.2 & 7.7 & 10.8 & 10.9 \\
\hline Second Home Equity & 7,857 & 9,262 & 8,591 & 7,956 & 11,032 \\
\hline Primary Home Equity & 87,159 & 90,351 & 91,128 & 95,499 & 95,129 \\
\hline Total Housing Equity & 95,016 & 99,613 & 99,719 & 103,455 & 106,161 \\
\hline Total Net Worth & 217,933 & 311,417 & 302,214 & 312,356 & 304,137 \\
\hline $\begin{array}{l}\text { \% of 2 } \mathbf{2}^{\text {nd }} \text { Home Equity in } \\
\text { Total Housing Equity }\end{array}$ & 8.3 & 9.3 & 8.6 & 7.7 & 10.4 \\
\hline $\begin{array}{l}\text { \% of 2 } \mathbf{2}^{\text {nd }} \text { Home Equity in } \\
\text { Total Net Worth }\end{array}$ & 3.6 & 3.0 & 2.8 & 2.5 & 3.6 \\
\hline
\end{tabular}

Note: Total net worth is a combination of the total housing equity and non-housing assets, which exclude "trusts not reported earlier". All the housing equity and net worth variables are weighted means in 2002 dollars. Both the second home ownership and equity now show more consistent time-series patterns. The percentage of second home equity in total net worth in AHEAD 1993 seems to be on the high side, but that is due to the very low level of net worth in AHEAD 1993. 


\section{The AHEAD 1993 Problem}

The AHEAD93 problem (i.e., second home equity combined with real estate investment equity) is different from the problem troubling HRS96 and AHEAD95. But it may be handled in a way similar to what we have done for HRS96 and AHEAD95. Basically, we may continue to use the information about second home in a later wave (e.g., purchase year, housing transaction history in AHEAD 1995) to predict the existence (or the lack of it) of second home in AHEAD93, and then impute second home equity for those identifiable second home owners.

Two points need to be made here. First, in predicting the second home ownership for AHEAD 1993, one needs to use the corrected—not just reported-second home ownership information in AHEAD 1995. Second, to impute second home equity, one has to make an assumption about the rate of appreciation of the housing market.

Table 8, Column 1 summarizes the second home ownership and equity results for AHEAD 1993. According to the table, $7.8 \%$ of the households owned second homes in AHEAD 1993 , and the mean value of the second home equity was about $\$ 7,857 .{ }^{3}$ Compared to the results in other AHEAD waves, both the numbers seem to be quite reasonable.

\footnotetext{
${ }^{3}$ To impute second home equity for AHEAD 1993, we first estimated a simple linear relationship between the second home equities in AHEAD 1995 and HRS 1998. We then predicted the AHEAD 1993 equity based on the relationship and the observed or imputed equity values in AHEAD 1995 or HRS 1998.
} 
